\title{
Development of a High Performance Micropropulsion System for CubeSats
}

\author{
A Thesis \\ presented to \\ the Faculty of the College of Engineering \\ California Polytechnic State University, San Luis Obispo
}

\author{
In Partial Fulfillment \\ of the Requirements for the Degree \\ Master of Science in Mechanical Engineering \\ by \\ Christopher Lorian Biddy
}

August 2009 
(C) 2009

Christopher Lorian Biddy

ALL RIGHTS RESERVED 


\section{Committee Membership}

TITLE:

AUTHOR:

DATE SUBMITTED:

COMMITTEE CHAIR:

COMMITTEE MEMBER:

COMMITTEE MEMBER:
Development of a High Performance Micropropulsion System for CubeSats

Christopher Lorian Biddy

August 27, 2009

Dr. Andrew Kean, Professor

Dr. Jordi Puig-Suari, Professor

John Fabijanic, Professor 


\begin{abstract}
Title: Development of a High Performance Micropropulsion System for CubeSats
\end{abstract}

Author: Christopher Lorian Biddy

Picosatellites are defined as satellites with a mass between 0.1 and $1 \mathrm{~kg}$ (Miniaturized satellite). Picosatellites are typically designed to work together or function in formations (Miniaturized satellite). A specific type of Picosatellite known as CubeSats were introduced in 1999 and since then have increased in popularity so that there are now over 80 CubeSat programs around the world. CubeSats are defined as cubic units $10 \mathrm{~cm}$ on each side and no more than $1 \mathrm{~kg}$ in mass. CubeSats are required to conform to the CubeSat Standard created by California Polytechnic State University and Stanford University and be compatible with Cal Poly's P-POD deployment system (Toorian, 2005). Some CubeSat uses include earth imaging, communications projects and various scientific experiments. CubeSats currently require attitude control and in the future, may require, maintaining a specific orbit, or changing orbit. With this ability many new activities may be possible for CubeSats. These activities could include rendezvous, vehicle inspection, formation flying and de-orbiting. For these activities to be possible, a high performance propulsion system is required. The goal of this thesis is to design and test an affordable, safe, and effective micro-propulsion system for CubeSats.

Keywords: CubeSat, monopropellant, bipropellant, propulsion, Picosatellite, thruster 


\section{Acknowledgements}

I would like to thank everyone who helped me with this project. First of all I would like to thank my wife Jessica for encouraging me and keeping me on task. Thank you to my family and friends for also encouraging and supporting me. I would like to thank Dr. Tomas Svitek for hiring me and sponsoring this project. Thanks to the whole Stellar Exploration team, especially Alex Diaz for helping me with all the circuit design, manufacturing, and troubleshooting I needed during testing and Dave Imbaratto for the technical assistance. I would also like to give special thanks to Brain Miller and Chris Maglio from Maglio Inc. Thanks for all the technical advice and brainstorming sessions as well as your manufacturing skills. Also thanks to Bud Fraze of Vector Engineering for all your ideas and guidance. Thank you to Graham Edney for your catalyst design input and your laser welding skills. Finally thank you to all the members of my thesis committee: Professor Andrew Kean, Professor John Fabijanic and Professor Jordi PuigSuari for your guidance and support. 


\section{Table of Contents}

Table of Contents ......................................................................................................................... vi

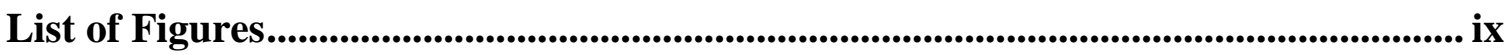

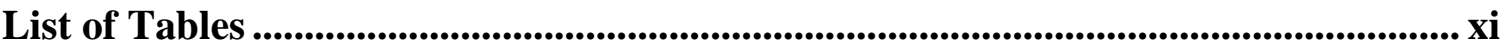

Introduction ............................................................................................................................................. 1 1 -

Propulsion System Requirements......................................................................... 3 -

CubeSat Compatibility ..................................................................................... 3 -

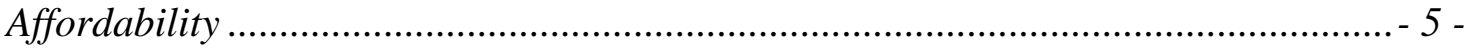

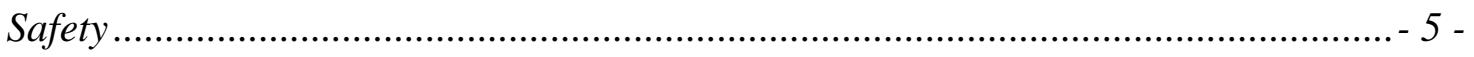

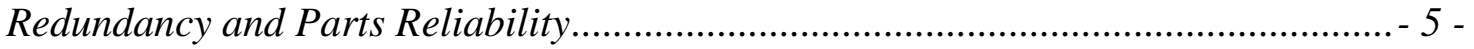

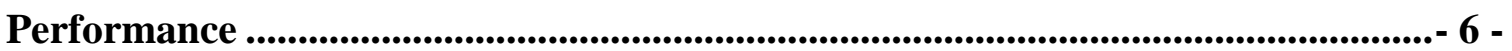

Propulsion System Comparison ..................................................................................................- 12 -

Monopropellant t............................................................................................ 12 -

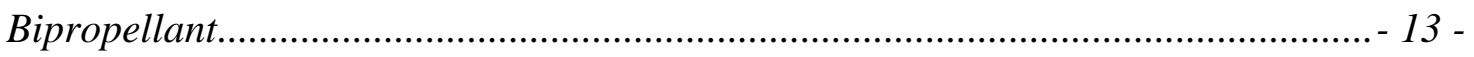

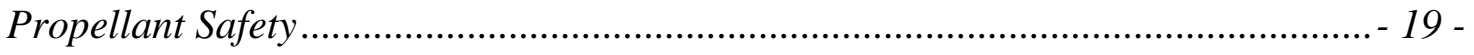

Storage and Ground Handling ............................................................................ 19 -

Thruster Configuration ...........................................................................................................- 21 - 
Required Thrust..................................................................................................................... 22 -

Thruster Combustion Chamber Pressure ..........................................................................- 23 -

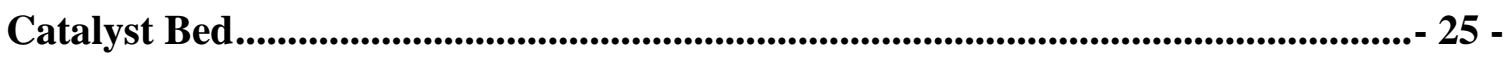

Storage Pressure.............................................................................................................................- 27 -

Thruster Valve Design and Integration .................................................................................- 28 -

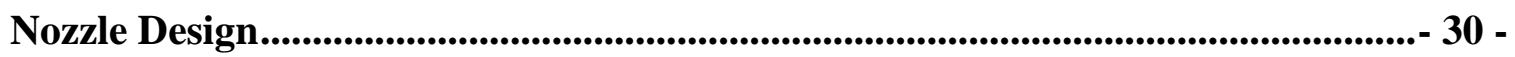

Tank Material and Fabrication ................................................................................. 33 -

Tank Design Concepts .........................................................................................................- 34 -

Proposed Designs Comparison and Evaluation ....................................................- 36 -

Tension Joint Details and Analysis ....................................................................... 46 -

Propellant Management t.................................................................................. 48 -

Testing ................................................................................................................................................ 48 -

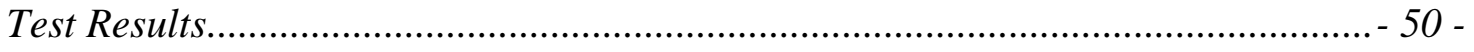

Future Work ...........................................................................................................................................- 66 -

Conclusions......................................................................................................................................... 68 -

Works Cited................................................................................................................................... 71 -

Appendix A. Mass Fraction vs. $I_{\mathrm{sp}}$ Required Hand Calculation ................................- 74 - 
Appendix B. Performance vs. Dry Mass Fraction data for Figure 3.

Appendix C. Graham Edney catalyst design sketches.

- 76 -

Appendix D. Nozzle Area Ratio Calculation and Derivation.

77 -

Appendix E. I $\mathbf{s}_{\text {sp }}$ vs. Expansion Ratio data for Figure 6.

- 79 -

Appendix F. Micropropulsion system data sheets and drawings.......................... 80 -

ASCO miniature solenoid valve ...................................................................... 80 -

Vented Cap Screw Drawing .......................................................................... 83 -

Parker EDPM O-Ring Data Sheets................................................................. 84 -

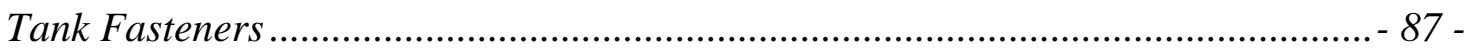

Micropropulsion tank and cap detailed drawings ............................................... 89 -

Appendix G. COSMOS simulation results with table of mechanical properties

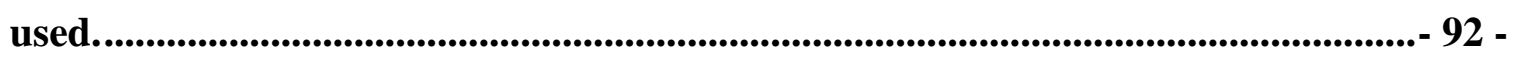

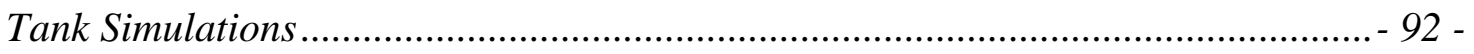

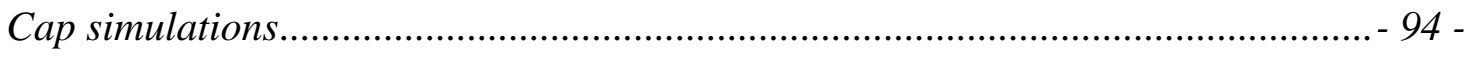

Appendix H. Tension Joint Analysis data for Figure 20..................................... 98 -

Appendix I. Thrust Calculation for Cold Gas Test Hand Calculations................... 99 - 


\section{List of Figures}

Figure 1. CubeSat P-POD satellite deployment system................................................- 2 -

Figure 2. CAN-X2 triple CubeSat. ........................................................................... 8 -

Figure 3. Performance vs. Dry Mass Fraction for various $I_{\mathrm{sp}}$ values............................- 10 -

Figure 4. Nozzle section view with catalyst screen concept.......................................- 26 -

Figure 5. Assembled catalyst shown next to the valve stud (left) and partially

loaded into combustion chamber (right).................................................................- 27 -

Figure 6. ASCO miniature solenoid valve........................................................... 29 -

Figure 7. Plot of theoretical $I_{\mathrm{sp}}$ vs. Nozzle Expansion Ratio for a chamber pressure

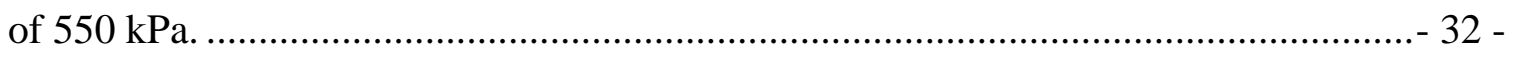

Figure 8. FOX Schrader valve and cap with o-ring rated at $1380 \mathrm{kPa}$ operating.........- 37 -

Figure 9. Cubic tank and cap prototype micropropulsion system assembly. ...............- 38 -

Figure 10. Cylindrical tank and cap prototype micropropulsion system assembly......- 39 -

Figure 11. Cylindrical tank with vertically mounted thruster prototype

Micropropulsion system assembly....................................................................... 40 -

Figure 12. Tank and cap shown with respective raw materials before machining .......- 42 -

Figure 13. Underside of cap with o-ring installed. ................................................- 42 -

Figure 14. Cap alignment tabs shown on the underside of the cap...............................- 43 -

Figure 15. Stainless steel stud with EPDM o-ring and laser cut through hole. .............- 43 -

Figure 16. Stainless steel stud mounted into cap.......................................................- 44 -

Figure 17. Solenoid valve mounted to stud and seated against mounting boss face....- 44 -

Figure 18. Fill and drain valve shown installed in the tank cap. ................................- 45 - 


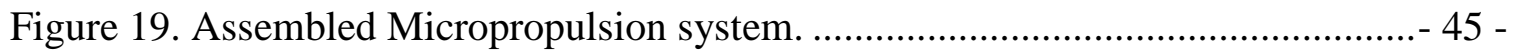

Figure 20. Details of tank and cap fastener orientation. ....................................... 46 -

Figure 21. Bolted joint and bolt yield factor of safety as a function of tank storage

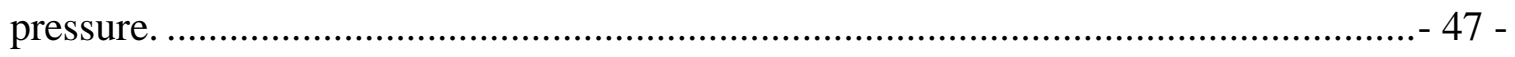

Figure 22. Assembled Micropropulsion system. ................................................ 50 -

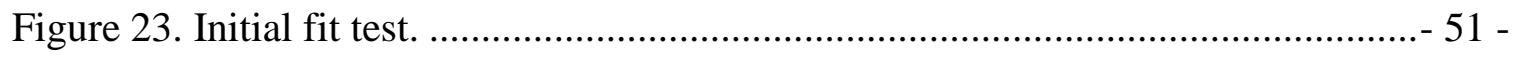

Figure 24. Valve Function test layout and equipment. ....................................... 52 -

Figure 25. Assembled Micropropulsion system with non-bored stainless studs.........- 53 -

Figure 26. Cinderblock bunker used during system burst testing............................. 53 -

Figure 27. Blast shield used during system burst testing...................................... 54 -

Figure 28. Digital Pressure gauge connected to propulsion system. .......................... 55 -

Figure 29. Propulsion system with adapters and quick connect fittings..................... 56 -

Figure 30. Micropropulsion system connected and ready for pressurization..............- 56 -

Figure 31. O-ring shown protruding out of the tank and cap................................. 57 -

Figure 32. Micropropulsion bolts, o-ring, tank and cap after first burst test. ..............- 58 -

Figure 33. Cold gas thrust measurement test setup........................................... 60 -

Figure 34. Test setup shown after first test......................................................... 61 -

Figure 35. Nozzle used for cold gas test. ........................................................ 63 -

Figure 36. Thruster standoff bracket design. .................................................. 67 -

Figure 37. Design Flow chart for Micro-propulsion system.................................... 69 - 


\section{List of Tables}

Table 1. CubeSat mass and geometry requirements. ................................................ 4 -

Table 2. CubeSat mechanical requirements............................................................. 4 -

Table 3. Required propellant mass for desired performance. ................................... 9 -

Table 4. Advantages and disadvantages of monopropellant and bipropellant

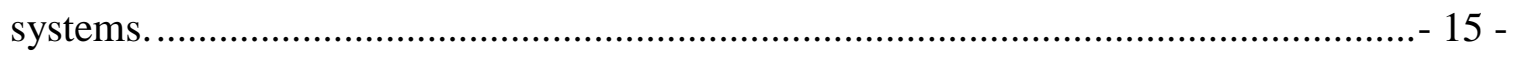

Table 5. Advantages and disadvantages of electrothermal thrusters. .........................- 17 -

Table 6. Chamber pressure and corresponding throat diameter. ................................ 24 -

Table 7. Tank geometry, mass, volume and corresponding delta V.......................... 40 -

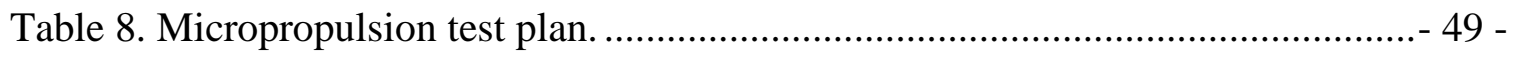

Table 9. Cold gas test results for three tests with three $2 \mathrm{~Hz}$ pulses per test. ............... 62 -

Table 10. Cold gas test calculated results. ...................................................... 65 - 


\section{Introduction}

Due to student interest in having an affordable, viable satellite program, California Polytechnic State University and Stanford University teamed up to develop a program that limits some of the open ended design objectives encountered in satellite design. They limited the scope in such a way as to define the shape, weight, format, mounting, and deployment interface. This is known as the CubeSat program. The CubeSat Standard developed by California Polytechnic State University and Stanford University in 1999 has provided an interface and system for deploying CubeSats as well as a definition of form factor and mass constraints. This CubeSat standard is designed to provide a base upon which students can design and manufacture a satellite to perform a desired research experiment. The standardization of CubeSats resulted in decreasing the overall satellite cost from design and manufacture to launch, as well as the time it takes for the overall design, procurement, and manufacturing. With this program a student entering college may be able to work on a CubeSat project and actually see that satellite built and launched into orbit before graduating.

The CubeSat standard outlines requirements for proper function inside the Poly Picosatellite Orbital Deployer (P-POD). The P-POD structure is a cuboid with the capacity to hold up to three CubeSat units at a time (Figure 1). It consists of slide rails on all four corners that the CubeSats interface with. At one end of the P-POD is a door that opens during CubeSat deployment and at the other end is a slider with a spring that pushes the CubeSat out into orbit at the appropriate time. The slider and slide rails can be seen in Figure 1 on the next page. 


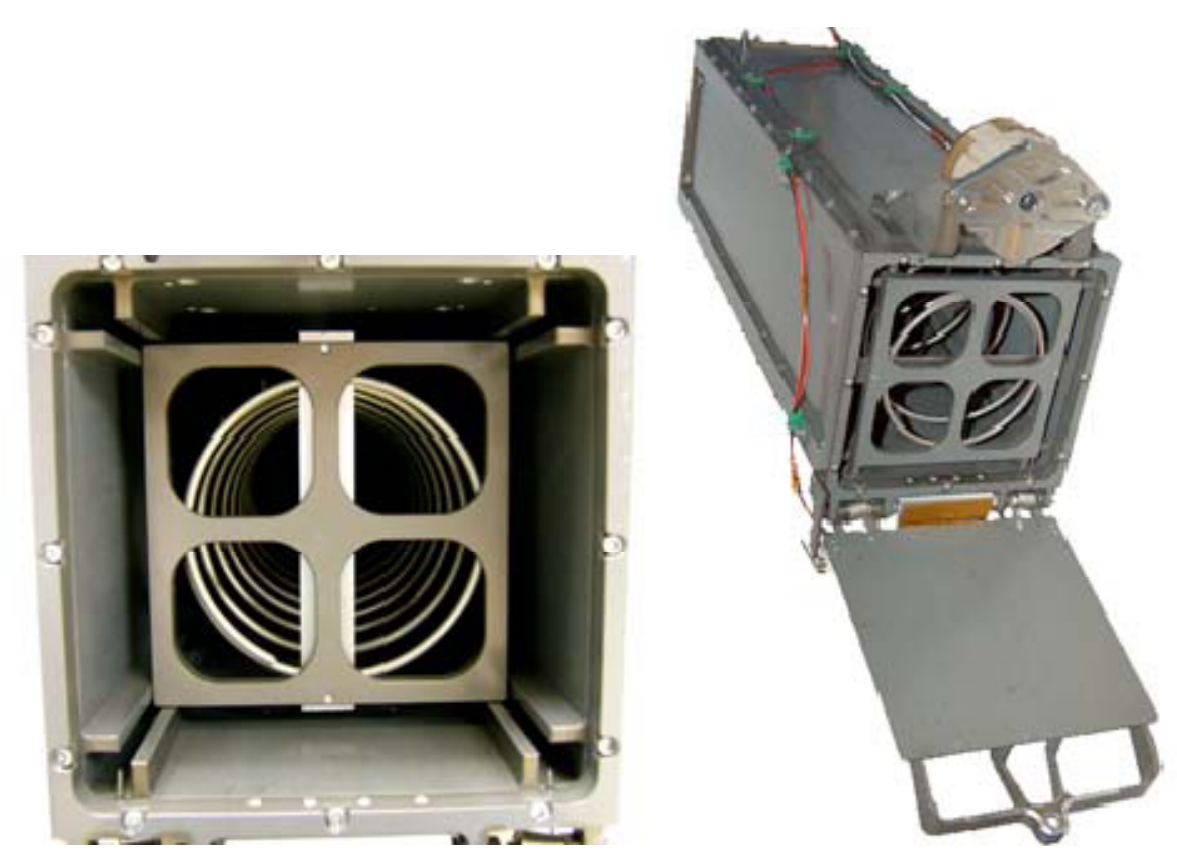

Figure 1. CubeSat P-POD satellite deployment system.

In general, CubeSat projects consist of a single $1 \mathrm{~kg}, 10 \mathrm{~cm}$ cube. Then the CubeSat is loaded into the P-POD with two other CubeSats with spring plungers separating them from one another. Some CubeSat projects have expanded to "Double Cube" and "Triple Cube" configurations. A "Double Cube" or 2 unit configuration refers to a satellite with dimensions of $10 \mathrm{~cm}$ by $10 \mathrm{~cm}$ by $20 \mathrm{~cm}$ long and $2 \mathrm{~kg}$. It is basically just 2 CubeSats machined into one unit. A "Triple Cube" or 3 unit configuration has a similar definition with dimensions of $10 \mathrm{~cm}$ by $10 \mathrm{~cm}$ by $30 \mathrm{~cm}$ and $3 \mathrm{~kg}$. An attractive feature of the "Double Cube" and "Triple Cube" CubeSats is the fact that a whole one unit may be reserved for a propulsion system and coupled to additional one or two units to form the overall satellite. 
The launch vehicles used to deliver the CubeSats into orbit include the EUROROCKET, Japan's M-V-8, and the Russian DNEPER rocket. Because of the size and weight of the CubeSats, they can be affordably added to the payload of the large launch vehicles because in most cases the launch vehicles are not designed around their primary payload so there is usually some mass margin left for the CubeSats to exploit. Since the CubeSats are "hitching a ride" on a launch vehicle and are not the primary payload, the launch time and profile is dictated by the primary payload. Because of this, the CubeSat may not be released at a desired time or in a desired orbit. A high performance propulsion system would allow the CubeSat to attain a more desirable orbit or orientation once it is deployed, where a CubeSat without propulsion will be deployed with an arbitrary orientation and an orbit that may or may not be desirable.

\section{Propulsion System Requirements}

The general requirements for the Micropropulsion system will be discussed in the following sections. Since the Micropropulsion system will be designed specifically for CubeSats, all CubeSat related requirements must be met. The design philosophy used throughout this project will be simplification, the use of commercial of the shelf components, and rapid prototyping to support component and system testing rapidly.

\section{CubeSat Compatibility}

To ensure compatibility between the CubeSat and P-POD, a CubeSat Standard outlining interface and safety requirements was developed by Cal Poly and Stanford University. The general requirements state that the CubeSat must not present any danger to the P-POD, launch vehicle, or other CubeSats. Pyrotechnic devices which use 
explosive charges to perform a specific task such as opening a valve are not allowed inside the CubeSat. In addition, the CubeSat must be designed to operate as smoothly as possible inside the P-POD.

The quantitative and qualitative requirements as outlined by the CubeSat Standard are summarized below in the following tables (Toorian, 2005).

Table 1. CubeSat mass and geometry requirements.

\begin{tabular}{|c|c|}
\hline Specification & Value \\
\hline Dimensions per unit & $10 \mathrm{~cm} \times 10 \mathrm{~cm} \times 10 \mathrm{~cm}$ \\
\hline Mass per unit & $1 \mathrm{~kg}$ \\
\hline Maximum Number of units & 3 \\
\hline Center of mass location per unit & Within $2 \mathrm{~cm}$ of geometric center \\
\hline & \\
\hline
\end{tabular}

Table 2. CubeSat mechanical requirements.

\begin{tabular}{|c|c|}
\hline Specification & Value \\
\hline Rails must be smooth and edges rounded & Minimum radius of 1mm \\
\hline $\begin{array}{c}\text { Minimum length of CubeSat rail in contact } \\
\text { with guide rails }\end{array}$ & $\begin{array}{c}75 \% \text { (up to 25\% of CubeSat rail length } \\
\text { can be recessed) }\end{array}$ \\
\hline $\begin{array}{c}\text { Rails must prevent cold welding, reduce wear } \\
\text { and electrically isolate CubeSat from P-POD }\end{array}$ & $\begin{array}{c}\text { Rails must be hard anodized } \\
\text { points }\end{array}$ \\
\hline $\begin{array}{c}\text { Separation spring included at designated } \\
\text { Similar thermal expansion to Aluminum } \\
\text { 7075-T73 used for main CubeSat structure }\end{array}$ & $\begin{array}{c}\text { Aluminum 7075 or 6061-T6 } \\
\text { recommended }\end{array}$ \\
\hline $\begin{array}{c}\text { Deployables must be constrained within } \\
\text { CubeSat }\end{array}$ & $\begin{array}{c}\text { P-POD rails and walls not to contain } \\
\text { deployables }\end{array}$ \\
\hline
\end{tabular}

Additional requirements that apply to this application include: no electronics active during launch and a remove-before-flight pin to be removed after P-POD integration for CubeSat activation. 


\section{Affordability}

A very important goal in the creation of the CubeSat program is space access at low cost. In order for University clubs and small companies to participate in the CubeSat program, overall mission costs must be kept to a minimum. For a CubeSat micropropulsion system to be viable, its cost must also be kept low. Based on cost estimates by Dr. Tomas Svitek the CubeSat propulsion system overall cost per unit should be within \$100k-\$250k (Svitek, 2008-2009). This cost estimate is based on a fully qualified, flight

ready assembly including all mechanical components fully assembled and ready to be fueled.

\section{Safety}

All ground handling and range safety requirements as outlined in Air Force Space Command Manual 91-710 Volume 4 must be met. Additional multiple redundant systems shall be implemented and part reliability verified.

\section{Redundancy and Parts Reliability}

All sealing components in the propulsion system including valves and o-rings shall be redundant as much as possible up to triple redundancy. Since this is a new application with major mass and volume constraints, redundancy may not always be possible. When this is the case, extremely high part reliability is required. This includes testing all components at operating conditions extensively. 


\section{Performance}

The most common performance parameter used to compare propulsion systems is specific impulse or $\left(\mathrm{I}_{\mathrm{sp}}\right)$. Specific impulse compares the amount of thrust produced by a propulsion system as a function of the mass flow rate through the thrusters. Equation 1 below shows the definition of specific impulse $\left(I_{s p}\right)$ in units of seconds, with $F$ being the thrust produced in Newtons, $g$ the acceleration due to gravity in $\mathrm{m} / \mathrm{s}^{2}$ and $\dot{m}$ the mass flow rate of propellant through the thruster in $\mathrm{kg} / \mathrm{s}$.

$$
I_{s p}=\frac{F}{g * \dot{m}}
$$

Some definitions of $I_{s p}$ leave the gravity term out for units of velocity, but the gravity term will be used in this paper because it allows for direct comparisons of propulsion systems using either English or SI units.

Most propulsion systems use either stored pressure energy or a chemical reaction to accelerate a fluid through a nozzle. This causes a change in momentum which produces thrust. The effects of these forces on the motion of the spacecraft will be detailed below. The momentum equation derived from Newton's Second Law and presented in Introduction to Fluid Mechanics is shown below (Fox, 2004). It states that the sum of the forces on the system is equal to the sum of the rate of change of momentum inside the control volume and the net rate of flux of momentum out through the control surface.

$$
\vec{F}=\frac{\partial}{\partial t} \int_{C V} \rho \vec{v} d V+\int_{C S} \vec{v} \rho(\vec{v} \cdot \hat{n}) d A+\Delta P \cdot A
$$


Starting with equation 2 and assuming a 1-dimensional, incompressible, steady flow, and a constant cross-sectional area control volume, equation 3 is derived (Fox, 2004). Note that the $\Delta \mathrm{P}$ in equation 2 refers to the difference in atmospheric and fluid exit pressure.

$$
F=\dot{m} V_{e}+\left(P_{e}-P_{a}\right) A_{e}
$$

Equation 3 relates the total thrust due to both the momentum flow of the fluid through the thruster as well as the thrust produced by the exit pressure of the fluid with $\dot{m}$ being the mass flow rate through the thruster in $\mathrm{kg} / \mathrm{sec}, V_{e}$ the exit velocity in $\mathrm{m} / \mathrm{s}, P_{e}$ the exit pressure in $\mathrm{kPa}, P_{a}$ the ambient pressure in $\mathrm{kPa}$ and $A_{e}$ the exit cross-sectional area in $\mathrm{m}^{2}$.

Overall spacecraft performance is described in terms of a change in velocity for the entire spacecraft over the mission. The term $\Delta \mathrm{V}$ (said "delta- $\mathrm{V}$ ") is used to describe this performance. Mission design analysis is used to calculate the required $\Delta \mathrm{V}$ for all the spacecraft maneuvers for the mission. The propellant weight required for the mission can be calculated from the required $\Delta \mathrm{V}$ using the Tsiolkowski equation also known as the basic rocket equation and its corollaries, equation 5 and 6 (Brown, 1996). This equation written in its final form (equation 5) relates the propellant weight to the $\Delta \mathrm{V}$ in $\mathrm{m} / \mathrm{s}$, specific impulse ( $\left.\mathrm{I}_{\mathrm{sp}}\right)$ in seconds and the final vehicle weight $\left(W_{f}\right)$ in $\mathrm{kg}$.

$$
\begin{aligned}
& \Delta V=g * I_{s p} * \ln \frac{W_{i}}{W_{f}} \\
& W_{p}=W_{f}\left[\exp \left(\frac{\Delta V}{g * I_{s p}}\right)-1\right]
\end{aligned}
$$


From the previous equations, with a desired $\Delta \mathrm{V}$ and initial or final spacecraft weight, the required propellant weight for a given specific impulse can be calculated. Since CubeSats have a defined maximum allowable mass and the $\Delta \mathrm{V}$ is calculated from the mission requirements, a propellant weight can be calculated for a given specific impulse. In order to take a modular approach to this project, it was decided to allocate a full $1 \mathrm{~kg}, 10 \mathrm{~cm}$ cube unit for propulsion integrated into a 3-unit configuration or "Triple Cube" CubeSat. An example of a "Triple Cube" is the CAN X2 built by the University of Toronto Space Lab shown below in Figure 2.
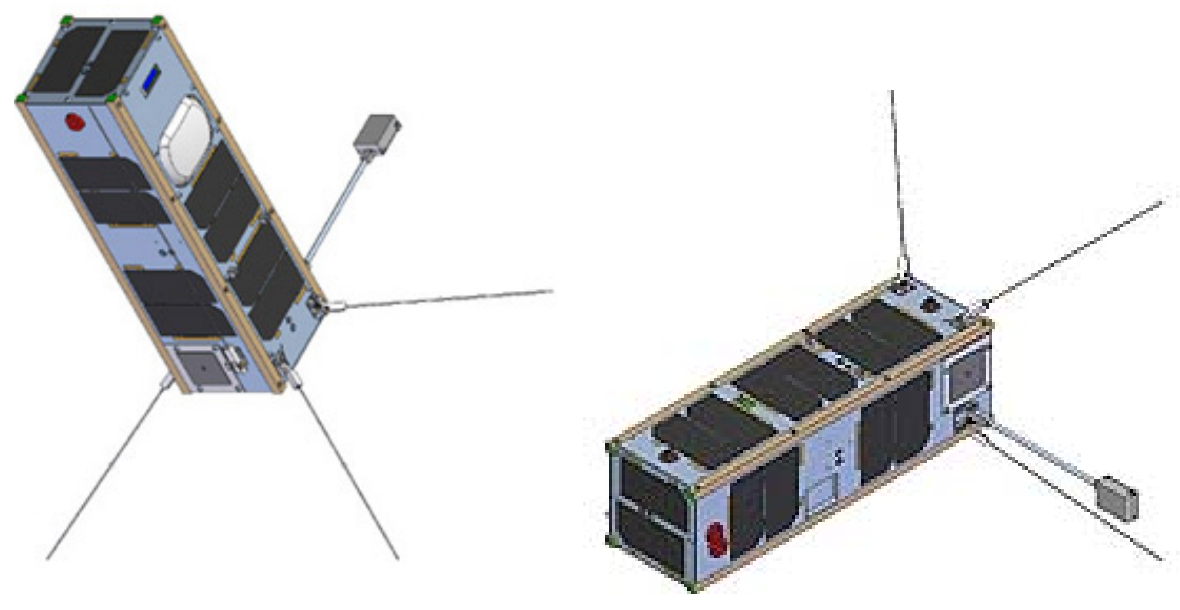

Figure 2. CAN-X2 triple CubeSat.

From mission analysis calculated by Dr. Tomas Svitek of Stellar Exploration Inc., the micro-propulsion system shall produce a $\Delta \mathrm{V}=500 \mathrm{~m} / \mathrm{sec}$ in a 3-unit configuration for substantial orbit maintenance and maneuvers to be possible. With a $\Delta \mathrm{V}=500 \mathrm{~m} / \mathrm{sec}$ the propulsion system will be capable of changing a circular $300 \mathrm{~km}$ orbit to an elliptical 
orbit with minimum radius of $300 \mathrm{~km}$ and maximum radius of $2400 \mathrm{~km}$. This will be the design target for the propulsion system.

Table 3 below shows the required propellant weight for a given specific impulse for the desired $\Delta \mathrm{V}$ of $500 \mathrm{~m} / \mathrm{s}$ and the maximum allowable 3-unit CubeSat mass of $3 \mathrm{~kg}$. Since each CubeSat unit can weigh a maximum of $1 \mathrm{~kg}$, the propellant mass percentage of the propulsion system unit is also included in the table. Note that propulsion system propellant mass fraction is defined as the mass of propellant divided by the total mass of the propulsion system with propellant.

Table 3. Required propellant mass for desired performance.

\begin{tabular}{|c|c|c|}
\hline Propellant Mass (kg) & $\begin{array}{c}\text { Specific Impulse, } \mathbf{I}_{\mathbf{s p}} \\
\mathbf{( s )}\end{array}$ & $\begin{array}{c}\text { Propulsion } \\
\text { System } \\
\text { Propellant Mass } \\
\text { Fraction }\end{array}$ \\
\hline 1.01 & 175 & 1.01 \\
\hline 0.87 & 200 & 0.87 \\
\hline 0.76 & 225 & 0.76 \\
\hline 0.68 & 250 & 0.68 \\
\hline 0.61 & 275 & 0.61 \\
\hline 0.56 & 300 & 0.56 \\
\hline 0.51 & 325 & 0.51 \\
\hline 0.47 & 350 & 0.47 \\
\hline 0.44 & 375 & 0.44 \\
\hline
\end{tabular}

As shown by the table above, any $\mathrm{I}_{\mathrm{sp}}$ below $175 \mathrm{~s}$ will require over $100 \%$ of the propulsion system unit allowable mass to be propellant, which is not possible. A more likely specific impulse requirement would be in the range of $220 \mathrm{~s}$ or larger to allow for the mass of the thrusters, valves, and storage tank to be included in the $1 \mathrm{~kg}$ maximum mass requirement. 
Typical cold gas systems which use inert gas stored at high pressure can achieve specific impulses between 50 to $120 \mathrm{~s}$ which is not enough to meet the $500 \mathrm{~m} / \mathrm{s}$ design goal since the required propellant mass would be greater than the maximum allowable mass (Sutton, 2001). Well designed monopropellant Hydrazine engines have achieved an Isp of around 220-230 s, which would require approximately $75 \%$ of the allowable 1 unit mass, leaving approximately $250 \mathrm{~g}$ for the tank, valves, catalysts and thrusters. Bipropellant propulsion systems typically produce specific impulses between 230 and $325 \mathrm{~s}$ (Sutton, 2001). Shown below in Figure 3 is the effect of $\mathrm{I}_{\mathrm{sp}}$ and dry mass fraction, on the overall spacecraft performance (Brown, 1996). The dry mass fraction is defined as the empty spacecraft mass divided by the fueled spacecraft mass.

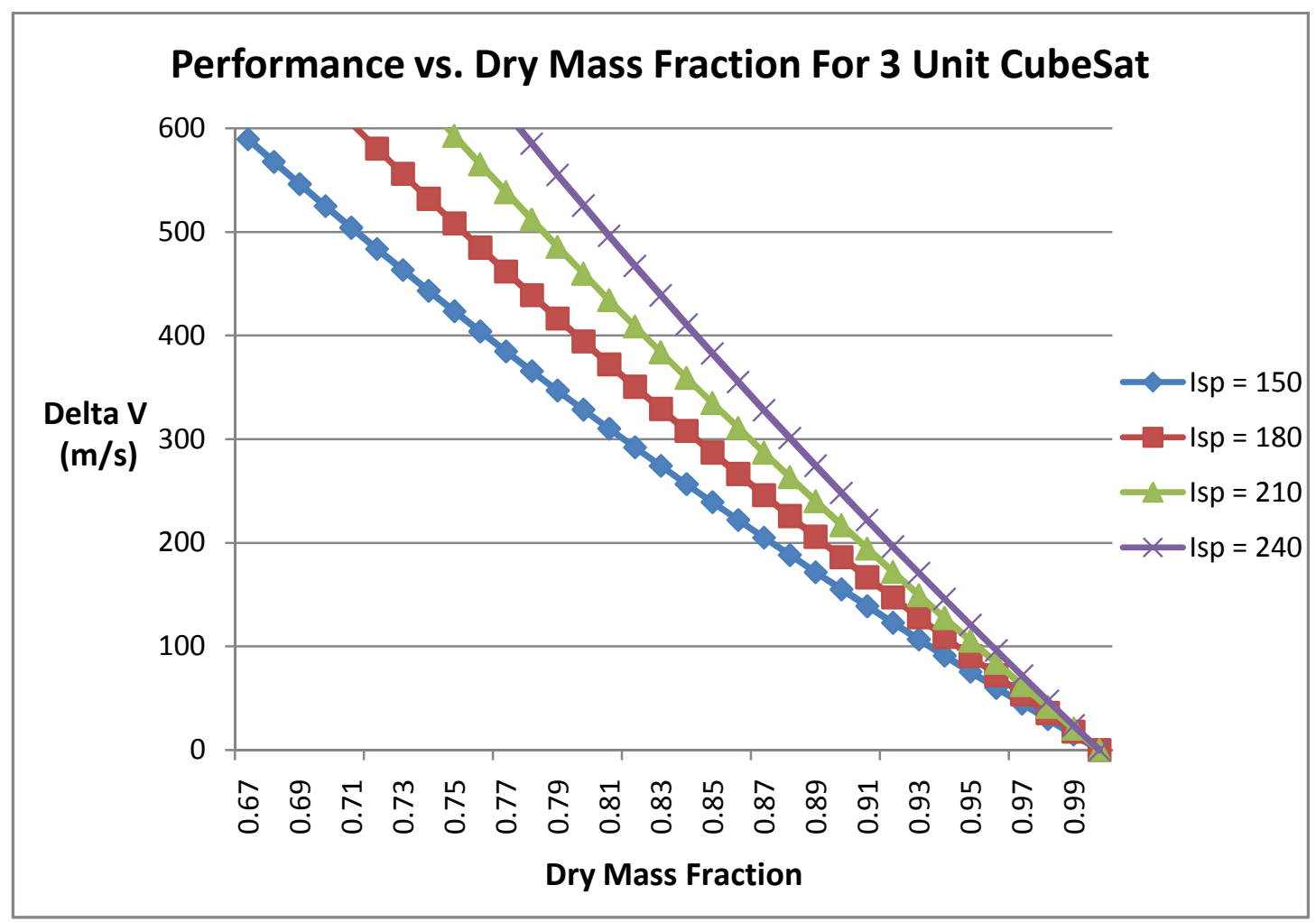

Figure 3. Performance vs. Dry Mass Fraction for various $\mathbf{I}_{\mathrm{sp}}$ values. 
If the objectives of the mission can be accomplished with a 2-unit CubeSat or "Double Cube" with one of those units being the Micro Propulsion system, a much larger Delta $\mathrm{V}$ is possible. However, for this project only a 3-unit CubeSat will be considered.

To estimate proper thrust requirements, the thrust to weight ratio of past spacecraft with similar mission objectives was studied. Since the thrust to weight ratio is a dimensionless quantity, the overall spacecraft mass is not important for the analysis to be valid. This process was described in "Space Propulsion Analysis and Design" (Humble, 1995). A general trend in past spacecraft includes a thrust to weight ratio of at least 0.2 for missions requiring orbital transfer. For missions only requiring orbit maintenance or attitude control, a thrust to weight ratio of less than 0.1 is recommended (Humble, 1995). The mission requirements for the CubeSat propulsion may include both orbit transfer and orbit maintenance, a thrust to weight ratio of $0.25-0.35$ will be considered to allow for orbit transfer maneuvers. The mass of the 3-unit CubeSat is defined as $3 \mathrm{~kg}$, following the past trends of spacecraft, a total thrust level of around 7.410.3 Newtons is recommended. For this project, the thrusters will be designed to fall within these values and adjusted if empirical testing deems necessary. This requirement puts more importance on valve response and the control system to act quickly to pulse the thrusters for orbital maintenance and attitude control since the thrusters may be oversized for these types of maneuvers. This is necessary to ensure proper thruster performance for orbital transfer capability. 


\section{Propulsion System Comparison}

Two types of propulsion systems will be considered and evaluated to choose the most appropriate system. These two systems include the monopropellant and the bipropellant propulsion systems. From this, further design studies will be conducted to choose the propellant and other details required to fully define the propulsion system with components.

\section{Monopropellant}

A monopropellant system uses a single fluid that is injected through a catalyst bed or an electrically heated combustion chamber, where it decomposes generating hot, high velocity gas. The hot gas flows through a converging diverging nozzle producing thrust (Brown, 1996). A compatible fluid for use in a monopropellant system must be a slightly unstable chemical that decomposes exothermically (Brown, 1996). According to Charles D. Brown only three monopropellants have ever been used on flight vehicles including: hydrazine, hydrogen peroxide, and propyl nitrate. Propyl nitrate use was discontinued due to shock sensitivity. Hydrogen peroxide was used considerably starting with the German V2 rockets however; slow decomposition during storage problems has discontinued its mainstream use (Brown, 1996). Hydrazine was experimented with and found to have difficulty in initial ignition. This problem was solved by the Shell Development Company and Jet Propulsion Laboratory developing the Shell 405 iridium pellet catalyst bed in 1962, allowing for almost unlimited spontaneous restart capability. Due to the high performance, spontaneous restart capability, clean exhaust, low flame temperature, and the relative stability of hydrazine made it the chosen propellant for monopropellant systems and is the only monopropellant in mainstream use today (Brown, 1996). Since 
hydrazine is used exclusively in current monopropellant systems, its use will be assumed for the trade studies in this paper.

The gas produced after Hydrazine decomposition is in the $2200^{\circ} \mathrm{F}$ range which means that high-temperature alloys should be used for the nozzle, but a cooling system is not generally required (Brown, 1996). Monopropellant Hydrazine thrusters have achieved thrust levels between 0.1 and $600 \mathrm{lbs}$ and many systems are in use today.

\section{Bipropellant}

A bipropellant system uses two fluids stored separately consisting of a fuel and an oxidizer. A bipropellant system can be pressure or pump fed. The oxidizer and fuel are fed in their liquid state through the injector (Brown, 1996). Combustion takes place in the combustion chamber as the liquids mix producing a hot, high velocity gas that flows through the converging diverging nozzle producing thrust (Brown, 1996). The role of the injector is to promote stable, efficient combustion in the combustion chamber without overheating the chamber (Brown, 1996). The injector design in a bipropellant system is the most important component relating to stability and performance (Brown, 1996). Typical exhaust temperatures are in the range of $6000^{\circ} \mathrm{F}$ and velocities around $2000 \mathrm{ft} / \mathrm{s}$ (Brown, 1996). These high temperatures require cooling of the combustion chamber and nozzle. Some cooling methods used include: film cooling which washes liquid propellant down the combustion chamber wall cooling the wall by transferring heat from the wall for fuel vaporization and ablative cooling which requires the use of special materials for the chamber wall that are evaporated and eroded away during firing (Brown, 1996). 
The fuel most commonly used in a bi-propellant system today is a mixture of Hydrazine and monomethylhydrazine (MMH) (other than cryogenics as used in the Space Shuttle) (Brown, 1996). Nitrogen Tetroxide is used with Hydrazine based fuels and is hypergolic, meaning it ignites spontaneously on contact (Brown, 1996). This property allows for pulsing of the thruster. The exhaust gases of this bipropellant system are generally compatible with stainless steel, aluminum, and Teflon. Since the Hydrazine and MMH mixture with Nitrogen Tetroxide oxidizer is the most common fuel-oxidizer pair in a bipropellant system, its use will be assumed in the bipropellant system for the system comparison in this paper (Brown, 1996). Table 4 shown on the next page outlines advantages and disadvantages between monopropellant and bipropellant propulsion systems. 
Table 4. Advantages and disadvantages of monopropellant and bipropellant systems.

\begin{tabular}{|c|c|}
\hline \multicolumn{2}{|c|}{ Monopropellant Propulsion System } \\
\hline Advantages & Disadvantages \\
\hline Reliable & Catalyst bed miniaturization complexity \\
\hline Demonstrated required $\mathrm{I}_{\mathrm{sp}}$ & Cold start damage to and Flow erosion of catalyst bed \\
\hline \multicolumn{2}{|l|}{ Pulsing capable } \\
\hline \multicolumn{2}{|l|}{ Rapid start/stop capable } \\
\hline \multicolumn{2}{|l|}{ High $\mathrm{I}_{\mathrm{sp}}$} \\
\hline \multicolumn{2}{|l|}{ Part availability } \\
\hline \multicolumn{2}{|l|}{ Propellant availability } \\
\hline \multicolumn{2}{|l|}{$\begin{array}{l}\text { Compatible with CubeSat material requirements } \\
\text { (Aluminum) }\end{array}$} \\
\hline \multicolumn{2}{|c|}{ Bipropellant Propulsion System } \\
\hline Advantages & Disadvantages \\
\hline Increased $\mathrm{I}_{\mathrm{sp}}$ over monopropellant & Most complex propulsion system (Injector design etc.) \\
\hline \multirow[t]{7}{*}{ No catalyst bed required } & Most expensive propulsion system \\
\hline & $\begin{array}{l}\text { Larger mass due to plumbing and storage of fuel and } \\
\text { oxidizer }\end{array}$ \\
\hline & Miniaturization very complex \\
\hline & $\begin{array}{l}\text { Oxidizer compatibility issues with tank/bladder } \\
\text { material }\end{array}$ \\
\hline & Cooling system/systems required \\
\hline & $\begin{array}{l}\text { Decreased volumetric efficiency from fuel oxidizer } \\
\text { storage }\end{array}$ \\
\hline & Increased number of failure modes due to complexity \\
\hline
\end{tabular}

The monopropellant propulsion system is the better choice in this case since it has demonstrated the performance required while being the least complex and the overall less expensive system. The catalyst bed degradation problem can be solved by redesigning the catalyst or by using electrothermal thrusters which will be considered next. 


\section{Electrothermal Thrusters}

The $\mathrm{I}_{\mathrm{sp}}$ of a hydrazine monopropellant system can be greatly increased if the temperature of the decomposition products is increased. One way of achieving this includes the use of electrothermal thrusters over conventional monopropellant system thrusters (Brown, 1996). This method should be considered when adequate time before firing is allowed to condition the thrusters, steady-state burns are required, low thrust levels are required and substantial spacecraft power is available for a short time (Brown, 1996).

The electrothermal thrusters use electric energy to both cause decomposition and heat decomposition products (Brown, 1996). The hydrazine is injected into the combustion chamber and decomposes over a platinum thermal capacitance screen pack that has been heated to approximately $1300^{\circ} \mathrm{F}$ prior to firing (Brown, 1996). The decomposition products then enter a vortex heat exchanger tangentially and are heated further to approximately $3500^{\circ} \mathrm{F}$ (Brown, 1996). This can increase the $\mathrm{I}_{\mathrm{sp}}$ up to $28 \%$ (Brown, 1996). A commercial thruster, Intelsat V, produces a thrust of $0.1 \mathrm{lbs}$. and requires a maximum of $414 \mathrm{~W}$. The main advantage of this type of thruster over the conventional monopropellant system is the fact that a catalyst bed is no longer required which eliminates the problem of catalyst bed degradation. Table 5 shown on the next page summarizes the advantages and disadvantages of using an Electrothermal Thruster over the conventional thruster used in a monopropellant system 
Table 5. Advantages and disadvantages of electrothermal thrusters.

\begin{tabular}{|l|l|}
\hline \multicolumn{2}{|c|}{ Adectrothermal Thrusters } \\
\hline $\begin{array}{l}\text { Increased Isp over conventional monopropellant } \\
\text { system }\end{array}$ & Time needed before firing to heat components \\
\hline No Catalyst bed required & Large electrical power required \\
\hline & Added complexity to conventional monopropellant system \\
\hline & Higher cost over conventional monopropellant system \\
\hline & More mass over conventional monopropellant system \\
\hline & $\begin{array}{l}\text { Arcjet thrusters require time to start arc, short pulses not } \\
\text { practical }\end{array}$ \\
\hline
\end{tabular}

The Electrothermal thruster is not a viable option for CubeSat propulsion due to the added mass and the large electrical power required for heating. In addition, the extra time needed before firing the thruster to heat the chamber would not be acceptable for attitude control thrusters.

The Arcjet thruster also uses electrical energy to heat the decomposition products (Brown, 1996). The hydrazine is decomposed over an iridium catalyst bed similar to a typical monopropellant propulsion system (Brown, 1996). A gas manifold directs the hot decomposition products into the electrode region while inducing a rotary motion (Brown, 1996). The products pass through the throat of the thruster were they are heated and accelerated producing thrust (Brown, 1996). Similar decomposition product temperatures to the electrothermal thrusters as well as power requirements are expected. The Arcjet thruster acts as a conventional monopropellant thruster with the arc turned off. To start the arc requires a process which includes firing the thruster in conventional form for approximately $20 \mathrm{~s}$ to ensure propellant flow through the arc region of the thruster, then the arc is started and steady-state temperature and performance are reached. This process 
clearly shows that Arcjet thrusters are used in longer, steady-state burns and not necessarily for short burns used in attitude control. For the same reasons listed above for the Electrothermal Thrusters, Arcjet thrusters are not a viable option for use in CubeSats. However, if the mass requirements were relaxed slightly the Electrothermal or Arcjet thrusters may be an attractive option for missions requiring longer steady state burns (Brown, 1996).

The monopropellant system using a conventional catalyst bed decomposition thruster is the most appropriate propulsion system for CubeSat propulsion.

\section{Hydrogen Peroxide vs. Hydrazine}

Hydrogen Peroxide $\left(\mathrm{H}_{2} \mathrm{O}_{2}\right)$ has had success as a monopropellant in the past and has received more attention presently due to its environmentally friendly decomposition products and less stringent handling requirements. Hydrogen Peroxide decomposes into water and oxygen making it a non-toxic propellant. Problems in the past with slow decomposition during long storage periods have seen it replaced by Hydrazine (Brown, 1996). Another reason for Hydrogen Peroxide's replacement is the fact that Hydrazine thrusters have been developed to produce a specific impulse on the high end of approximately 220-230 s while Hydrogen Peroxide is on the order of $150 \mathrm{~s}$ (Micci, 2000). The fact that Hydrogen Peroxide is non toxic is attractive from a cost standpoint also because the ground handling and storage may require less infrastructure and equipment than that of Hydrazine. However, care needs to be taken in the storage of Hydrogen Peroxide because it will decompose when it comes into contact with a catalyst and almost any organic material can act as a catalyst. Since Hydrazine systems have been the most common monopropellant propulsion systems in use, the testing and launch site range 
safety personnel have the processes and infrastructure needed for the handling of Hydrazine. Even though Hydrogen Peroxide may be a "greener" propellant it may require more effort from a range safety standpoint to handle it since it has not been extensively used.

Because the estimated required specific impulse for this application is on the order of $220 \mathrm{~s}$ as shown in Table 1, the lower specific impulse of Hydrogen Peroxide eliminates it from consideration in this application. If the required $\Delta \mathrm{V}$ requirements decreased, Hydrogen Peroxide as a propellant may be acceptable. This may decrease the overall mission cost due to possibly less stringent handling requirements as compared with Hydrazine.

For this application a monopropellant propulsion system using Hydrazine propellant gives the best chance of project success.

\section{Propellant Safety}

With the use of Hydrazine for the propellant in the micro propulsion system, come safety concerns. Since Hydrazine propulsion technology is mature, many guidelines and procedures have been established to ensure safe handling and use of Hydrazine as a propellant. These guidelines and procedures must be followed closely to ensure personnel safety.

\section{Storage and Ground Handling}

Anhydrous Hydrazine can be handled safely with strict adherence to safety requirements. It is preferred to store Hydrazine outside in a free standing storage container separate from other buildings (Company). If the Hydrazine is stored inside it 
should be stored in a standard flammable liquid storage room or cabinet (Company). The storage tanks should be located in a diked area, meaning any spilled Hydrazine will not be able to escape its designated storage area (Company). Hydrazine must be stored away from heat, sparks, open flame, and oxidizers (Company). All Hydrazine storage containers and cabinets must be clean and must not be contaminated (Company). Hydrazine may be stored in DOT approved containers in which it had been shipped (Company). Since Hydrazine is Hygroscopic meaning it absorbs moisture from the air, any open containers must be purged with nitrogen to prevent exposure to moisture (Company). For this application small amounts of Hydrazine will need to be handled and stored. An open hydrazine storage container is not expected to be needed and the hydrazine will probably be stored in its DOT approved shipping container (Company). Since hydrazine is stable it can be stored for long periods of time without decomposition (Company). The storage container should always remain securely closed and should be carefully vented when opened (Company). Anhydrous Hydrazine is insensitive to shock and friction (Company).

Since Hydrazine is toxic and a suspected carcinogen, special care must be taken during handling to avoid exposure to the skin and eyes. In the event of exposure to eyes or skin, flushing with water for at least 15 minutes is recommended. Ingestion of Hydrazine is also very dangerous and immediate medical attention is required. In order to avoid ingestion or inhalation exposure the National Institute of Occupational Safety and Health (NIOSH) has published recommendations for proper respirators. These respirators were selected based on their assigned protection factor. The estimated concentration of a contaminant is divided by its exposure limit to attain a hazard ratio. The assigned 
protection factor must be greater than the hazard ratio. For this application NIOSH recommends a respirator with an assigned protection factor of at least 10,000. Only respirators with a positive pressure fresh air supply meet this requirement (Stellman). In

order to avoid exposure to the skin and eyes, OSHA recommends anyone near hydrazine should wear an acid resistant coverall suit with boots, gloves, goggles, a respirator and a face shield.

In the case of a spill, dilute spilled Hydrazine to $40 \%$ Hydrazine $60 \%$ water solution. Hydrazine can be disposed of after dilution and subsequent neutralization using dilute sulfuric acid. This solution may be drained in the sewer with abundant water (Organization, 1991). Foam may be applied to slow vaporization and small spills may be absorbed using sand (Organization, 1991). Any personnel attempting to clean up a spill must ensure personal protection including a self contained positive pressure respirator as described in the preceding paragraph (Organization, 1991).

\section{Thruster Configuration}

Many different thruster configurations have been proposed and used on spacecraft. These configurations range from 24 thrusters used on spacecraft with deep space missions to 4 thrusters on small satellites (Svitek, 2008-2009). The larger number of thrusters is used when maneuvers in any of the 6 degrees of freedom are required instantly. As this requirement is relaxed, thrusters may be removed down to the simplest 4 thruster configuration. The four thruster configuration uses thrusters that are canted outward to allow for rotation and translation on all three axes but lose efficiency because the canted angle of the thrusters forces them to act against each other, wasting propellant 
(Svitek, 2008-2009). For this application, a four thruster configuration will be used because it is the simplest configuration and will still allow for translation and rotation in all three principal axes. This configuration will provide useful maneuvers especially orbit maintenance and transfer. In addition, the propulsion system can be modified in the future for more maneuverability as mission requirements dictate by incorporating more thrusters when mass and geometric requirements allow.

\section{Required Thrust}

The thrust required for any spacecraft is determined by the mission requirements. Since this is a new application, the required thrust magnitude and duration is not well defined because it is not known what maneuvers will be required of the micro propulsion system. As discussed in the performance section of this paper, the thrust to weight ratio of previous spacecrafts have been studied and a general thrust to weight ratio defined for desired maneuvers. From this analysis a required total trust level of $7-10 \mathrm{~N}$ was derived. Since a four thruster configuration will be used, a corresponding thrust of between 1.8 2.6 $\mathrm{N}$ per thruster will be assumed in the thruster design. With the desired thrust and assumed $\mathrm{I}_{\mathrm{sp}}$, the mass flow rate can be calculated using Equation 1 in the performance section of this paper. From this the corresponding thruster combustion chamber pressure, combustion chamber dimensions, and converging- diverging nozzle shape and dimensions can be derived. 


\section{Thruster Combustion Chamber Pressure}

The thruster combustion chamber pressure is related to the desired thrust and the combustion chamber dimensions including the nozzle throat diameter. The propellant $I_{\mathrm{sp}}$ is also affected by the thruster combustion chamber pressure for a hydrazine system. Hydrazine decomposes into ammonia and nitrogen in an exothermic reaction. The ammonia then breaks down into hydrogen and nitrogen endothermically (Brown, 1996). Since this reaction is endothermic the overall specific impulse is reduced compared with a decomposition of Hydrazine into ammonia and nitrogen only. Ammonia dissociation can be reduced with one of the affecting factors being the thruster combustion chamber pressure (Jurgen Mueller). Because of the large number of coupled variables involved in thruster design including the thruster combustion chamber pressure, historical data on commercial thrusters was collected to use as a starting point.

A survey of commercial, off-the-shelf thrusters in the range of $0.5-3 \mathrm{~N}$ was conducted. The specifications for each were collected including nozzle diameter, and inlet or chamber pressure (Monopropellant Hydrazine Thrusters, 2003). The chamber pressure for each ranged from $550-2250 \mathrm{kPa}$. Over this pressure range, a table was constructed comparing chamber pressure to the theoretical nozzle throat diameter required for a given thrust. From the required thrust, the minimum mass flow rate of propellant was calculated and used to calculate the nozzle throat diameter. The results are recorded in Table 6 on the next page and show that the required theoretical nozzle throat diameter is on the order of $0.9-2.1 \mathrm{~mm}$. 
Table 6. Chamber pressure and corresponding throat diameter.

\begin{tabular}{|c|c|c|c|}
\hline \multicolumn{2}{|c|}{ Thrust $=1.84 \mathrm{~N}$} & \multicolumn{2}{c|}{ Thrust $=2.58 \mathrm{~N}$} \\
\hline $\begin{array}{l}\text { Chamber Pressure } \\
(\mathbf{k P a})\end{array}$ & $\begin{array}{l}\text { Throat Diameter } \\
(\mathbf{m m})\end{array}$ & $\begin{array}{l}\text { Chamber Pressure } \\
(\mathbf{k P a})\end{array}$ & $\begin{array}{l}\text { Throat Diameter } \\
(\mathbf{m m})\end{array}$ \\
\hline 550 & 1.82 & 550 & 2.15 \\
\hline 650 & 1.67 & 750 & 1.98 \\
\hline 750 & 1.56 & 850 & 1.84 \\
\hline 850 & 1.46 & 950 & 1.73 \\
\hline 950 & 1.38 & 1050 & 1.56 \\
\hline 1050 & 1.31 & 1150 & 1.49 \\
\hline 1150 & 1.26 & 1250 & 1.43 \\
\hline 1250 & 1.21 & 1350 & 1.37 \\
\hline 1350 & 1.16 & 1450 & 1.28 \\
\hline 1450 & 1.12 & 1550 & 1.24 \\
\hline 1550 & 1.08 & 1650 & 1.21 \\
\hline 1650 & 1.05 & 1750 & 1.17 \\
\hline 1750 & 1.02 & 1850 & 1.14 \\
\hline 1850 & 0.99 & 1950 & 1.11 \\
\hline 1950 & 0.96 & 2050 & 1.09 \\
\hline 2050 & 0.94 & 2150 & 1.06 \\
\hline 2150 & 0.92 & 2250 & \\
\hline 2250 & 0.90 & & \\
\hline
\end{tabular}

Table 6 demonstrates that as the chamber pressure is increased the throat diameter for a given thrust decreases. This means that a smaller engine both in mass and volume can be used for a system with a higher chamber pressure. However, to get a higher chamber pressure, the tank storage pressure must be increased which then increases the storage tank mass. In the range of nozzle throat diameters listed in the table above, as the nozzle throat diameter decreases, the complexity and cost of machining the nozzles increase rapidly. Also, because of the small size of the nozzle and combustion chamber, the mass savings due to increased pressure allowing for an overall smaller engine is not significant. Therefore the manufacturability of the nozzle and combustion chamber will drive the design of the nozzle and dictate the chamber pressure accordingly. Five hundred 
and fifty $\mathrm{kPa}$ was chosen based on the manufacturability of the nozzle and combustion chamber and the fact that the lower pressure will allow for a much lighter storage tank design. The chamber pressure of $550 \mathrm{kPa}$ corresponds to a throat diameter in the range of $1.8-2.1 \mathrm{~mm}$. This may be modified if needed after empirical testing of the thruster. The throat diameter used in the thruster design will be $2.0 \mathrm{~mm}$.

\section{Catalyst Bed}

Historically, the catalyst used in most commercial spacecraft applications is the SHELL 405 iridium coated ceramic catalyst (Monopropellant Rocket, 2009). These catalyst pellets are held in place with retaining screens on the entrance and outlet sides of the chamber. A ceramic pellet with a catalyst coating is also common in automotive and industrial pollution control applications. The ceramic acts as the structure for the platinum or iridium based catalyst. A common catalyst design challenge is reducing the erosion of the catalyst material. This occurs due to the high pressure and temperature of the entering propellant "washing" the catalyst coating or plating from the support structure. Armadillo Aerospace has conducted experiments with stainless steel wire with platinum plating for use as a catalyst as well. This came with poor results due to the platinum being "washed off" of the wire from the flow of propellant (News Archive, 2003). Don Platt of Micro Aerospace Solutions has experimented with platinum metal "gauze" for use as a catalyst with good results. Because of the difficulty in obtaining Shell 405 catalyst which is now owned and produced by Aerojet, a platinum wire or platinum coated wire or mesh catalyst may be the right choice for this application. 
A platinum wire mesh disc with a platinum/iridium ring support welded around the circumference was designed with the intention of "stacking" as many of these catalyst washers inside the combustion chamber as required (Edney, 2009). Graham Edney of Santa Barbara aided in the design of the catalyst structure and came up with the modular catalyst design approach. This design allows for adding or subtracting catalyst surface area in order to use the right amount of catalyst for complete decomposition of hydrazine. In order to hold the screens in place, the combustion chamber will be machined in a way that the catalyst screens will be held by an internal machined shoulder.

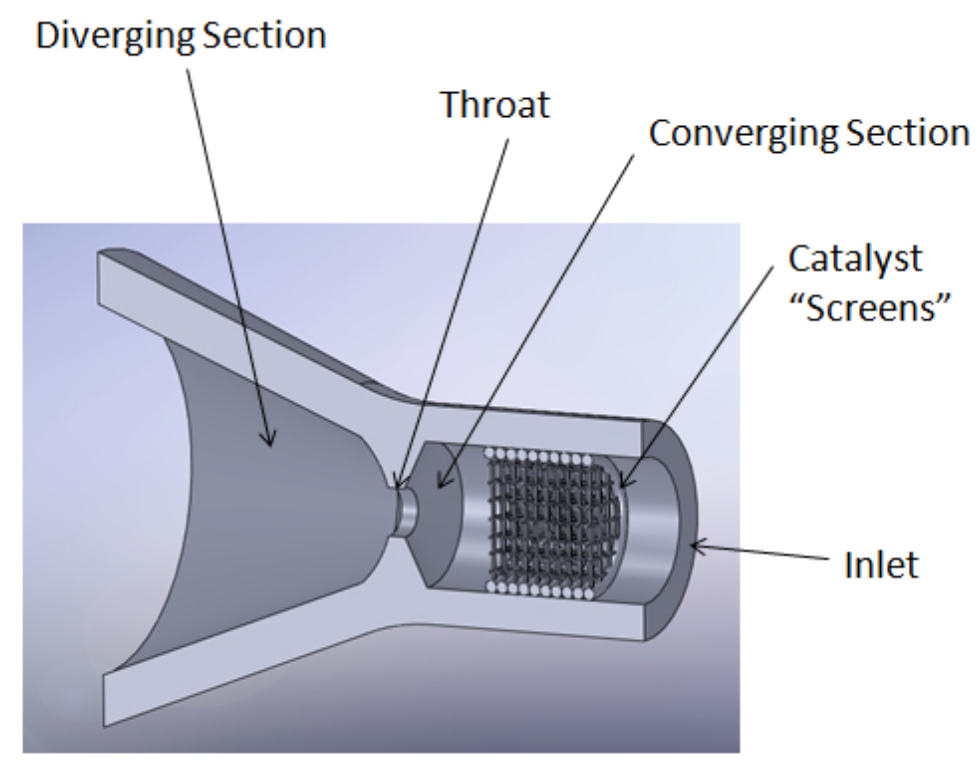

Figure 4. Nozzle section view with catalyst screen concept.

Another catalyst iteration uses the same structure shown in Figure 4 with the addition of a bolt through the center of the "screens" with a nut attached to hold the entire unit together. This was another design idea provided by Graham Edney. This results in both keeping the assembly together during impact from the propellant stream as well as making the loading of the catalyst into the thruster assembly easier by loading the entire 
catalyst at once rather than each individual screen at a time. Because of the small size of the rings and very fine mesh size, a laser welder was required to manufacture the catalyst. Graham Edney formed the rings and cut the wire mesh to the appropriate size by hand and laser welded each individual screen assembly. The assembled catalyst is shown in Figure 5. Hot fire testing will be required to verify the proper function and structural integrity of the catalyst. Also the correct amount of catalyst surface area can be attained empirically by a series of hot fire tests.

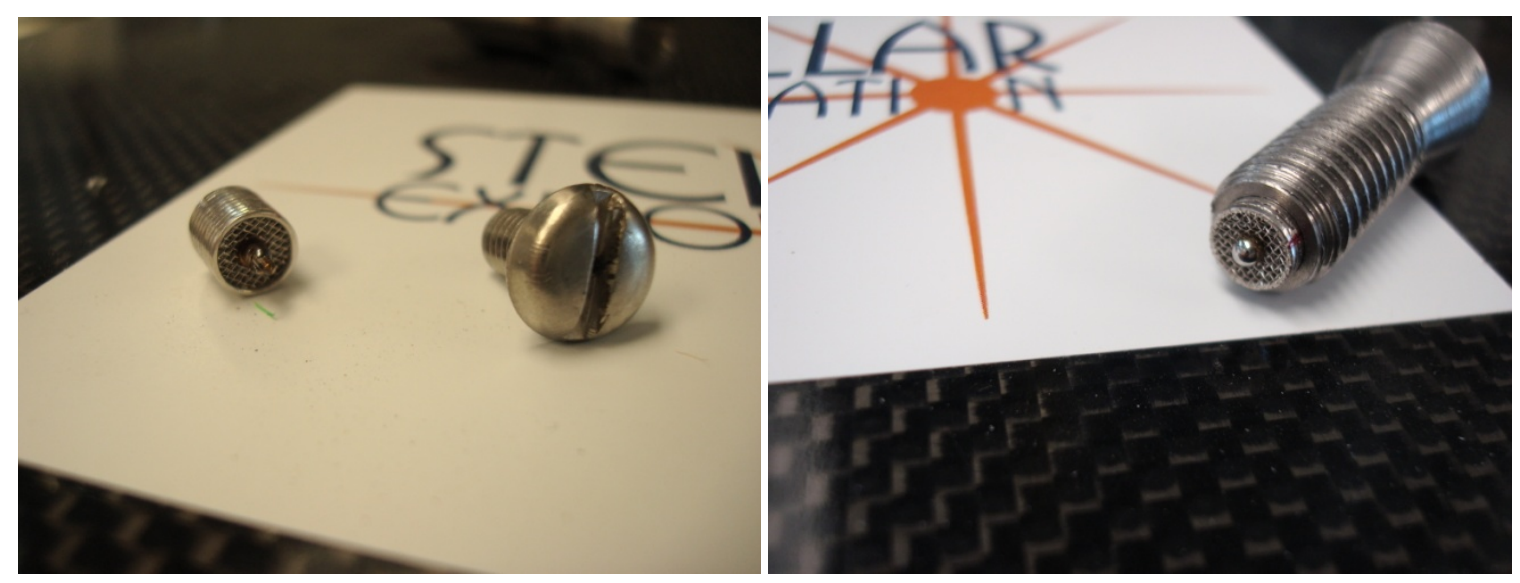

Figure 5. Assembled catalyst shown next to the valve stud (left) and partially loaded into combustion chamber (right).

\section{Storage Pressure}

The main factor driving the storage pressure is the chamber pressure required for a specific thrust (Humble, 1995). The thrust is proportional to the mass flow rate of the propellant which is proportional to the chamber pressure and chamber throat area (Humble, 1995). Based on this, the throat area can be reduced by increasing the chamber pressure for a given mass flow rate (Humble, 1995). And if the chamber dimensions can be reduced the entire engine's dimensions can be reduced thus reducing the overall mass 
of the engine (Humble, 1995). However, as chamber pressure increases the storage pressure increases leading to greater storage tank mass (Humble, 1995).

The hydrazine propellant is pressurized with a small volume of gas at the required storage pressure. Since the designed operating pressure is at $550 \mathrm{kPa}$, the initial storage pressure must be larger in order to have a longer operating time. The theoretical minimum tank absolute pressure for thruster operation is equal to the pressure losses through the valves, catalyst bed, and the nozzle throat. Based on historical data about 75$80 \%$ of the propellant is used over the lifetime of the mission (Svitek, 2008-2009). Dr. Tomas Svitek proposed calculating a storage pressure by assuming that $20 \%$ of the storage pressure is equal to the pressure losses through the system and multiplying that value by five to get the storage pressure (Svitek, 2008-2009). This is referred to as the blow down ratio and is defined by the ratio of initial pressurant gas pressure over the final pressurant gas pressure. Charles D. Brown, the author of "Spacecraft Propulsion", states that blow down ratios of 3-4 are in common use and ratios of up to 6 have been flown (Brown, 1996). He also provided a function for the decrease in $I_{\mathrm{sp}}$ over the blow down period, which predicted an $\mathrm{I}_{\mathrm{sp}}$ decrease of $2.5 \%$ for a blow down ratio of 5 (Brown, 1996). It was assumed that approximately $220 \mathrm{kPa}$ would be required for thruster operation which led to an initial storage pressure of approximately $1100 \mathrm{kPa}$ (Svitek, 2008-2009). For this project $1100 \mathrm{kPa}$ will be assumed for the initial storage tank pressure.

\section{Thruster Valve Design and Integration}

The thruster valve requirements are based on the pressure and mass flow rate of the thrusters. The maximum pressure rating of the thruster valves should be at least equal 
to the storage pressure of the propellant tank. The flow rate through the valve must be greater than or equal to the minimum flow through the thruster. The valve must not allow any propellant leakage over the entire pressure range. The entire propulsion system will be designed around the valve, catalyst bed and nozzle. Off the shelf components or modified off the shelf components will be used if possible in order to narrow the scope of this project and begin testing a viable propulsion system.

The valve chosen for this application is an ASCO micro-solenoid valve (Figure 6). The valve is rated to $760 \mathrm{kPa}$ but will be modified in order to accept $1100 \mathrm{kPa}$ if possible. The input and outlet ports use a \#10-32 thread and contain a $0.635 \mathrm{~mm}$ diameter orifice. The valve has a diameter of approximately $19 \mathrm{~mm}$ and is constructed of steel and polymers.

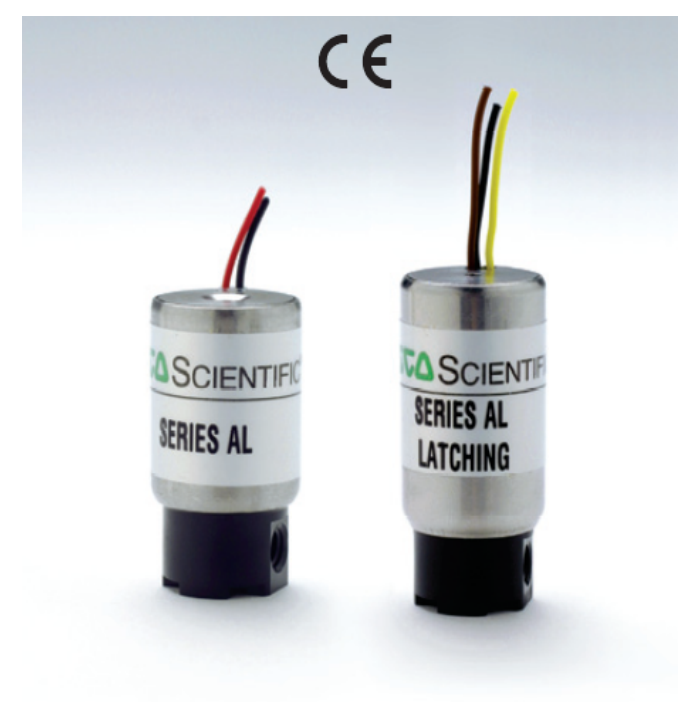

Figure 6. ASCO miniature solenoid valve.

The valve will be placed between the tank and thruster and mounted to the tank cap, via a treaded steel stud threaded into the cap with an o-ring seal and a $1.17 \mathrm{~mm}$ orifice. This is 
the best off-the-shelf valve in respect to mass and meeting the requirements found up to this point.

\section{Nozzle Design}

The converging-diverging nozzle in the engine has four main sections that include the combustion chamber, converging section, the throat, and the diverging exit section. The throat diameter is determined by the mass flow rate of the propellant and the combustion chamber pressure and is the first of the three main sections to be designed. As discussed in the feed pressure section, the required throat diameter is $2 \mathrm{~mm}$ as calculated for an ideal case. From this, the combustion chamber and nozzle dimensions can be estimated. As stated in Space Propulsion Analysis and Design, the combustion chamber design is largely based on empirical data (Humble, 1995). To find appropriate combustion chamber dimensions, gas dynamics as well as empirical data will be combined. The first step was to find a theoretical combustion chamber area.

In order to determine appropriate combustion chamber dimensions the chamber contraction ratio needs to be evaluated. The contraction ratio is defined as the area ratio of the combustion chamber and the throat. This ratio is used in calculating the appropriate combustion chamber cross sectional area. From the appropriate cross sectional area, and assuming a cylindrical cross section, the combustion chamber diameter can be calculated.

Assuming isentropic, one-dimensional flow of an ideal gas, the continuity equation relates the density, cross-sectional area, and velocities of a flow at axial locations inside the combustion chamber. From this relationship, an area ratio between the two locations can be derived and the velocities at the two locations can be written in 
terms of Mach number. By assuming one location is the nozzle throat where the velocity is known results in Equation 7. The velocity is known at this location assuming choked flow. This allows for calculation of the chamber contraction ratio. Equation 7 below is the final form of the chamber to throat area ratio.

$$
\frac{A_{c}}{A_{t}}=\frac{1}{M}\left[\left(\frac{2}{\gamma+1}\right)\left(1+\frac{\gamma-1}{2}\right) M^{2}\right]^{\frac{\gamma+1}{2(\gamma-1)}}
$$

With an assumed gas velocity inside the combustion chamber, the chamber area to throat area ratio was calculated. The combustion chamber velocities are typically Mach 0.2-0.4. A conservative approach is to assume a Mach number of 0.1 for this analysis (Humble, 1995). A small chamber Mach number corresponds to a larger chamber volume which means a longer residence time for the chemical reaction to occur within the combustion chamber (Humble, 1995). Assuming a Mach number of 0.1, the chamber contraction ratio was calculated to be approximately 6 . This result leads to a chamber diameter of $5 \mathrm{~mm}$. In order to specify a combustion chamber length, a survey of length to diameter ratios of previous engines was created to use as a starting point. From the historical data gathered by the authors of Space Propulsion Analysis and Design, common combustion chamber length to diameter ratios range from $0.5-2.5$, which means the ratio, may be driven by many factors not including combustion performance such as volume constraints. A length to diameter ratio of 1.5 was chosen for this project. It was decided to add a small margin to the diameter for ease of manufacturing both the combustion chamber and the catalyst itself. This lead to combustion chamber dimensions of $6 \mathrm{~mm}$ in diameter and $9 \mathrm{~mm}$ in length. 
For the nozzle design, an appropriate expansion ratio must be determined as well as the overall shape. The theoretical $\mathrm{I}_{\mathrm{sp}}$ of the thruster is a function of the propellant properties as well as the chamber pressure, ambient pressure, and exit pressure which is a function of the nozzle expansion ratio. Assuming an ambient pressure of $0 \mathrm{kPa}$ and a nozzle efficiency of $90 \%$, the theoretical $\mathrm{I}_{\mathrm{sp}}$ as a function of expansion ratio was plotted in order to pick an appropriate expansion ratio (Figure 7).

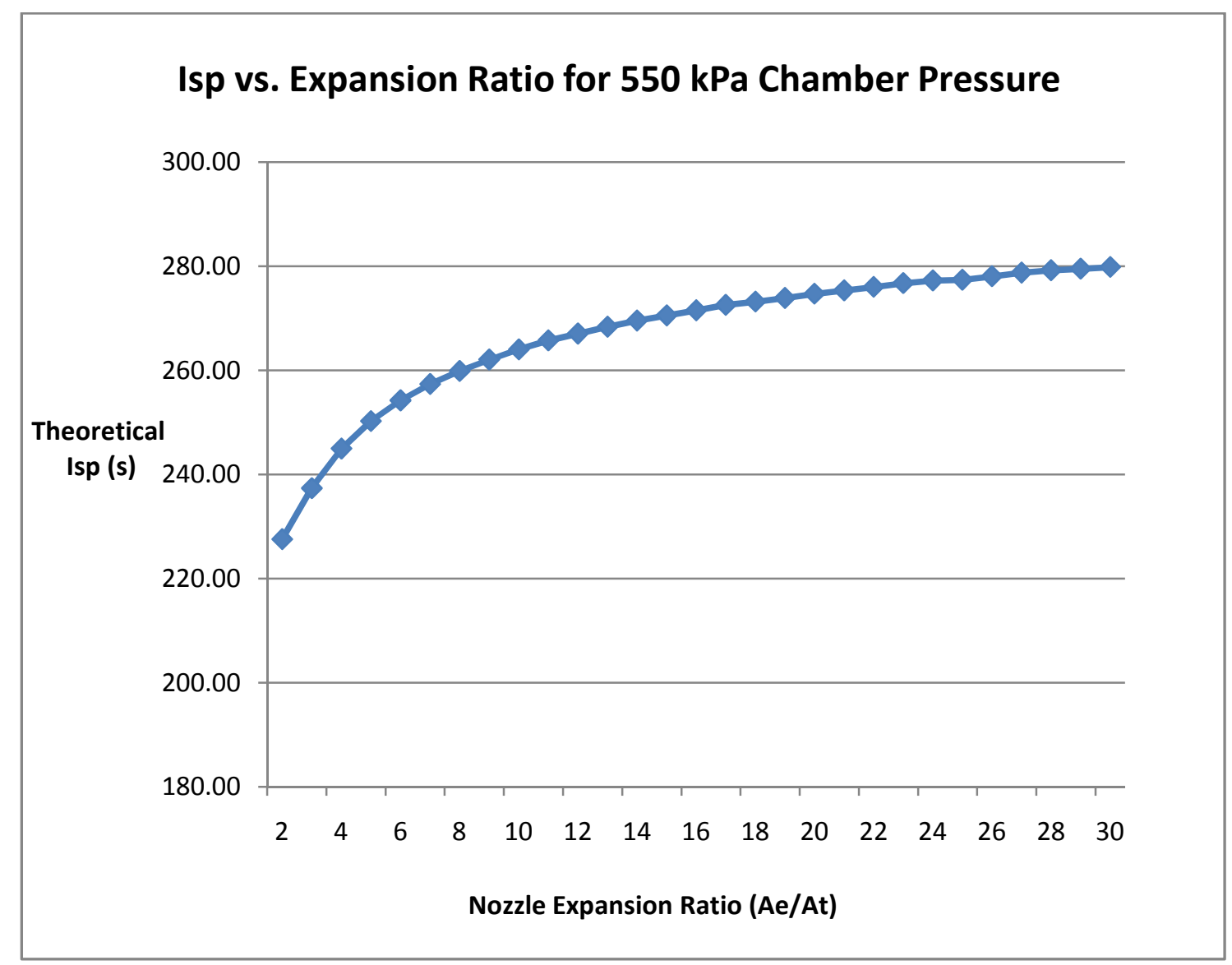

Figure 7. Plot of theoretical $I_{\mathrm{sp}}$ vs. Nozzle Expansion Ratio for a chamber pressure of $550 \mathrm{kPa}$.

Ideally the exit pressure at the end of the nozzle should equal the ambient pressure, but in this application that would require a nozzle of infinite length, since the exhaust exit is at zero absolute pressure. Also the length and mass constraints may 
override a longer nozzle if the gain in performance is not great. As shown by Figure 7, the $\mathrm{I}_{\mathrm{sp}}$ increases greatly for increasing expansion ratio for small expansion ratio values then starts to level off for larger expansion ratios. A table of the change in $\mathrm{I}_{\mathrm{sp}}$ divided by the change in expansion ratio was also constructed and an expansion ratio of 15 was chosen based on good performance without an excessive nozzle length and diameter. This expansion ratio leads to a nozzle exit diameter of approximately $7 \mathrm{~mm}$ and a length of $13 \mathrm{~mm}$.

The nozzle shape is driven by the overall reduction of exhaust gas velocity not normal to the nozzle exit plane. These velocities do not contribute to axial thrust which is considered an energy loss. Many nozzle shapes have been proposed and studied from a general conical shape to an Aerospike and bell mouthed. For this application a conical $15^{\circ}$ half angle nozzle is chosen based on the manufacturability and acceptable performance. According to Charles E. Rodgers, a gain in performance of about 3.5-8\% was shown in solid rocket nozzle design experiments using a bell-shaped throat and nozzle exit versus a straight cut conical nozzle (Rogers, 2004). This is a significant gain in performance, however because of the size of the nozzle and the required development of the overall system, the simpler straight cut conical nozzle will be used.

\section{Tank Material and Fabrication}

The storage pressure of the hydrazine will be the main driver of the tank design and thickness. Other considerations to take into account in the tank design include the launch loads and the proper function between the propulsion module and the P-POD which may be affected by deflections of the tank. Special care is taken to ensure no 
leakage of Hydrazine from the tank which means all mounting and sealing interfaces must have minimal deflections. According to the CubeSat Standard, the material used in the propulsion system module must have a thermal expansion coefficient comparable to 7075 or 6061 Aluminum. The recommended material is either 7075-T6 or 6061-T6 Aluminum. This fits with the material compatibility of Hydrazine which is generally Aluminum, Nickel and Stainless Steel (Riegel, 2003). The benefits of using 7075-T6 over 6061-T6 include a greater yield and ultimate strength, however 7075 is not weldable (Miller, 2008-2009). For this design a thin walled pressure tank of either cubic or cylindrical cross-section was studied. If 7075 Aluminum was to be used the tank must be machined or cast then attached to the CubeSat unit with some type of mechanical hardware since welding is not possible. The tank may have a mounting flange machined or cast into it for mounting to the CubeSat 3-unit structure.

A drawback of using a cylindrical or spherical tank to store propellant is the volume loss over a cubic tank. Cylindrical or Spherical tanks will have a mass savings over a cubic tank due to the large overall wall thickness and large internal radii to reduce stress concentrations required by the cubic tank. Since this application is both mass and volume critical, design studies of several different tank and cap shapes have been conducted and iterations performed to arrive at the maximum allowable propulsion system weight of $1 \mathrm{~kg}$ with the lowest dry mass fraction.

\section{Tank Design Concepts}

A brainstorming session was conducted at Stellar Exploration, San Luis Obispo and Maglio Inc. on December 15-18, 2008 in order to discuss the storage tank shape and 
dimensions along with the layout and initial sizing of the propulsion system components. Present at the meeting include: Dr. Tomas Svitek, Raymond "Bud" Fraze, Chris Maglio, Brian Miller, Alex Diaz, Brian Riskas, and Chris Biddy.

The content of the meeting included a discussion on CNC machining the propellant tank and cap with a cubic cross-section using as much of the $10 \mathrm{~cm}$ by $10 \mathrm{~cm}$ by $10 \mathrm{~cm}$ CubeSat volume constraint as possible and using 7075-T6 aluminum for its superior material strength properties and preferred thermal expansion. Also discussed was a welded sheet metal tank design with welded hypodermic needle tubing to deliver the propellant to the catalyst bed and nozzle. Some concerns were raised with the welded structure which included micro cracks at the weld surface due to both thermal and mechanical cycling. Also as the large stress concentrations in the storage tank at the weld bead, and larger costs associated with weld bead x-raying and laser welding manufacturing led to concerns (Miller, 2008-2009).

It was agreed upon that a cubic tank structure with the CubeSat interface and rails for the P-POD integration, using 7075-T6 Aluminum and CNC machining was the proper solution considering the time, size, and cost constraints. Also, all components are to be mounted to the tank cap including the thruster assembly, fill and drain valves, and any ports required for pressure or temperature measuring devices. This is necessary due to the minimum thickness required by the threads for mounting these components and the greater wall thickness of the cap over the tank.

After the initial tank geometry and configuration discussion, valve design and integration was discussed. It was decided that a custom valve integrated into the cap and 
placed inside the tank would maximize propellant volume as well as minimize valve mass because the tank cap would also act as the valve case. In order to narrow the scope of the project to fit the time and cost constraints, it was decided that an off the shelf miniature solenoid valve should be used with the remaining propulsion system designed around the chosen valve. This would allow for the project focus to remain on a system design and integration without the redesign of each individual component.

From this brainstorming session a cubic prototype tank was designed and modeled using SolidWorks and the mass properties and volume capacity were studied. For this initial prototype a $10 \mathrm{~cm}$ by $10 \mathrm{~cm}$ by $8.5 \mathrm{~cm}$ tank was constructed and COSMOS analysis was used to help determine the dimensions required in order to ensure a desired factor of safety was met concerning both stress and deflections. COSMOS is an analysis tool available through SolidWorks which calculates and displays stresses and strains. It was used to compare different design iterations. After analysis of this initial design, it was shown that the maximum allowable weight of $1 \mathrm{~kg}$ for the propulsion module may be exceeded without even taking up the entire tank volume with propellant. From this result it was decided that both a cylindrical and cubic tank would be designed in parallel and compared.

\section{Proposed Designs Comparison and Evaluation}

Two prototype assemblies were created, one with a cubic tank and cap and another with a cylindrical tank and cap. Both initial designs consisted of a tank and matching cap with the thrusters mounted to the cap and facing normal to the cap. The valves would be threaded onto stainless steel studs with o-ring seals on the inlet end and the thruster assembly would be threaded into the valve in the outlet side of the valve. The 
catalyst bed and nozzle components will be machined separately and then laser welded together to seal the catalyst bed inside. Laser welding is required because of the small size of the components as well as the mass savings of a welded connection over a threaded connection.

High pressure Schrader valves were chosen for use as the drain and fill valves due to their widespread use, reliability and low mass. The Schrader valves used in this design come from a FOX nitrogen filled damper for off-road race vehicles and are rated at 1380 kPa maximum operating pressure (Products, 2009). They also incorporate an o-ring seal which is necessary for proper sealing.
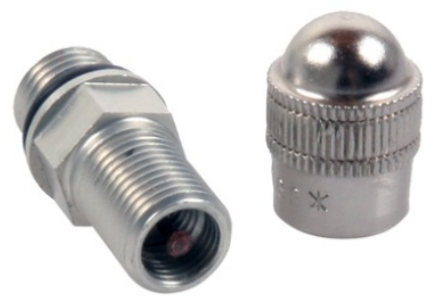

Figure 8. FOX Schrader valve and cap with o-ring rated at $1380 \mathrm{kPa}$ operating.

From the fixed dimensions of the valve and thruster assembly and the constraints described in the CubeSat standard a cubic tank and cap was designed while trying to minimize tank mass and hold an initial pressure of $1100 \mathrm{kPa}$. The cubic tank assembly is shown in Figure 9 below. 

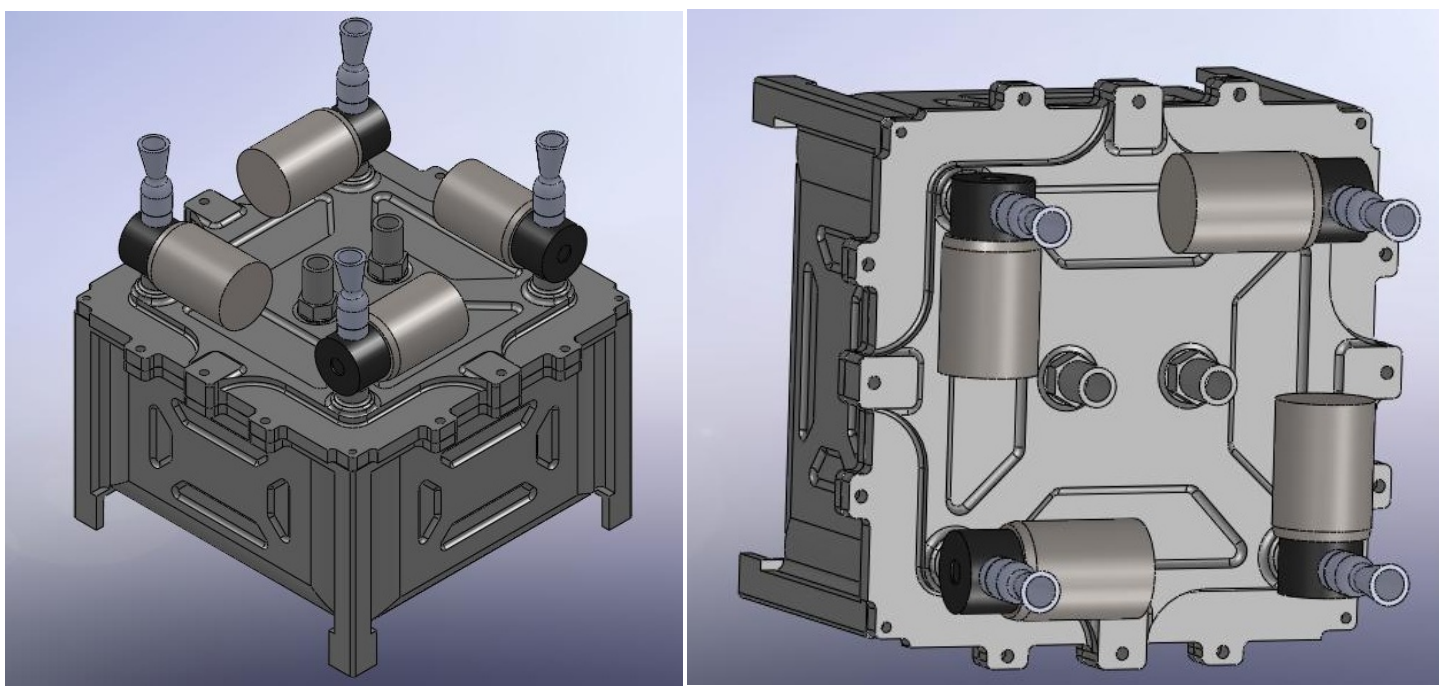

Figure 9. Cubic tank and cap prototype micropropulsion system assembly.

This design has a large internal volume capacity, but due to the large internal radii at the corners in order to reduce stress concentrations has a larger mass than a cylindrical tank. As per the CubeSat standard the mounting flanges of the tank and cap protrudes $6 \mathrm{~mm}$ from the four faces to allow access to the fasteners. This still allows for a $0.5 \mathrm{~mm}$ clearance with the P-POD walls while loaded in the P-POD. This design, while slightly less mass efficient, easily incorporates guide rails and utilizes the extra mass contained in the four vertical corners to satisfy the rail requirements as stated in the CubeSat standard.

A cylindrical tank was designed in order to reduce the dry mass required by the cubic tank while attempting to achieve internal volume capacity at or near that of the cubic tank design. Shown in Figure 10 is the cylindrical tank assembly with integrated guide rails as required by the CubeSat Standard. 

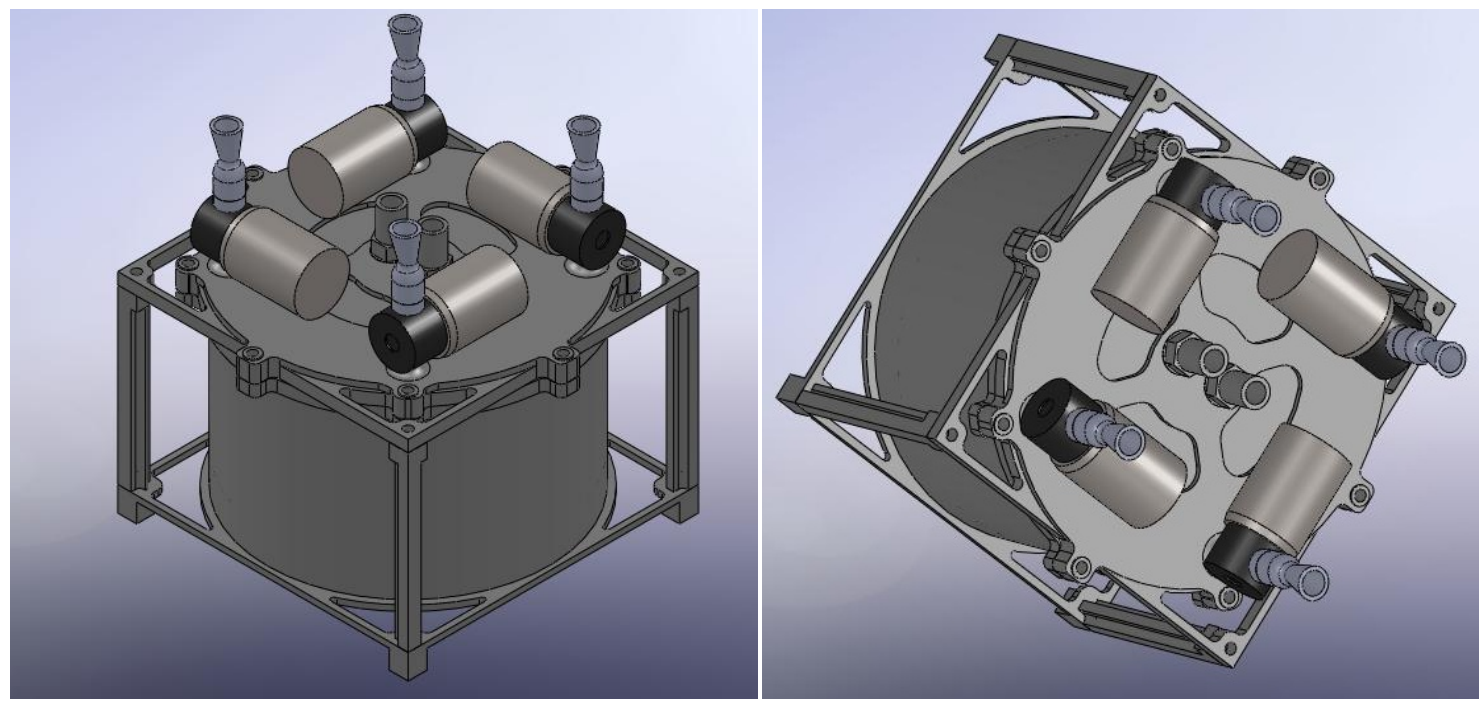

Figure 10. Cylindrical tank and cap prototype micropropulsion system assembly.

The cylindrical tank shown above reduces the overall mass of the assembly but at the expense of a large amount of fuel. As can be seen in Figure 10, a large amount of volume is wasted in the open space in the corners. While the wall thickness for this design is drastically reduced when compared to the wall thickness required for the cubic tank, too much propellant volume is lost.

Because of the overall length of the thruster assembly, the cubic and cylindrical tanks shown in Figure 9 and 10 are shorter than expected in order to meet the required maximum length. A second iteration of the cylindrical tank design includes a longer, narrower tank in order to mount the valves along the axis of the tank at the four corners of the assembly allowing for more tank height (Figure 11). This prototype was created in order to investigate if more internal volume can be gained while still achieving the lower mass benefits of having a cylindrical tank design. 

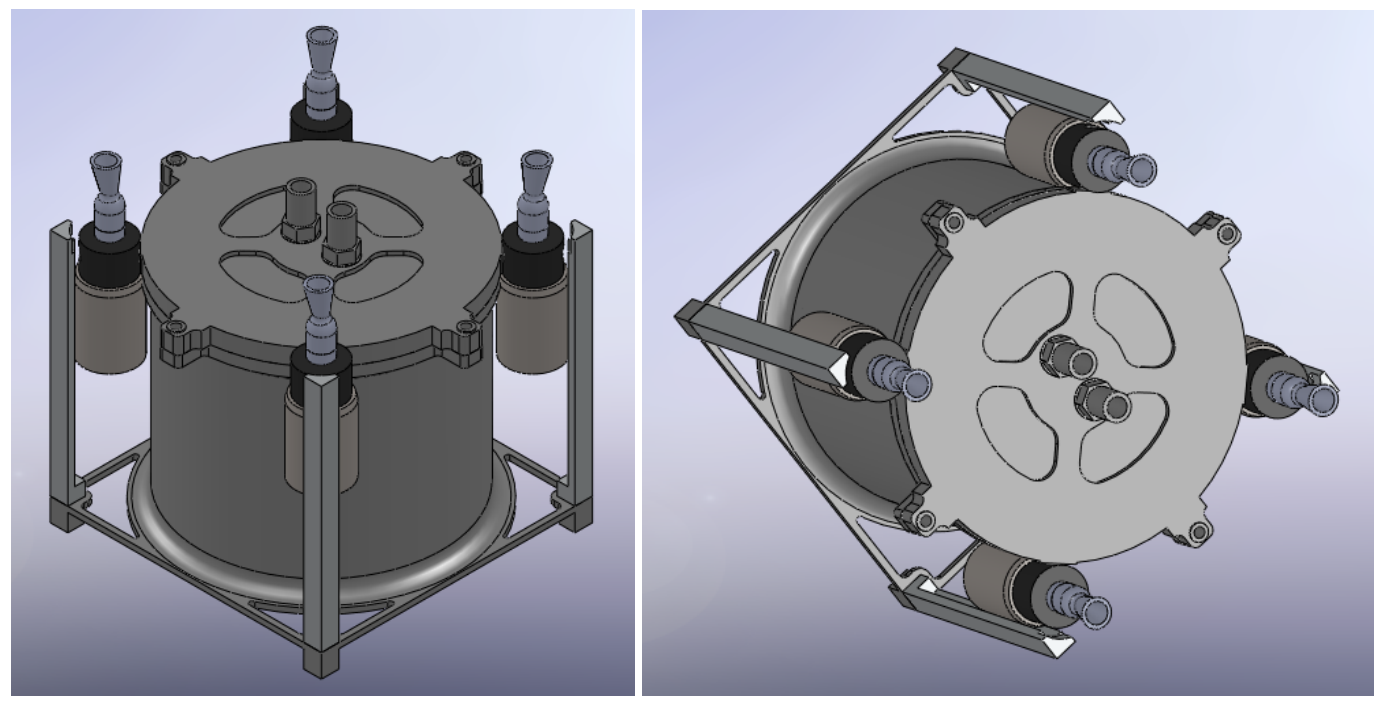

Figure 11. Cylindrical tank with vertically mounted thruster prototype Micropropulsion system assembly.

A table was created listing propulsion assembly dry mass and internal volume, along with an estimated overall spacecraft performance to compare the three concepts (Table 7).

Table 7. Tank geometry, mass, volume and corresponding delta V.

\begin{tabular}{|c|c|c|c|c|c|c|c|}
\hline $\begin{array}{c}\text { Tank Shape } \\
\text { and } \\
\text { Description }\end{array}$ & $\begin{array}{c}\text { Tank } \\
\text { Dimensions } \\
(\mathrm{mm})\end{array}$ & $\begin{array}{c}\text { Volume } \\
\text { Capacity } \\
(\mathrm{ml})\end{array}$ & $\begin{array}{c}\text { Assembly } \\
\text { Mass (g) }\end{array}$ & $\begin{array}{c}\text { Propellant } \\
\text { Mass (g) }\end{array}$ & $\begin{array}{c}\text { Fueled } \\
\text { System Mass } \\
(\mathrm{kg})\end{array}$ & $\begin{array}{c}\text { Dry } \\
\text { Mass } \\
\text { Fraction } \\
(\%)\end{array}$ & $\begin{array}{c}\text { Delta } \\
\mathrm{V}^{*} \\
(\mathrm{~m} / \mathrm{s})\end{array}$ \\
\hline $\begin{array}{c}\text { Cubic Tank } \\
\text { and Cap with } \\
\text { thruster } \\
\text { mounted to } \\
\text { cap }\end{array}$ & $\begin{array}{c}100 \mathrm{X} \mathrm{100X} \\
55\end{array}$ & 475.00 & 433.00 & 522.50 & 955.50 & 0.45 & 419.86 \\
\hline
\end{tabular}




\begin{tabular}{|c|c|c|c|c|c|c|c|}
\hline $\begin{array}{c}\text { Cylindrical } \\
\text { Tank and Cap } \\
\text { with thrusters } \\
\text { mounted } \\
\text { horizontally }\end{array}$ & $\begin{array}{c}97 \text { O.D. X } \\
77.85\end{array}$ & 443.00 & 345.00 & 487.30 & 832.30 & 0.41 & 407.48 \\
\hline $\begin{array}{c}\text { Cylindrical } \\
\text { Tank and Cap } \\
\text { with thrusters } \\
\text { mounted } \\
\text { vertically }\end{array}$ & 89 O.D. X 80 & 457.00 & 369.00 & 502.70 & 871.70 & 0.42 & 415.32 \\
\hline
\end{tabular}

*Assumes 220 second Isp

As shown from Table 7, the theoretical performance of the cubic tank is the largest of the three designs even though it has the highest unit dry mass fraction. The reason for this is because the cubic tank can hold much more propellant mass than the other two and when evaluated as a 3-unit CubeSat configuration the extra mass of propellant is of more importance than the greater mass of the tank. The cubic tank design is also beneficial from a manufacturability standpoint. The cubic tank shape is more easily manufactured with a CNC mill than the cylindrical tanks because of the undercuts required for the mounting flanges.

\section{Micropropulsion Design Details}

Since the cubic tank and cap design produced the largest theoretical performance it was chosen to pursue further with the construction of a prototype. The SolidWorks model was converted to a step file and sent to Maglio Inc. in San Luis Obispo for machining. Figure 12 shows the Aluminum 7075-T6 raw material next to a finished tank and cap. 

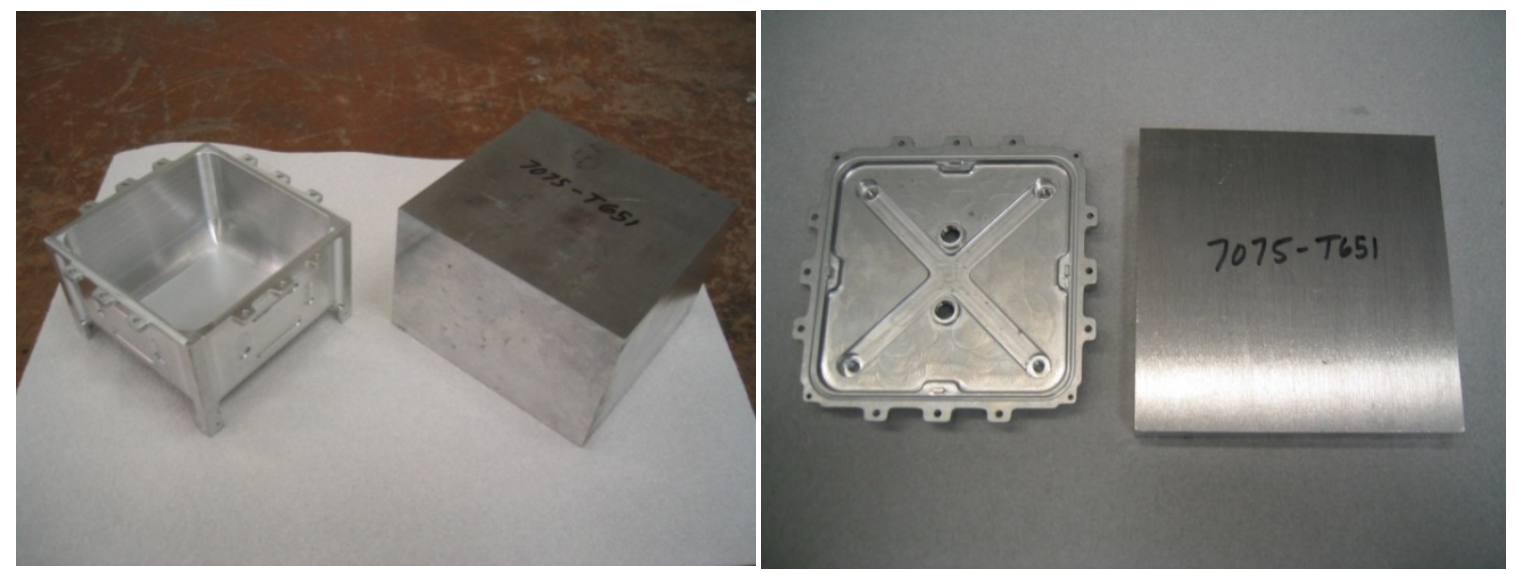

Figure 12. Tank and cap shown with respective raw materials before machining

To seal the tank and cap interface, a Parker EDPM o-ring was specified and a corresponding channel was machined into the cap. The channel with o-ring on the underside of the cap is shown in Figure 13.

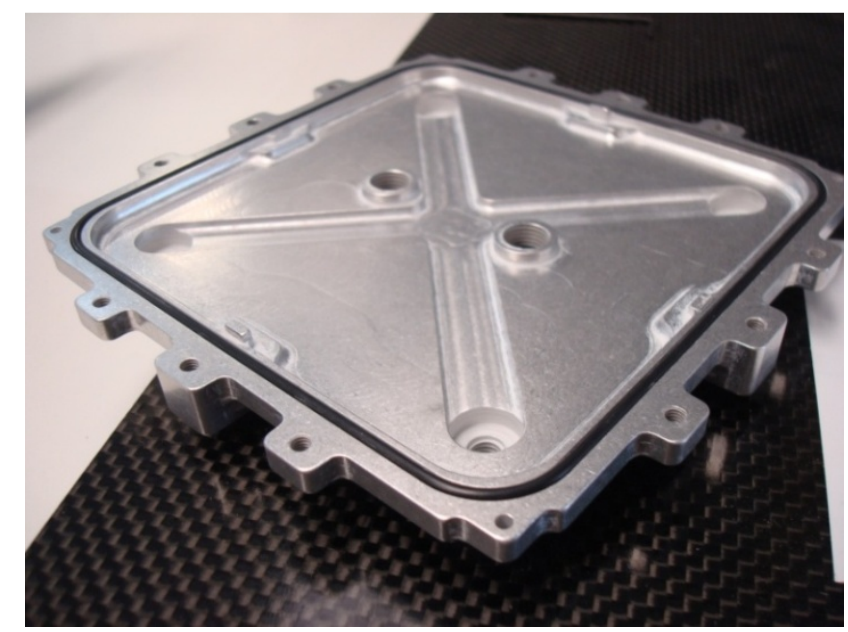

Figure 13. Underside of cap with o-ring installed.

In order to properly align the mounting holes between the tank and cap, four alignment tabs were machined on the underside of the cap. These tabs as shown in Figure 
14 in the circle contact the tank walls and align the cap such that the mounting hardware will properly engage all the threads.

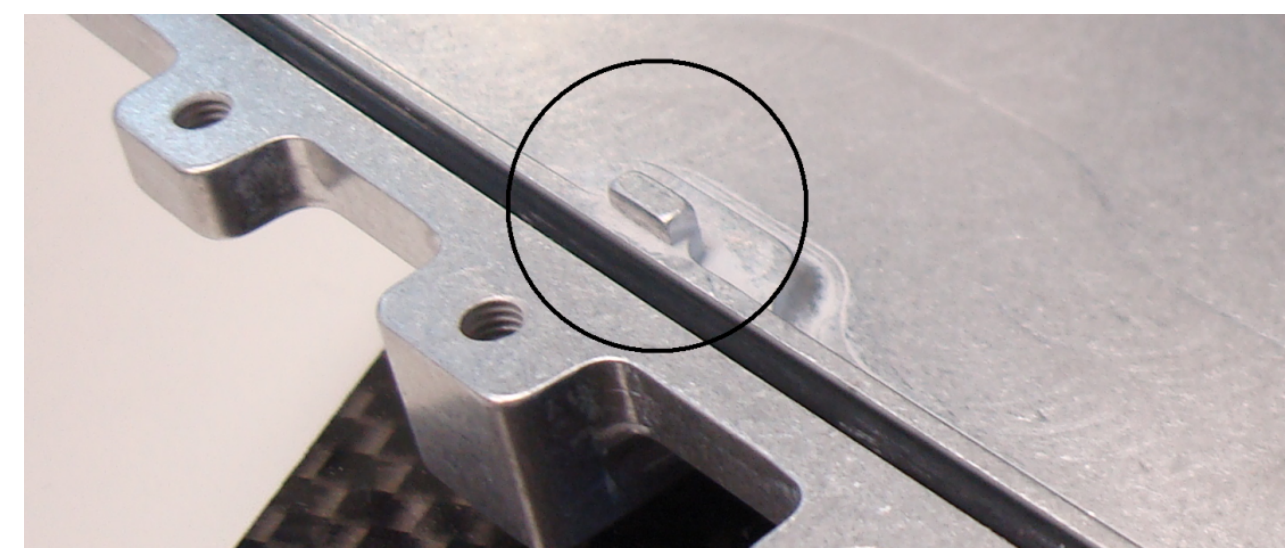

Figure 14. Cap alignment tabs shown on the underside of the cap.

To carry propellant from the tank to the valve inlet, stainless steel studs with laser cut holes through the center were used. The studs shown in Figure 15 act as both a mounting interface to the solenoid valve as well as propellant feed lines. An EDPM oring was used to seal the cap and is shown in Figure 15.
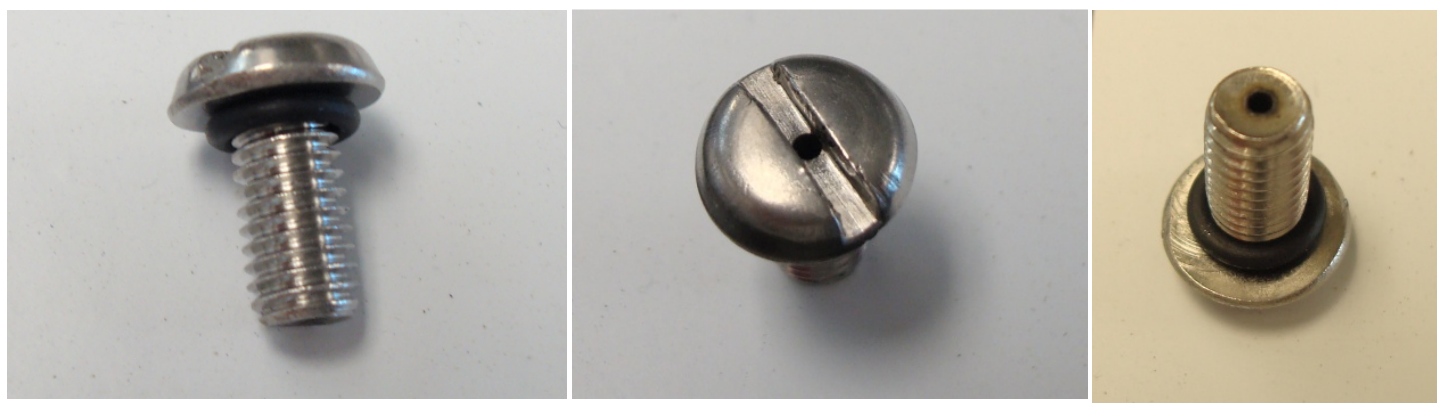

Figure 15. Stainless steel stud with EPDM o-ring and laser cut through hole.

The stainless steel stud is seated into the underside of the cap with the head flush with the propellant channel as shown below in Figure 16 on the left. The stud threads 
through the mounting boss on the cap to seat the o-ring. The external threads protruding from the mounting boss on the top side of the cap shown in Figure 16 on the right are engaged by the solenoid valve.

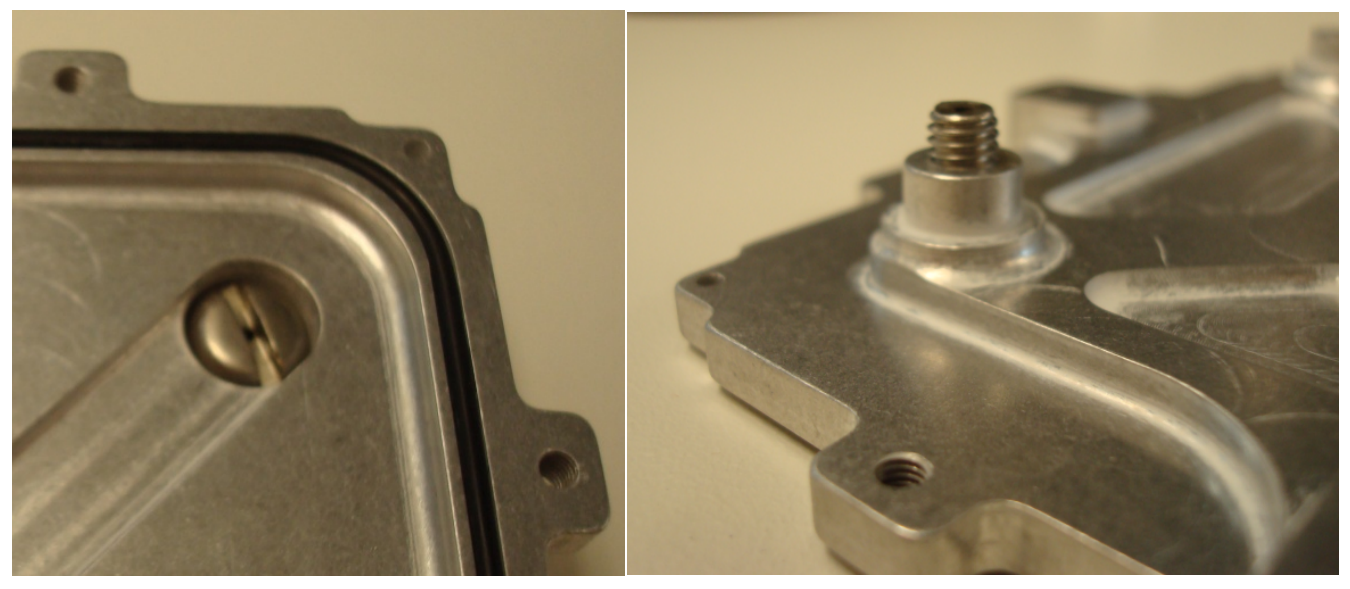

Figure 16. Stainless steel stud mounted into cap.

The solenoid valve is threaded onto the stud until it seats against the mounting boss as shown below in Figure 17.

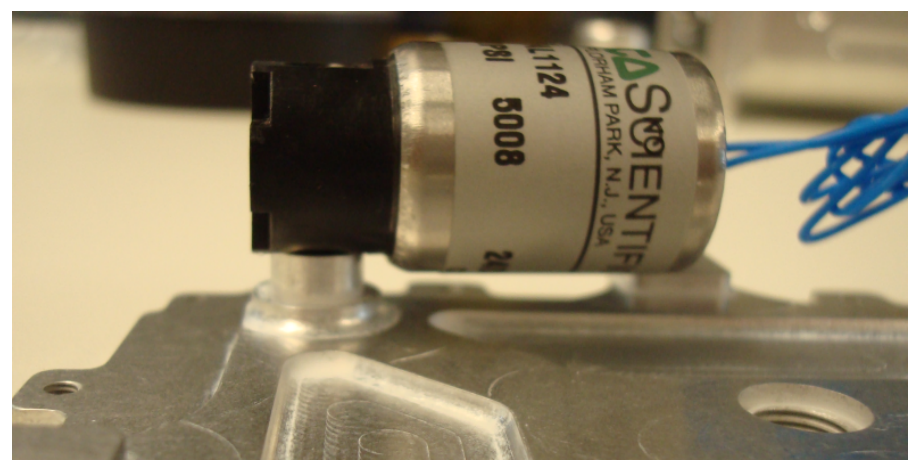

Figure 17. Solenoid valve mounted to stud and seated against mounting boss face.

The fill and drain valves thread into the top side on the cap and also utilize an o-ring for sealing. 

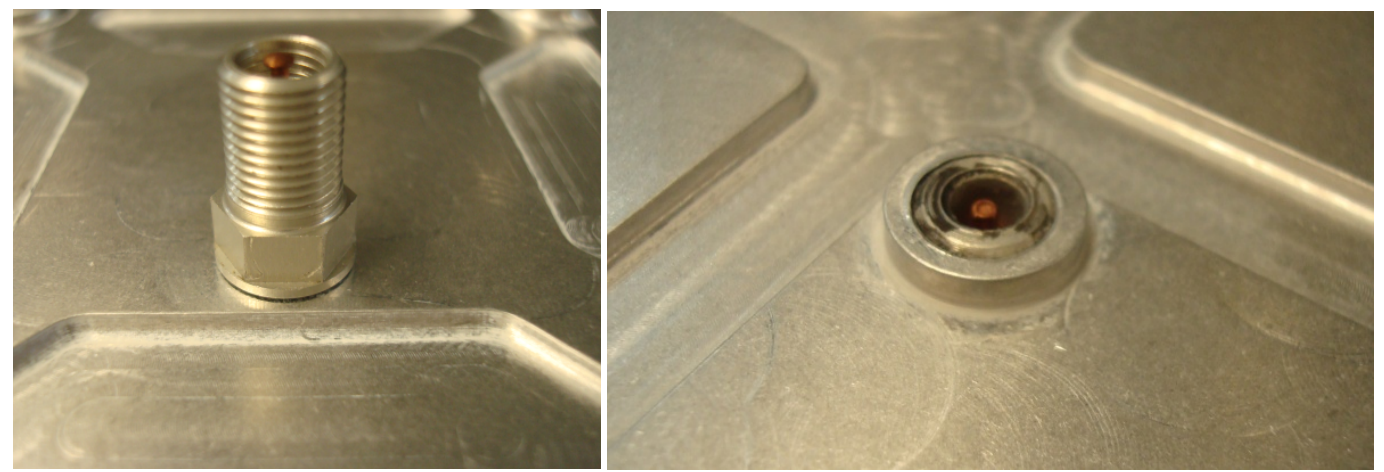

Figure 18. Fill and drain valve shown installed in the tank cap.

At any stage after the stainless steel stud assembly and cap o-ring installation, the cap may be bolted onto the tank with the appropriate hardware. The assembled propulsion system is shown below in Figure 19.

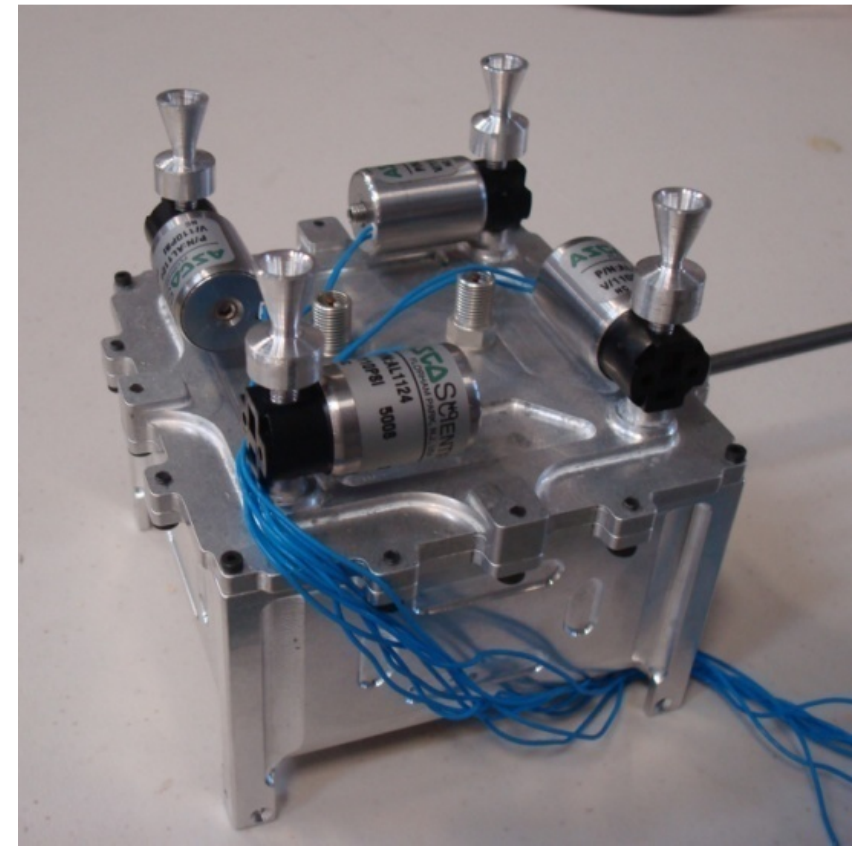

Figure 19. Assembled Micropropulsion system. 


\section{Tension Joint Details and Analysis}

As described above, small metric cap screws will be used for the connection between the tank and cap. Based on an initial estimate, twelve M3-0.5 with property class 12.9 screws would be required to join the cap and tank while providing enough compressive load to the sealing o-ring for no leakage of propellant at the joint. This would be achieved by tapping the through holes on the cap and routing the cap screws through the tank flange and into the threaded cap at the twelve points on the tank and cap. The four corners will use M2-0.4 property class 12.9 screws to take some of the load off of the twelve main bolts giving a larger factor of safety for the threaded connection. This will be achieved by using threaded blind holes $4 \mathrm{~mm}$ deep into the tank and $2 \mathrm{~mm}$ diameter through holes on the cap at the four corners. Figure 20 shows a detailed view of the tank and cap fastener orientation.

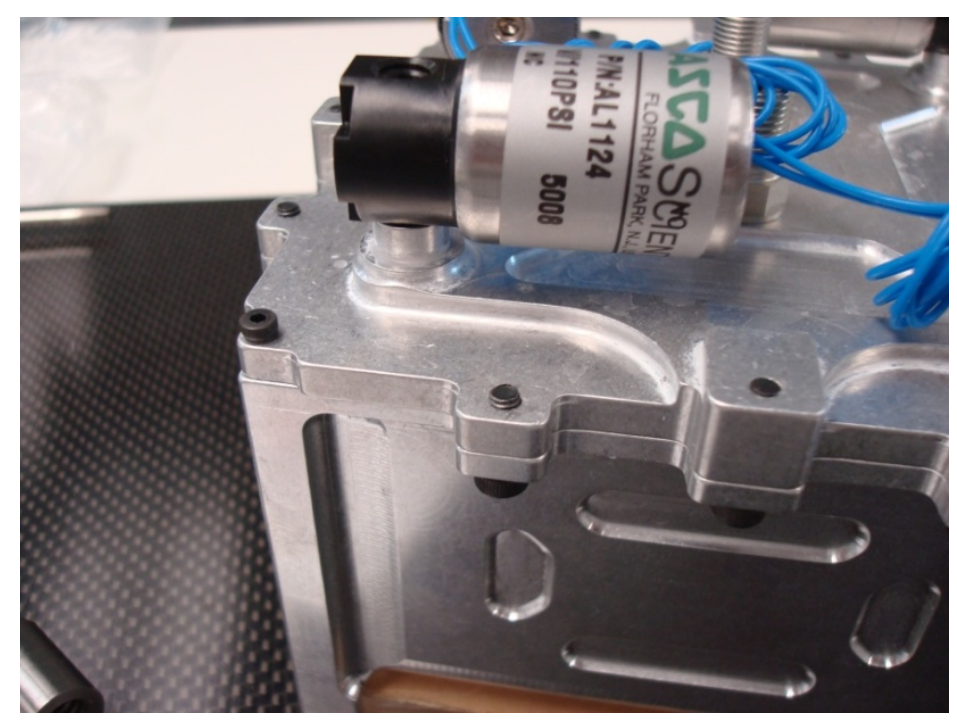

Figure 20. Details of tank and cap fastener orientation. 
A detailed analysis of the joined connection was performed with bolt stresses and joint loads evaluated. Figure 21 on the next page shows the factor of safety for yield of the bolts as well as the factor of safety for the joint connection. This is based on assuming that the twelve M3 bolts will take the entire load due to the pressure in the tank and that they have a yield strength of $1100 \mathrm{MPa}$ as published (Shigley, 2003).

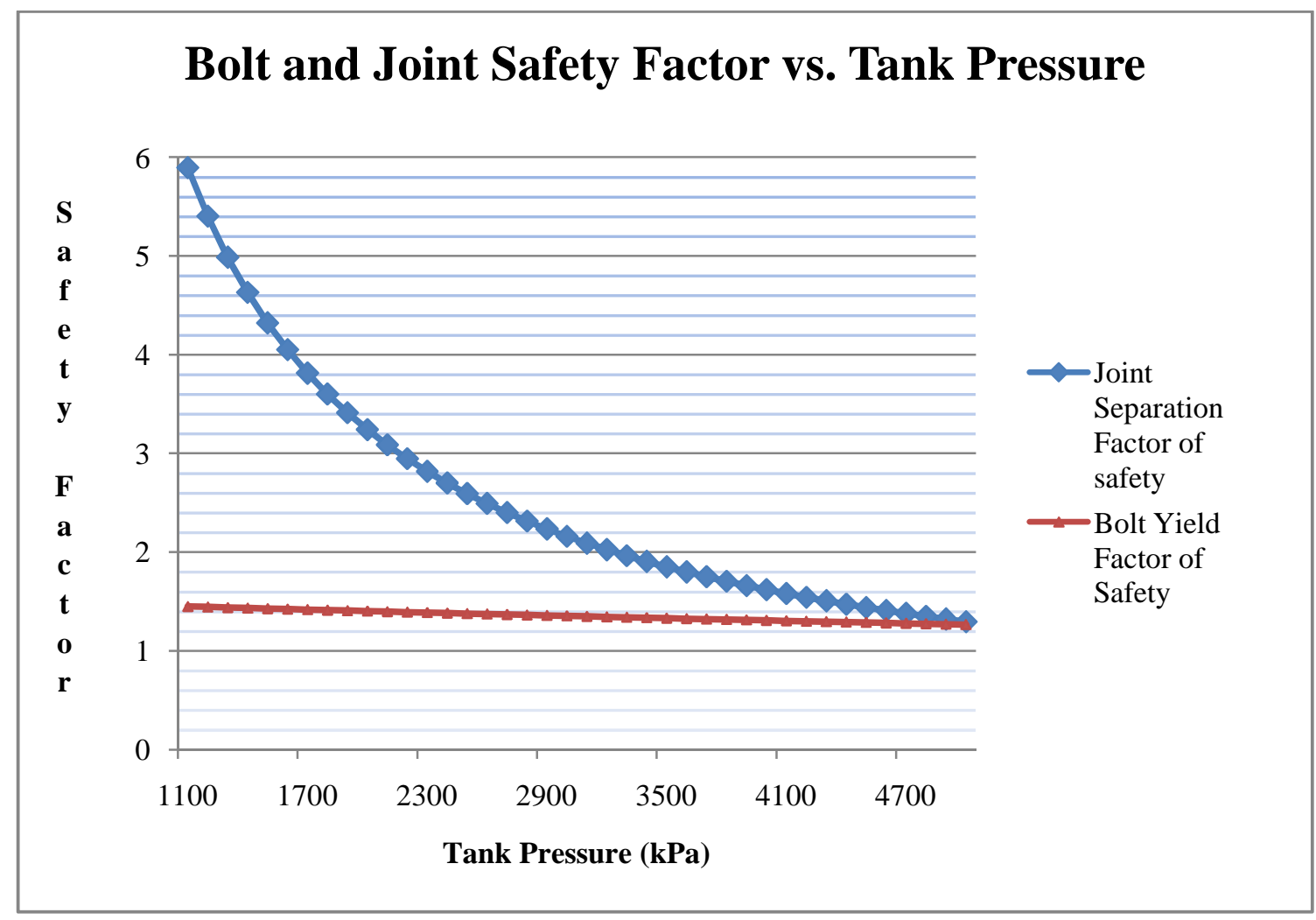

Figure 21. Bolted joint and bolt yield factor of safety as a function of tank storage pressure.

As shown from the figure above the factor of safety for bolt yield and joint separation are approximately 1.4 and 6.0 respectively for an operating pressure of 1100 MPa (Shigley, 2003). Also shown by the figure is the fact that acceptable joint separation and yield factors of safety are met throughout a large range of tank pressures. This 
ensures a safe joint even in the event of over pressurization of the tank due to operator error of elevated temperature of the propulsion system.

\section{Propellant Management}

Propellant Management Devices or PMDs are used to separate the pressurant gas from the liquid propellant. These devices range from bladders that physically separate the gas and liquid to vanes and screens that use the surface tension of the liquid propellant to separate it from the gas. Also used as a PMD are troughs and traps which use hydrostatics to keep only liquid entering into the thruster. Bladders are almost exclusively used in bipropellant applications where the fuel oxidizer ratio must be carefully controlled and free of pressurant gas. The penalty of using a bladder is complexity and extra mass. Most monopropellant propulsion systems today use some type of surface tension device utilizing screens, vanes or both to keep only liquid propellant entering the thruster (Svitek, 2008-2009). These types of devices are effective in zero g environments but attention must also be paid while the propulsion system is on the ground during fueling and loading. The propellant management device will be left for future work.

\section{Testing}

The design validation plan is summarized in Table 8 on the next page. The tests include proper o-ring and fastener fits and operations, proper valve function, proper PPOD operation, maximum pressure tests, and nozzle function tests. The purpose of the design validation plan is to ensure that the Micropropulsion system will be safe and reliable for hot fire tests to be performed in the future. 
Table 8. Micropropulsion test plan.

\begin{tabular}{|c|c|c|}
\hline Test & Description & Requirements \\
\hline Initial Fit Test & $\begin{array}{l}\text { Assemble Propulsion system, check that valves } \\
\text { thread onto studs and seat against flange, check } \\
\text { o-ring fitment in groove, threaded fasteners } \\
\text { engage threads and seat tank and cap together }\end{array}$ & Visual Inspection \\
\hline Initial Pressurization & $\begin{array}{l}\text { Fill tank with water and pressurize with } \\
\text { Nitrogen to } 800 \mathrm{kPa}\end{array}$ & $\begin{array}{l}\text { Visual Inspection ( No } \\
\text { visible leaks ) }\end{array}$ \\
\hline $\begin{array}{l}\text { Initial Valve function } \\
\text { check }\end{array}$ & $\begin{array}{c}\text { Pressurize to } 800 \mathrm{kPa} \text { with water and Nitrogen } \\
\text { and run valve test }\end{array}$ & $\begin{array}{l}\text { Verify valve function at } \\
1 \mathrm{~Hz} \text { pulses under pressure }\end{array}$ \\
\hline P-POD integration & $\begin{array}{l}\text { Load Propulsion system into P-POD, check for } \\
\text { binding, interferences (unpressurized) }\end{array}$ & Visual Inspection \\
\hline Tank Leak/Burst Test & $\begin{array}{l}\text { Incrementally increase pressure until tank } \\
\text { leakage is detected or until mechanical failure }\end{array}$ & $\begin{array}{l}\text { Record Pressure at } \\
\text { Visually detected leakage } \\
\text { or failure }\end{array}$ \\
\hline Nozzle Function Test & $\begin{array}{l}\text { Perform Cold Gas thrust measurements with } \\
\text { Nitrogen starting at } 800 \mathrm{kPa}\end{array}$ & $\begin{array}{l}\text { Compare actual thrust to } \\
\text { theoretical to verify nozzle } \\
\text { function }\end{array}$ \\
\hline
\end{tabular}

After machining was completed the micro-propulsion system was assembled and checked for proper fitment and operation. Next the valves were tested with incremental increases in pressure until they failed to operate. The Micropropulsion system was then proof tested to the design operating pressure of $1100 \mathrm{kPa}$. Following these initial tests the system was tested to failure. This test identified the structural design factor of safety as 
well as the failure mode. By identifying the failure mode, improvements can be tailored to it in order to increase the structural factor of safety.

A hot fire test will be conducted in the future but is out of the scope of this paper. The main goals of the hot fire test are to find the minimum tank pressure for proper thruster operation and to verify catalyst structural integrity after many thrust cycles. Qualification testing will also be conducted after initial hot fire tests which include random vibration testing as well as long term propellant exposure testing and temperature cycle testing.

\section{Test Results}

The initial fit test was successful for all components. All o-rings seated properly and all mechanical interfaces acted as designed. Some valve stud trimming or shimming may be necessary for the valves to seat against the mounting boss with the proper orientation. Shown in Figure 22 is the correct orientation of the four thruster valves.

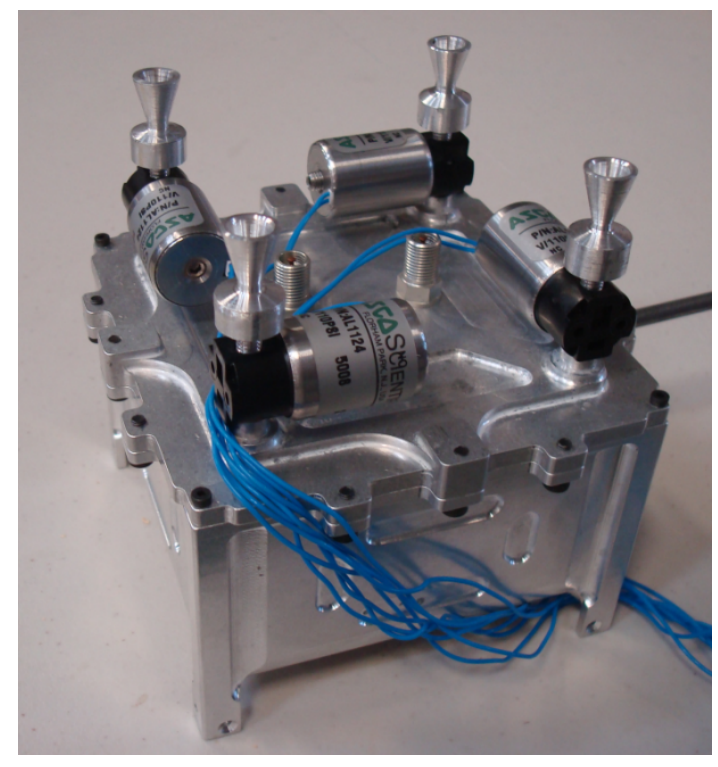

Figure 22. Assembled Micropropulsion system. 
Each valve was designed to seat against the mounting boss parallel with the edge of the tank forming a square pattern as it was threaded onto the valve mounting stud. However, during valve tightening a couple valves did not seat against the boss until they were rotated past the position parallel to the tank edge. This causes the center of gravity to move outward from the center of the tank towards the misaligned valve which is not desirable. Also for a more extreme case the valve can be rotated past the tank edge, "overhanging" the cap which can cause interference with the P-POD. This is most likely caused by the allowable length tolerance in the valve stud and can be solved by some light machining on the studs to ensure consistent lengths among batches or by adding small shims between the valve and boss.

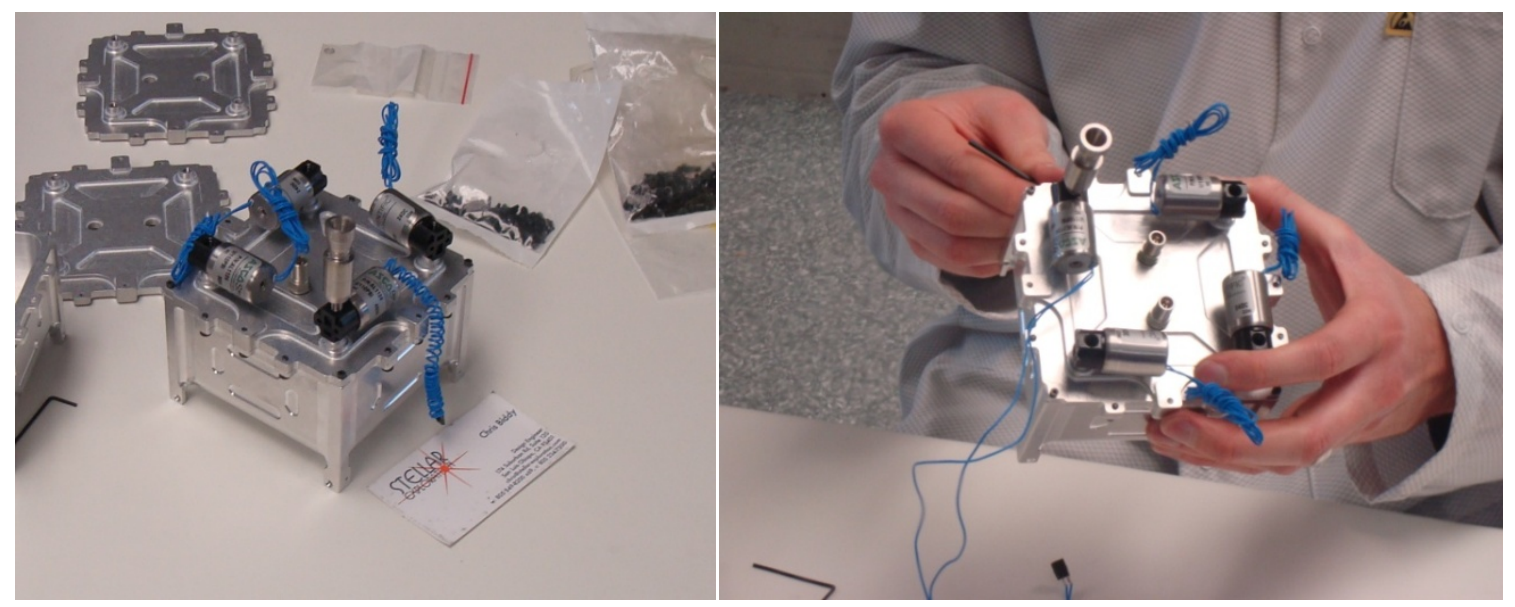

Figure 23. Initial fit test.

After the initial fit test was completed, the initial tank pressurization and valve function tests were conducted. The tank was filled with approximately $250 \mathrm{ml}$ of water and pressurized to $800 \mathrm{kPa}$ using Nitrogen. No leaks were detected. One valve was cycled with six, $1 \mathrm{~Hz}$ pulses at a time until the pressure was bled down to $100 \mathrm{kPa}$. At 
$825 \mathrm{kPa}$ the valve did not open for the first pulse, but did function properly after the initial pulse. This is evidence that $825 \mathrm{kPa}$ may be the maximum operating pressure even though the valve is rated at $760 \mathrm{kPa}$ operating. The test setup is shown in the figure on the next page. Alex Diaz of Stellar Exploration built the circuit to control the valves for testing.

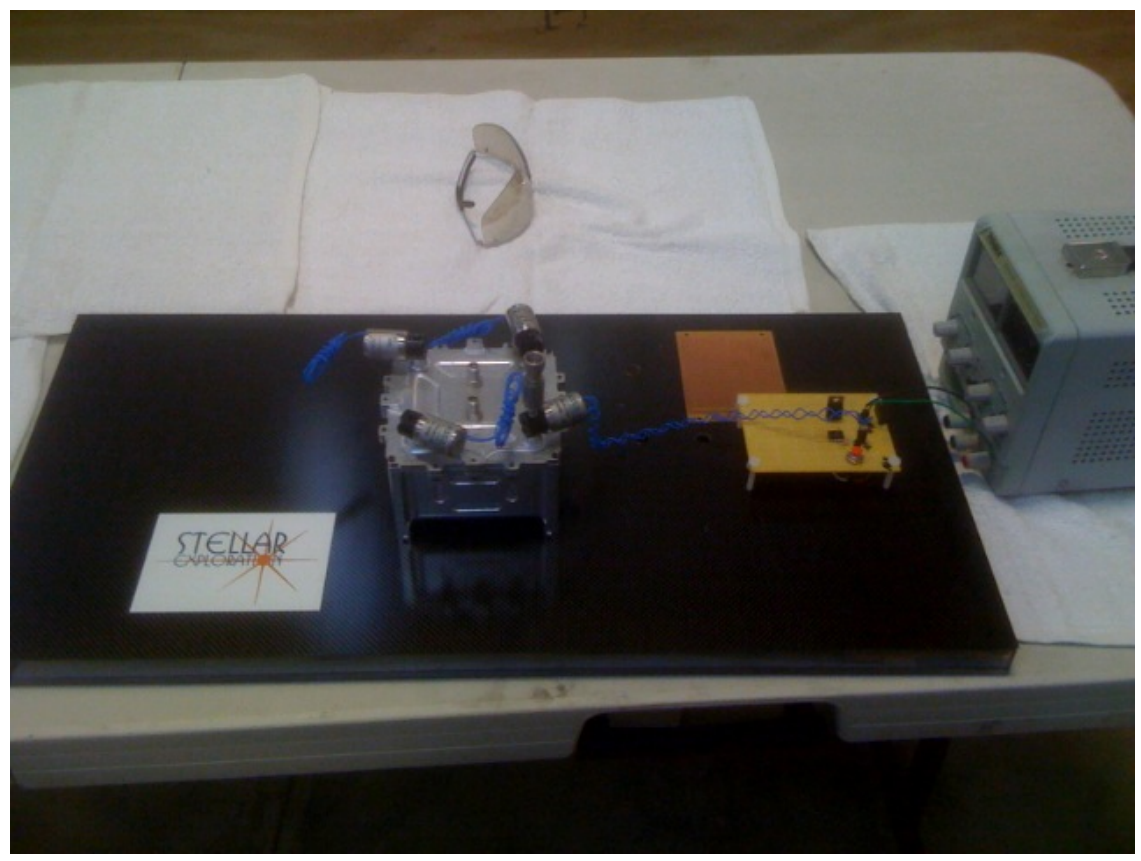

Figure 24. Valve Function test layout and equipment.

The next test performed was the system burst test. The goal of this test was to determine the failure mechanism of either the structure or the seals. It was decided that the valves would be left off of the system for this test. The stainless steel studs with the laser bored hole were replaced with a similar stud without the bored hole as shown in Figure 25 on the next page. 


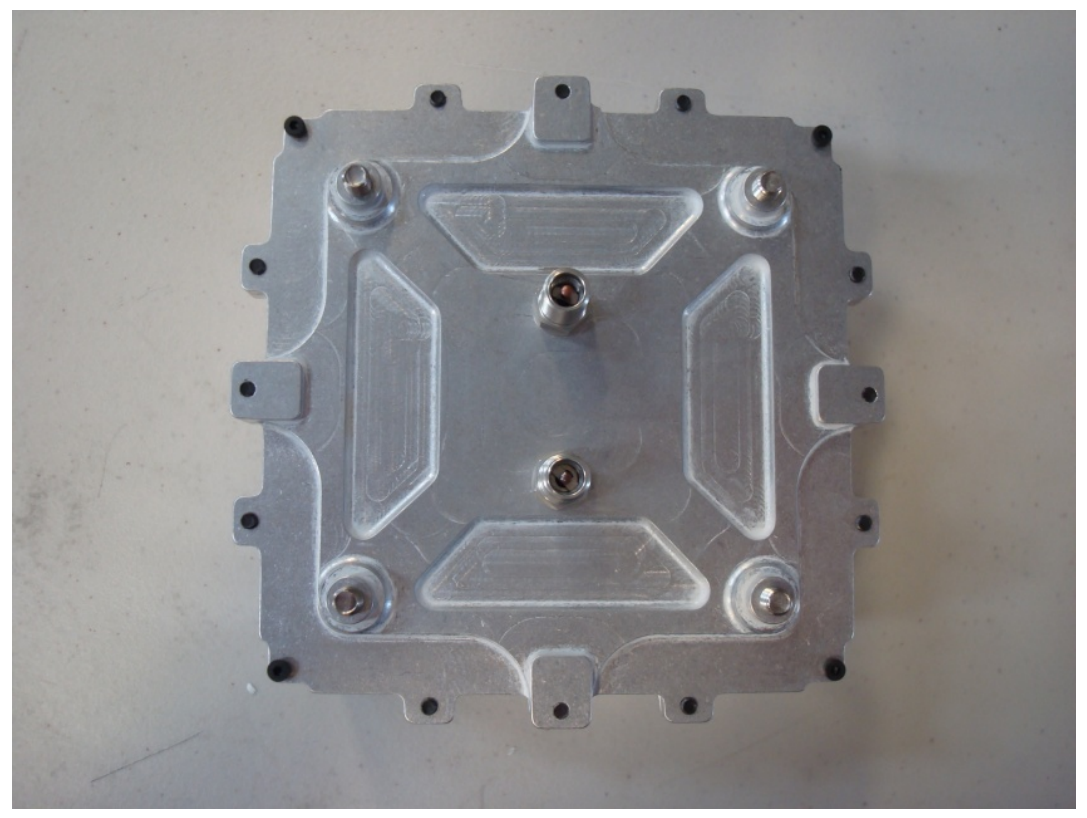

Figure 25. Assembled Micropropulsion system with non-bored stainless studs.

In addition, identical o-rings were used on the stud without the bored hole. The test was carried out at Stellar Exploration. The test area had a small cinderblock bunker which would be used to house the propulsion system during testing shown in Figure 26.

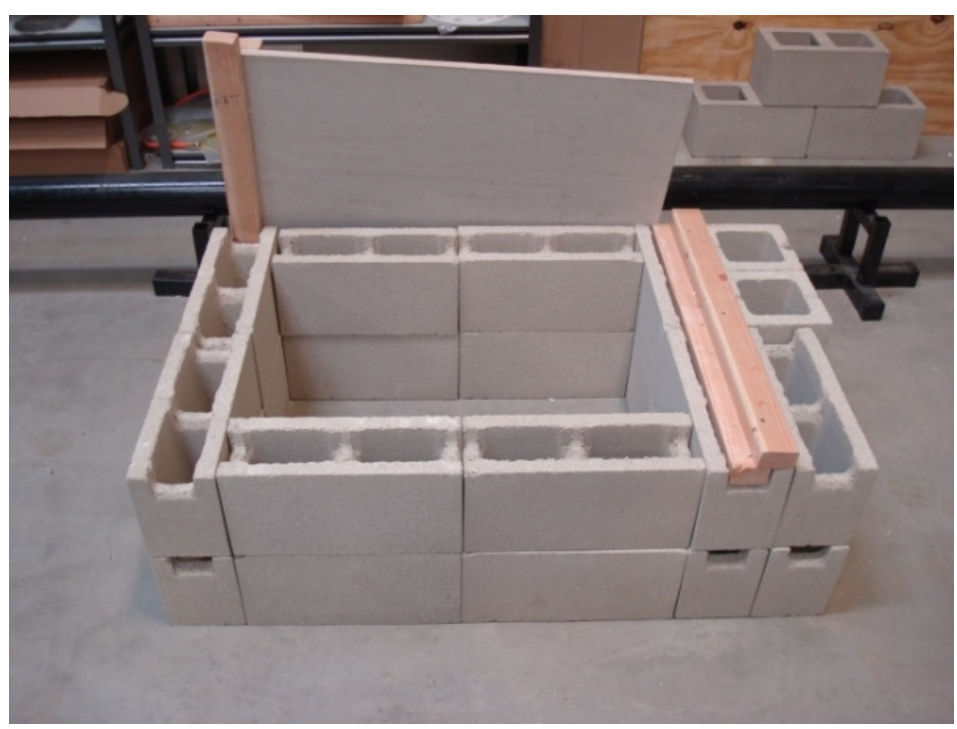

Figure 26. Cinderblock bunker used during system burst testing. 
A wooden structure with a polycarbonate viewing section constructed as a blast shield was another safety feature used during the test and is shown in Figure 27.

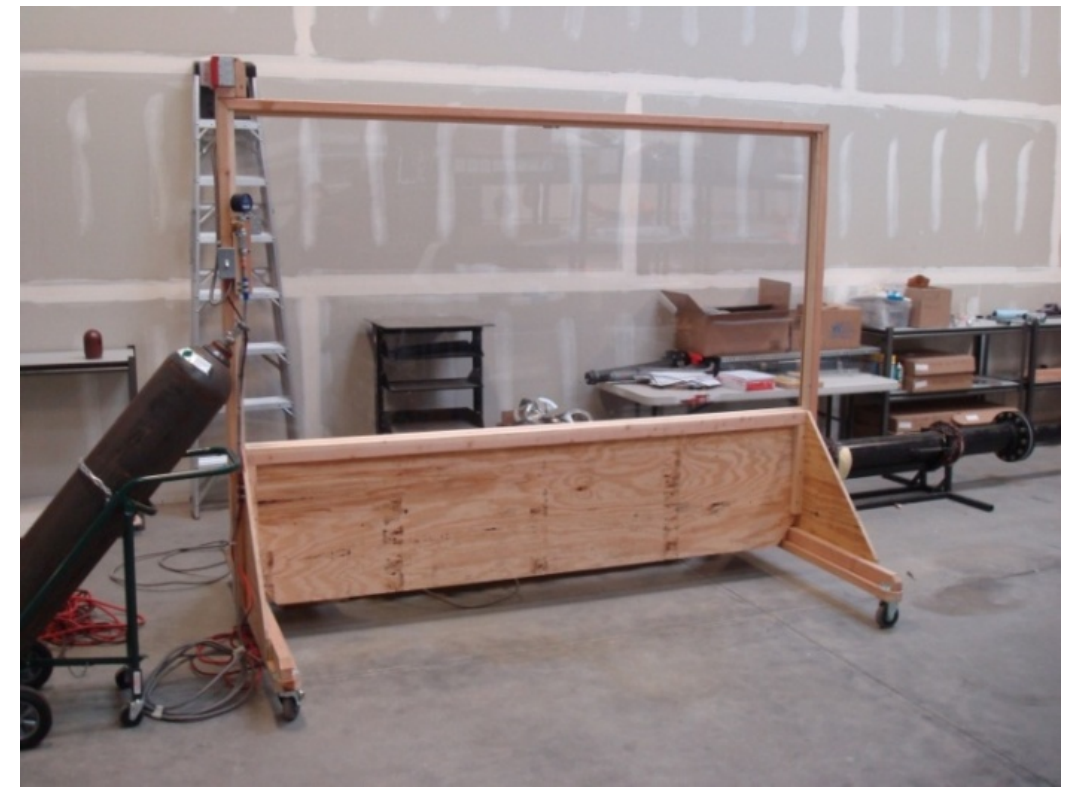

Figure 27. Blast shield used during system burst testing.

The Nitrogen source bottle was kept away from the test bunker with the use of 6 $\mathrm{m}$ sections of stainless steel braided hoses. One hose was used for the pressure source while the other connected to the remote digital gauge mounted to the blast shield shown in Figure 28 on the next page. 


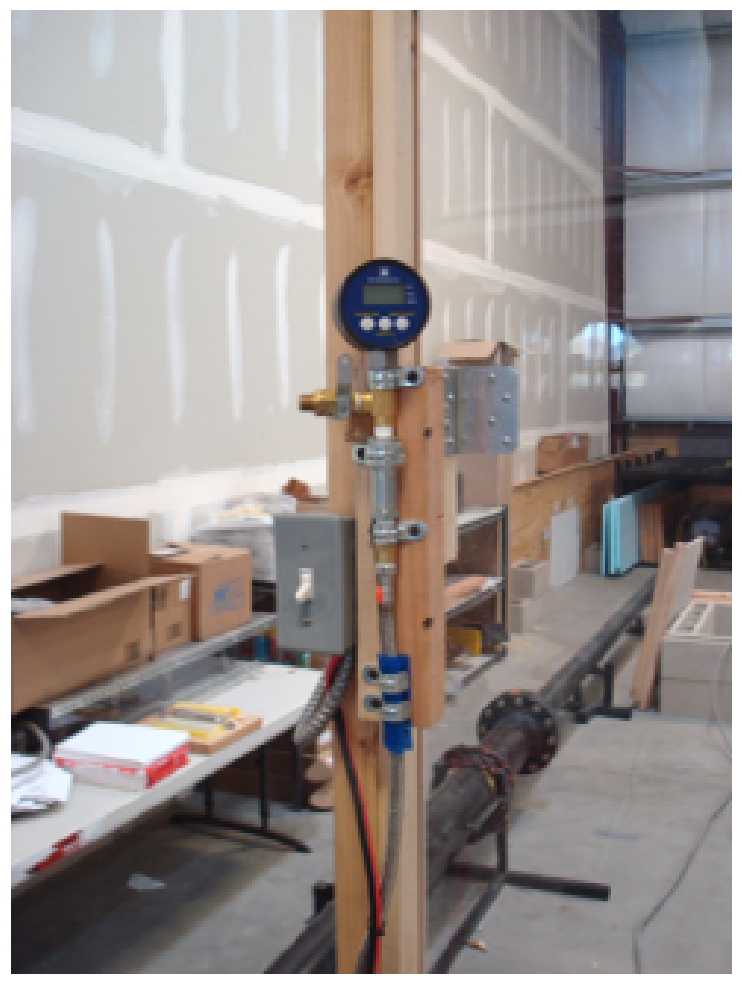

Figure 28. Digital Pressure gauge connected to propulsion system.

In order to connect the Nitrogen source to the propulsion system as well as the digital gauge feed line, two adapters were made. Since both lines were already configured for use with high pressure quick connect fittings which use $1 / 4$ " NPT threads the adapters were machined to couple these fittings to the Schrader drain and fill valves on the propulsion system. The adapters along with the quick connect couplers are shown in Figure 29 on the next page mounted to the propulsion system. 


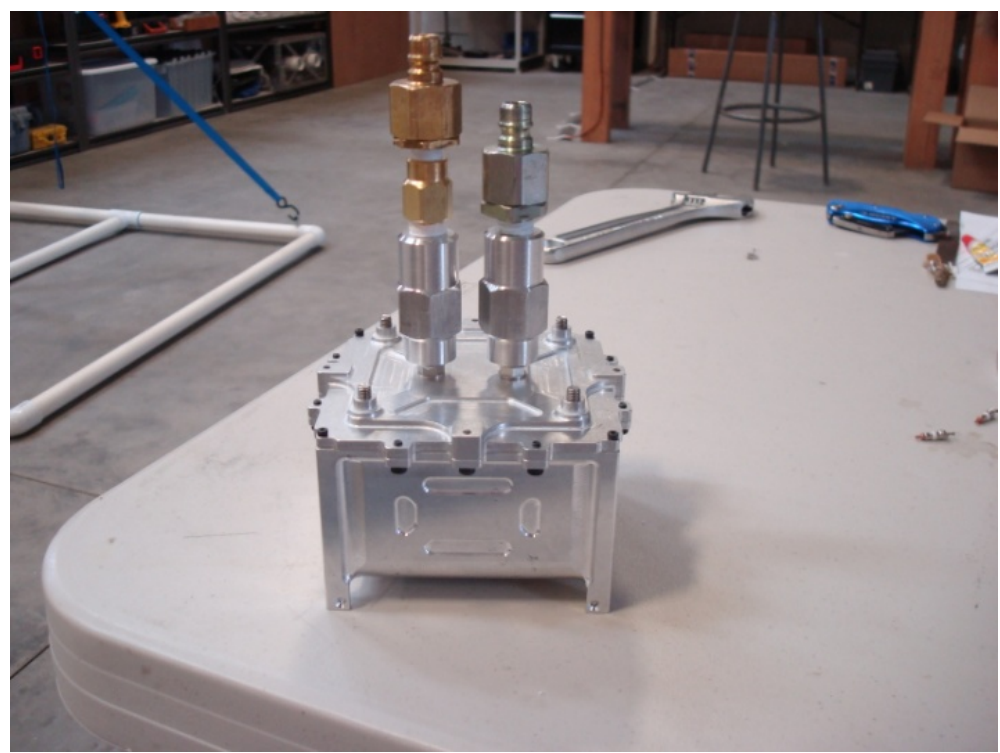

Figure 29. Propulsion system with adapters and quick connect fittings.

After the adapters were installed, the Micropropulsion system was connected to the Nitrogen source bottle and digital pressure gauge and pressurization began.

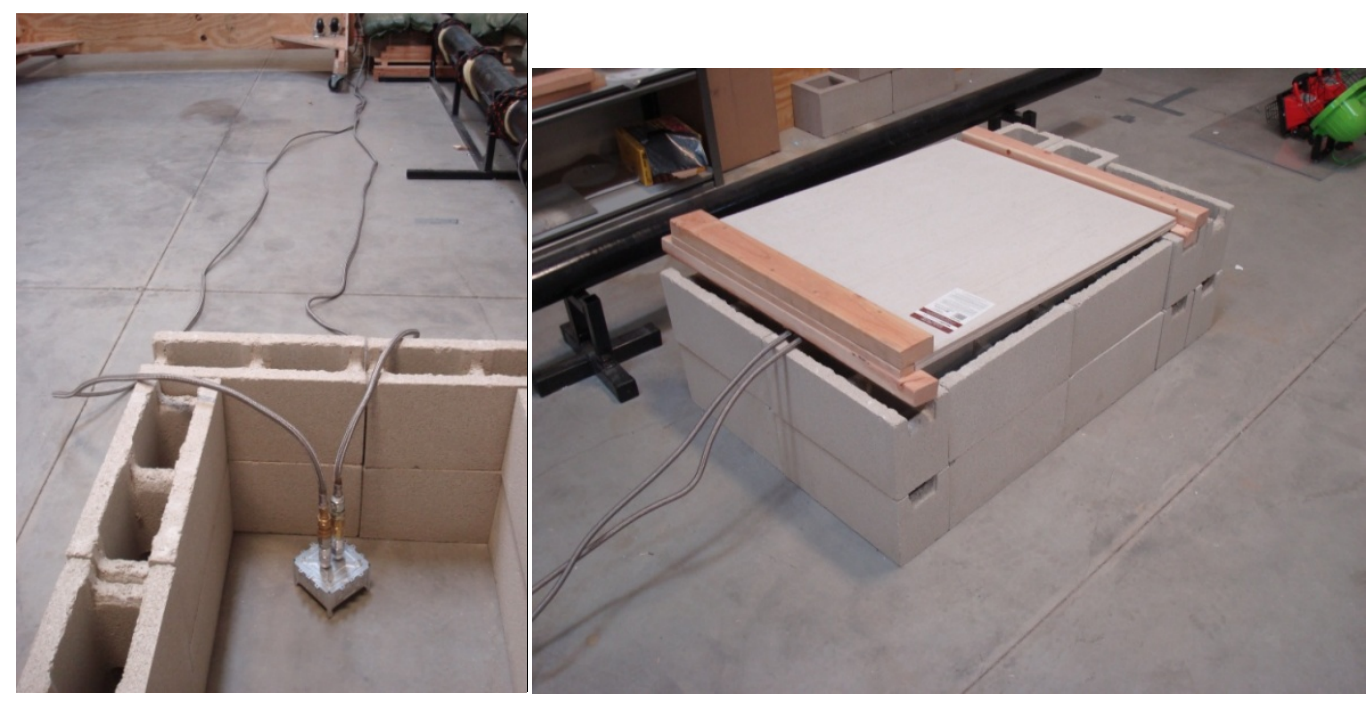

Figure 30. Micropropulsion system connected and ready for pressurization. 
The pressure inside the propulsion system was increased slowly until a drop in pressure was observed. This happened at $2310 \mathrm{kPa}$ with the main o-ring failure. The cap was lifted off of the tank surface just enough for the internal pressure to push the o-ring out of the groove and just outside the mounting flange as shown in Figure 31 below.

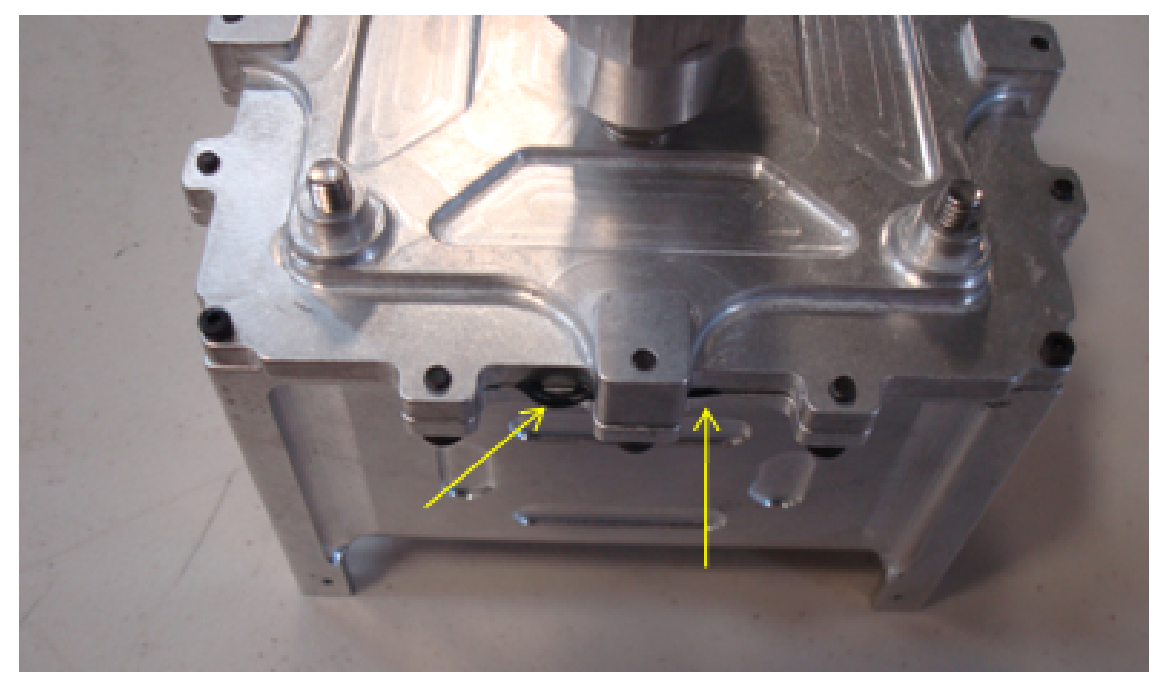

Figure 31. O-ring shown protruding out of the tank and cap.

After the o-ring was pushed out, the drop in pressure during this time caused the tank cap to re-seat against the tank mounting flange and only a slow leak was observed. The pressure dropped from $2310 \mathrm{kPa}$ to $800 \mathrm{kPa}$ in 30 minutes after the o-ring failure. As shown in the figure below, the o-ring did not tear, however it did yield at the location that the tank and cap re-seated against the o-ring. Also shown in the figure below, is the damage to the bolts. 

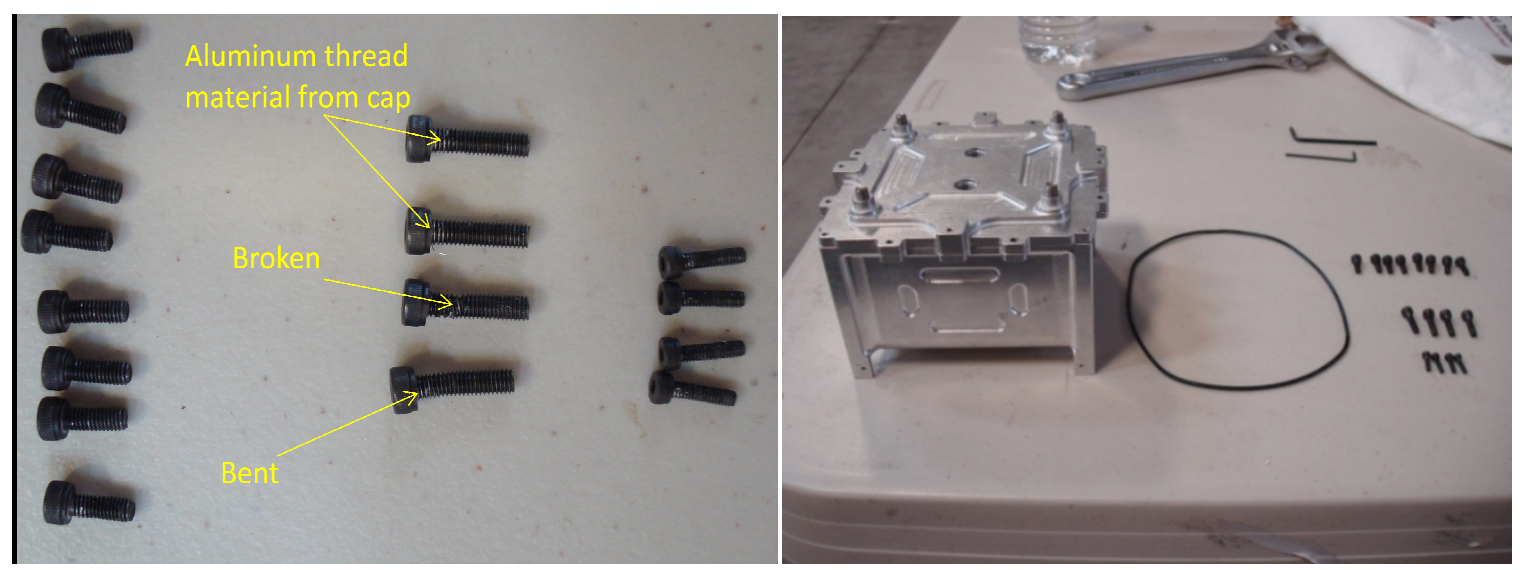

Figure 32. Micropropulsion bolts, o-ring, tank and cap after first burst test.

Although difficult to see in the figure, every bolt in the system was bent with the longest bolts located in the center of the cap on each side showing the most damage. In addition, small amounts of aluminum were left on the bolt threads from the tank. A second and third test was conducted with the same failure at pressures of $2206 \mathrm{kPa}$ and $2027 \mathrm{kPa}$ respectively. The location of the o-ring failure from the second test was marked on the cap in order to determine if local yielding in this location could have caused the failure and the test was run again. The third test had the same failure in the same location with respect to the cap. This may imply some kind of damage to the cap from the first test may be contributing to the failures of the second and third test.

The tank burst test was a success because it verified the design factor of safety as well as determined the failure mode. The measured factors of safety for these tests are $1.90,1.82$ and 1.68 respectively. This factor of safety is derived from the ratio of measured maximum pressure over the design maximum pressure of $1200 \mathrm{kPa}$. The failure mode as determined by this test is a desirable one since it is not an actual "burst" but a simple o-ring failure which allows the pressurant gas to escape slowly. This is known as a 
leak-before-burst failure mode which is a big advantage over a burst failure mode from a range safety standpoint. Although the Micropropulsion system performed successfully during this test, it exposed an error in the analysis used for the tension joint. From inspection of Figure 21 on page 59 the expected bolt yielding factor of safety at $2300 \mathrm{kPa}$ is approximately 1.4 and the factor of safety for joint separation is approximately 2.75 . The bolts yielded at this pressure and the joint separated allowing the o-ring to be pushed out. Possible sources of error may be the assumed spring rate of the mating surfaces, an incorrectly assumed bolt strength, or incorrect bolt preload during assembly.

The cold gas thrust test was conducted in order to verify proper nozzle function. The thrust and therefore specific impulse of the system will be measured and will indicate whether or not the nozzle is functioning properly. The specific impulse of this system would approach zero if the flow through the nozzle was not choked and therefore the gas was not supersonic at the exit plane. With a reasonable calculated specific impulse from this test it will be assumed that the flow is choked and the nozzle is functioning properly. The test setup is shown on the next page in Figure 33. 


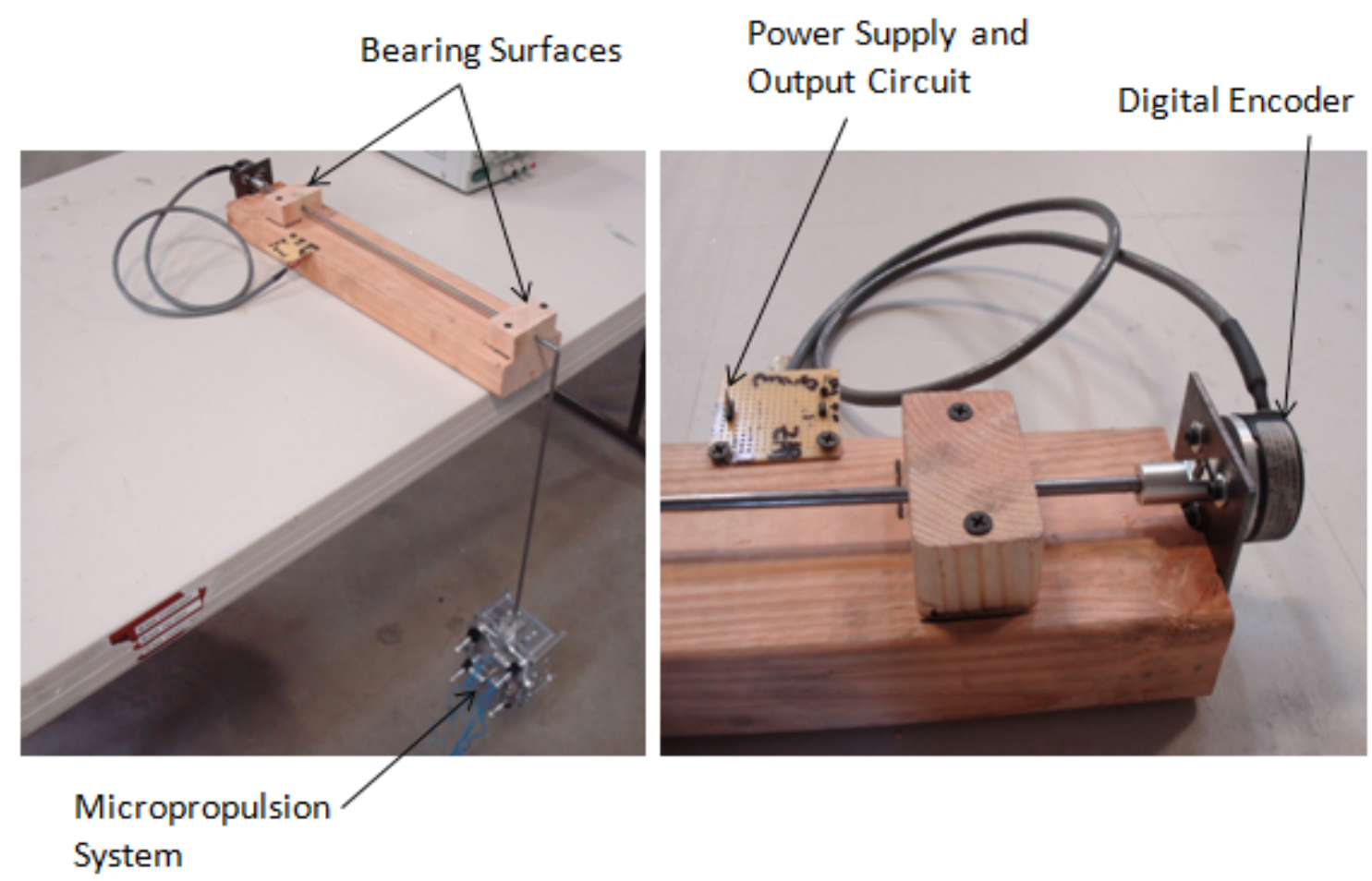

Figure 33. Cold gas thrust measurement test setup.

The test setup consists of the Micropropulsion system mounted to a bent steel rod acting as a pendulum. The end of the steel rod is coupled to an encoder to accurately measure the angular displacement. The encoder samples 10,000 points per rotation, allowing for small angular displacements to be measured accurately.

After a few trial runs a discrepancy was noticed between the portable pressure gauge used to measure the tank storage pressure and the regulator on the gas source. It was decided to mount a pressure gauge to the Micropropulsion system's Schrader valve so storage pressure could be read directly after the tank had been filled. Figure 34 shows the test setup during the first test. 


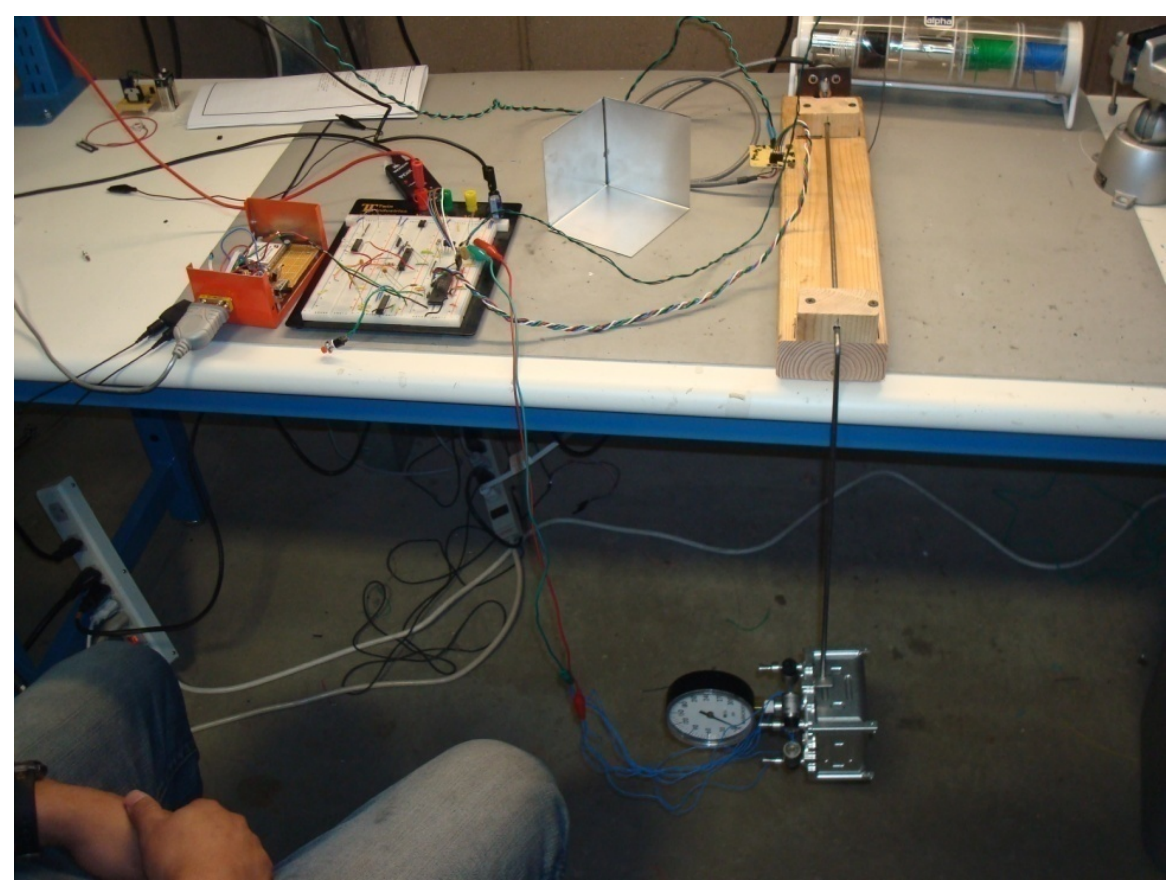

Figure 34. Test setup shown after first test.

All four thrusters were fired at the same time with $2 \mathrm{~Hz}$ pulses during this test. Angular displacement was measured during the thruster firing. Table 9 on the next page contains the results from the three tests including the starting tank storage pressure, the encoder output for the beginning and end of the thruster firing as well as the angular displacement for the thruster firing. The encoder has 65536 points per revolution. Once the encoder passes point 65536 it resets to zero. As shown in Table 9, the encoder start position varied slightly for each test due to the sensitivity of the encoder. 
Table 9. Cold gas test results for three tests with three $2 \mathrm{~Hz}$ pulses per test.

\begin{tabular}{|c|c|c|c|c|c|}
\hline & Tank Pressure & \multicolumn{2}{|c|}{ Encoder Output } & \multirow[t]{2}{*}{ Difference } & \multirow[t]{2}{*}{$\begin{array}{c}\text { Angular Displacement } \\
\text { (rad) }\end{array}$} \\
\hline Test 1 & & $\begin{array}{c}\text { Start } \\
\text { Position }\end{array}$ & $\begin{array}{c}\text { End } \\
\text { Position }\end{array}$ & & \\
\hline Pulse 1 & 95 & 65535 & 43 & 44 & 0.028 \\
\hline Pulse 2 & 73 & 65490 & 65524 & 34 & 0.021 \\
\hline Pulse 3 & 59 & 65500 & 65525 & 25 & 0.016 \\
\hline Test 2 & & & & & \\
\hline Pulse 1 & 91 & 2 & 49 & 47 & 0.030 \\
\hline Pulse 2 & 79 & 65489 & 65522 & 33 & 0.021 \\
\hline Pulse 3 & 60 & 65501 & 65525 & 24 & 0.015 \\
\hline Test 3 & & & & & \\
\hline Pulse 1 & 91 & 65511 & 22 & 46 & 0.029 \\
\hline Pulse 2 & 79 & 65488 & 65521 & 33 & 0.021 \\
\hline Pulse 3 & 60 & 65501 & 65527 & 26 & 0.016 \\
\hline
\end{tabular}

As shown in the table, the angular displacements are small due to the low thrust to weight ratio of the cold gas system.

The nozzles used in this test have large expansion ratios defined as the throat area over the exit plane area, which is common in spacecraft. For atmospheric conditions a nozzle with an optimum expansion ratio is one that expands the gas to atmospheric pressure at the exit plane of the nozzle. For this case, that corresponds to an expansion 
ratio on the order of 2 or 3 (Brown, 1996). Since the absolute pressure in space is zero, spacecraft generally have nozzles with large expansion ratios unless mass or volume constraints do not permit it. The reason for this is that the specific impulse increases as the exit pressure decreases for space applications. The nozzles used in this test have a throat diameter of $1 \mathrm{~mm}$ and an expansion ratio of 43 . It was decided to test the system with these nozzle expansion ratios because it is representative of what would actually be used in space. The only difference between these nozzles and those used with Hydrazine is a smaller throat diameter and the absence of the catalyst. Because of the over expansion of the gas by the nozzle, flow separation at the walls of the nozzle will occur decreasing the performance. However, the measured specific impulse will provide insight into the proper function of the nozzle. Choked flow conditions can be verified by a reasonable specific impulse of 10-50 s.

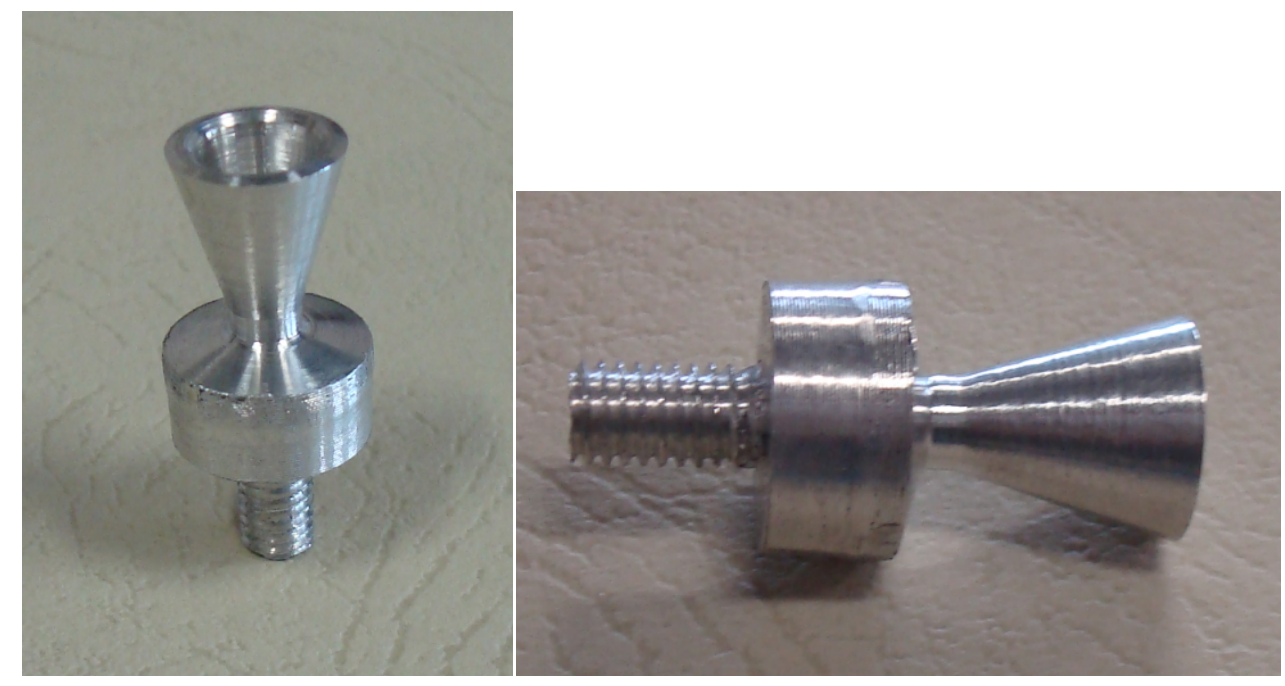

Figure 35. Nozzle used for cold gas test. 
In order to calculate the specific impulse attained during testing, both the thrust and mass flow rate must be measured. The mass flow rate was calculated by measuring the pressure drop in the tank and calculating the change in mass of the contained gas using the ideal gas equation. Next, the change in mass was divided by the amount of time the valve was open $(0.25 \mathrm{~s})$, giving the mass flow rate. The thrust was calculated by equating the sum of the moments caused by impulse forces around a fixed point to the change in angular momentum of the system about the same point. The moment of inertia of the propulsion system with pressure gauge and adapter about the center of gravity was calculated using SolidWorks. The parallel axis theorem was then applied to get the moment of inertia about the point of rotation, which was the chosen fixed point for the analysis. Next the moment of inertia for the bent steel rod was calculated about the same point. A friction force was calculated using a coefficient for the friction between steel and wood surfaces (Roy, 2009). These values along with the encoder outputs were used to calculate the total thrust produced by the system. The results of the cold gas tests are shown in Table 10. 
Table 10. Cold gas test calculated results.

\begin{tabular}{|c|c|c|c|c|c|}
\hline & $\begin{array}{c}\text { Tank Pressure } \\
\text { (psig) }\end{array}$ & Thrust (N) & $\begin{array}{l}\text { Mass Flow } \\
\text { Rate (kg/s) }\end{array}$ & Isp (s) & Delta V $(\mathbf{m} / \mathbf{s})$ \\
\hline \multicolumn{6}{|l|}{ Test 1} \\
\hline Pulse 1 & 95 & 0.41 & 0.0034 & 12 & \multirow{3}{*}{0.2} \\
\hline Pulse 2 & 73 & 0.32 & 0.0022 & 15 & \\
\hline Pulse 3 & 59 & 0.24 & 0.0020 & 12 & \\
\hline \multicolumn{6}{|l|}{ Test 2} \\
\hline Pulse 1 & 91 & 0.43 & 0.0019 & 24 & \multirow{3}{*}{0.2} \\
\hline Pulse 2 & 79 & 0.31 & 0.0030 & 11 & \\
\hline Pulse 3 & 60 & 0.24 & 0.0020 & 12 & \\
\hline \multicolumn{6}{|l|}{ Test 3} \\
\hline Pulse 1 & 91 & 0.43 & 0.0019 & 23 & \multirow{3}{*}{0.2} \\
\hline Pulse 2 & 79 & 0.31 & 0.0030 & 11 & \\
\hline Pulse 3 & 60 & 0.25 & 0.0020 & 13 & \\
\hline
\end{tabular}

As shown in Table 10 the thrust produced for each pulse during the three tests are all within 4-5\% of each other and . However, the pressure drop from pulse 1 to pulse 2 during the first test is much larger than the pressure drop observed in tests 2 and 3. This results in a much larger mass flow rate for the pulse and thus a much smaller specific impulse when compared to tests 2 and 3. A possible explanation for this is simply human error in reading the pressure at pulse 2. A maximum specific impulse of $24 \mathrm{~s}$ was measured at the first pulse of test 2 . This specific impulse is approximately half of common specific impulse for cold gas systems using air. This is probably due to the overexpansion of the gas through the nozzle. A specific impulse of 24 seconds is a reasonable result with a straight cut over expanded nozzle. This result gives high confidence of choked flow through the nozzle. 
The $\Delta \mathrm{V}$ of the system calculated for all three tests was $0.2 \mathrm{~m} / \mathrm{s}$. The $\Delta \mathrm{V}$ was calculated using an average specific impulse of the three pulses and assumed a 3-unit CubeSat.

\section{Future Work}

For the current system, concern was raised over the cantilevered mounting of the solenoid valves. Under launch loads, launch vehicle vibrations will cause loading on the valve at the mounting interface. The concern was that these loads could cause valve leakage around the mounting stud from deflections or even fracture at the thread root of the valve. Another concern raised was that while in the P-POD under launch loads, the thrusters would be loaded since they would be in contact with the P-POD door. Because the thrusters are designed for minimum mass, this loading may produce significant damage. A solution to both of these problems could be a standoff bracket that simultaneously constrains the valve and takes the load off of the nozzles at the P-POD door interface. An initial design was created and is shown in Figure 36. This design consists of a CNC machined aluminum 7075-T6 bracket that interfaces with two bolts on the cap as well as the valve. The bracket also has a machined pad that will contact the PPOD door taking the load off of the thrusters. In the current form each bracket has a mass of $6 \mathrm{~g}$. However the design will not be finalized until the combustion chamber dimensions are verified by a hot fire test. 


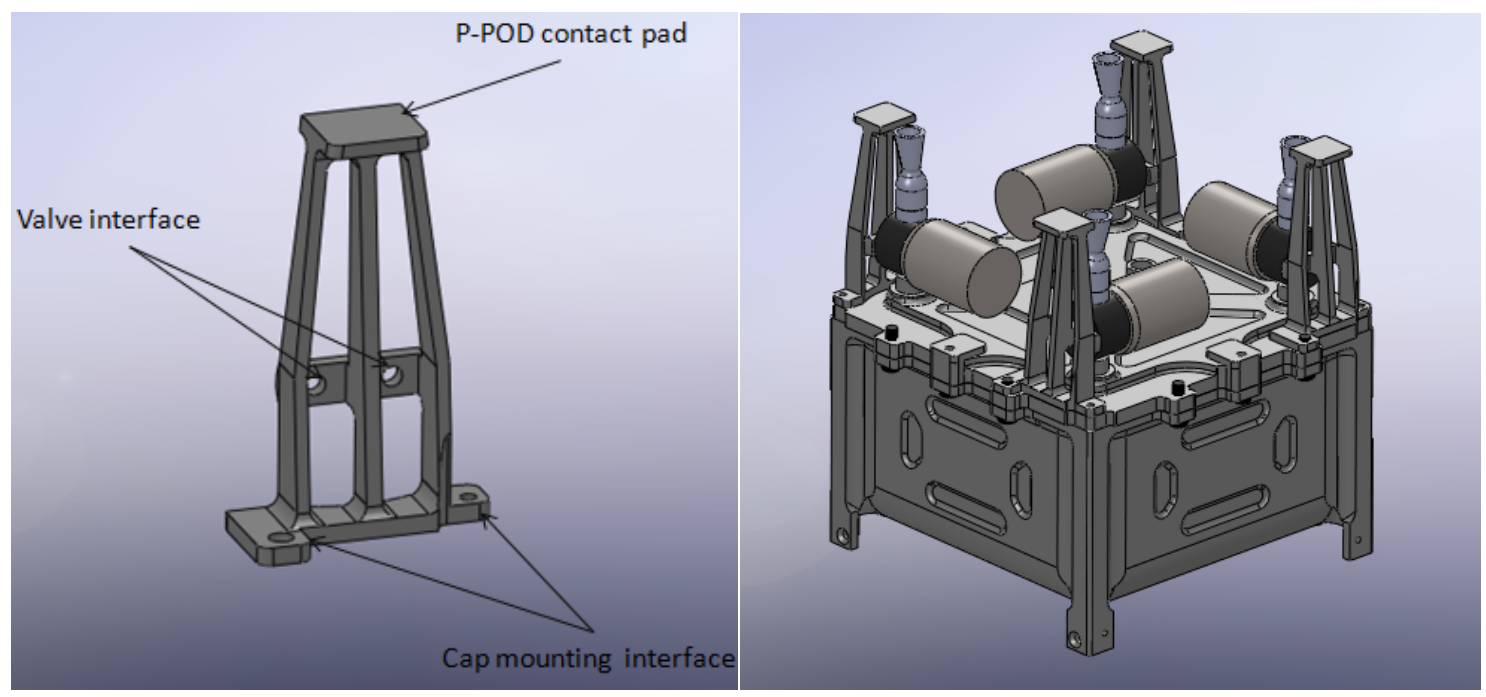

Figure 36. Thruster standoff bracket design.

In order to increase the delta $\mathrm{V}$ of this propulsion system from a theoretical maximum of $420 \mathrm{~m} / \mathrm{s}$, the volume of propellant held by the tank must be increased. A large amount of the allowable volume for the propulsion system is used up by the thruster valves and long combustion chambers and nozzles. Bud Fraze proposed machining the thruster nozzle into the tank cap itself and also integrating the thruster valves into the tank cap in order to use up more of the allowable volume for propellant (Fraze, 20082009). This has the potential to greatly increase the propellant volume and therefore increase overall performance. However, care must be taken to keep the overall mass of the system below $1 \mathrm{~kg}$.

A thrust control system will need to be developed in order to use the micro propulsion system. This system must be low mass and incorporate a navigation device to provide specific orientation of the spacecraft. 
Much more testing needs to be conducted before a flight is planned. The system must be flight qualified which means passing vibration and leak testing as well as long term material compatibility. A high frequency vibration environment will be encountered by the propulsion system caused by the solid rocket motors during launch. No significant oscillations are expected during operation. In addition many hot fire tests will need to be conducted to test the thermal and structural integrity of the catalyst and nozzle.

Additional thermal tests will include combustion chamber, valve head, and nozzle wall temperatures as a function of time. This will help determine a recommended pulse frequency to limit part damage due to thermal stresses.

\section{Conclusions}

The development of the Micropropulsion system for CubeSats is a difficult task requiring balancing multiple variables at a time while meeting the constraints imposed by the CubeSat standard. Each variable in the design of the micropropulsion system is coupled with at least one more variable. This makes changes to the system very difficult due to the undesirable effects a variable may have on another. It also makes the development of the micropropulsion system an iterative type of project because an "optimum" solution for one variable may drive another to an undesirable value. In order to look at the big picture concerning the design of this system, a flow chart was created to show the design process and how each variable is coupled to the assembly. This chart is shown in Figure 36. With the CubeSat Standard, the general shape, mass and dimensional constraints helped to decrease the number of open ended variables. Also, since a custom valve design was not part of this project, the valves became the uncontrolled fixed variable. This meant that the rest of the propulsion system was designed around the valve. 


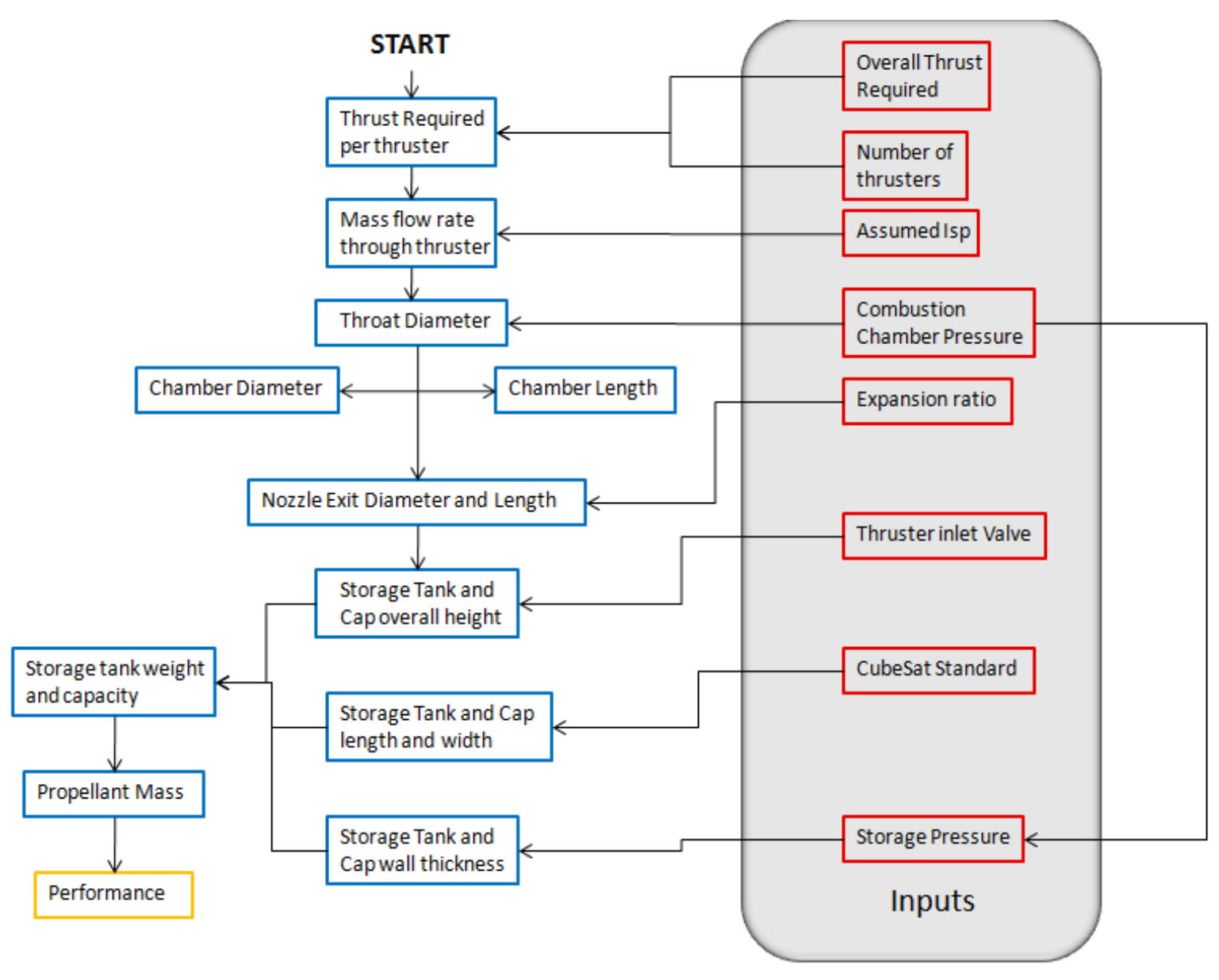

Figure 37. Design Flow chart for Micro-propulsion system.

This flow chart may be used during future iterations of the Micropropulsion system. This flow chart also illustrates how small changes to certain variable can affect the entire system.

The use of as many commercial-off-the-shelf components as possible is very important for developing a system like this rapidly. Also commercial-off-the-shelf 
components can provide a starting point for a design and allow for a big picture of the system to be developed early on. Significant cost savings are another result of using commercial-off-the-shelf components when available as opposed to a custom part. These components along with keeping the system as simple as possible at the beginning design stages helps insure project success. The design philosophy used throughout this project was simplification, the use of commercial of the shelf components, and rapid prototyping to support component and system testing rapidly. Many empirical relationships were used to size components with the intention of rigorous testing programs for component and system verification.

As discussed in the test results section of this paper, the leak-before-burst failure mechanism is very desirable because it is not a catastrophic failure. This failure mechanism poses much less threat to the range safety personnel, launch vehicle, and primary payload than a tank burst failure.

While much work still needs to be completed, the Micropropulsion system development up to this point is a great step towards a viable high performance propulsion system for CubeSats. A theoretical $\Delta \mathrm{V}$ of $419 \mathrm{~m} / \mathrm{s}$ is approximately $84 \%$ of the performance goal. This is encouraging because all required constraints were met as per the CubeSat Standard with the overall performance possibly being within $20 \%$ of the performance goal. The design goal of $\Delta \mathrm{V}=500 \mathrm{~m} / \mathrm{s}$ may be ambitious currently, but with new innovations with respect to the thruster valves it may be an attainable goal in the near future. 


\section{Works Cited}

Brown, C. D. (1996). Spacecraft propulsion. Washington: American Institute of Aeronautics and Astronautics, Inc.

Company, R. R. Hydrazine Handbook. Rocket Research Company.

Edney, G. (2009, Feb 19). Jeweler, Artist. (C. Biddy, Interviewer)

Fox, R. W. (2004). Intoduction to Fluid Mechanics Sixth Edition. Danvers: John Wiley and Sons, Inc.

Fraze, B. (2008-2009, Dec-May). President, Vector Engineering. (C. Biddy, Interviewer)

Humble, R. W. (1995). Space Propulsion Analysis and Design. New York: McGraw-Hill.

Jurgen Mueller. Thruster Options for Microspacecraft: A Review and Evaluation of Existing Hardware and Emerging Technologies. Pasadena: Jet Propulsion Laboratory.

Meriam, J. K. (2001). Engineering Mechanics Dynamics. Danvers: John Wiley and Sons.

Micci, M. M. (2000). Micropropulsion For Small Spacecraft. Danvers: American Institute of Aeronautics and Astronautics.

Miller, B. (2008-2009). President, Maglio Inc. (C. Biddy, Interviewer)

Miniaturized satellite. (n.d.). Retrieved 2008, from Wikipedia:

http://en.wikipedia.org/wiki/Miniaturized_satellite

Monopropellant Hydrazine Thrusters. (2003). Retrieved Dec-May 2008-2009, from EADS

Astrium: http://cs.astrium.eads.net/sp/SpacecraftPropulsion/MonopropellantThrusters.html

Monopropellant Rocket. (2009, April). Retrieved April 12, 2009, from Wikepedia: http://en.wikipedia.org/wiki/Monopropellant_rocket

News Archive. (2003, July 12). Retrieved Feb 2009, from Armadillo Aerospace: http://www.armadilloaerospace.com/n.x/Armadillo/Home/News?news_id=216

Organization, W. H. (1991). Hydrazine (HSG 56, 1991). Retrieved Jan-March 2009, from Inchem: http://www.inchem.org/documents/hsg/hsg/hsg056.htm\#SectionNumber:4.7

Platt, D. (2008, December 19). Micro Aerospace Solutions. (C. Biddy, Interviewer)

Products. (2009). Retrieved Jan 17, 2009, from Poly Performance:

http://www.polyperformance.com/shop/Fox-2.0-Air-Bump-Stop-Schrader-Air-Valves-p17641.html

Riegel, E. R. (2003). Riegel's Handbook of Industrial Chemistry. New York: Springer. 
Rogers, C. E. (2004). The Solid Rocket Motor-Part 4 Departures from Ideal Performance for Conical Nozzles and Bell Nozzles, Straigth-Cut Throats and Rounded Throats. Charles E. Rodgers.

Roy. (2009, March 26). Coefficients of Friction. Retrieved May 16, 2009, from RoyMech: http://www.roymech.co.uk/Useful_Tables/Tribology/co_of_frict.htm

Shigley, J. E. (2003). Mechanical Engineering design. McGraw Hill Professional.

Stellman, J. M. Encyclopedia of Occupational Health. International Labour Organisation.

Sutton, G. E. (2001). Rocket Propulsion Elelments. Danvers: John Wiley and Sons.

Svitek, D. T. (2008-2009, Dec-May). President, Stellar Exploration Inc. (C. Biddy, Interviewer)

Toorian, A. (2005). CubeSat Design Specifications. San Luis Obispo: California Polytechnic State University, Stanford University.

Zakharov, V. S. Specifics of Small Satellite Propulsion: Part 1. 
- $73-$ 
Appendix A. Mass Fraction vs. $I_{\text {sp }}$ Required Hand Calculation

$$
\begin{aligned}
& \text { Constunts } \\
& W_{f}=3 \mathrm{~kg} \\
& \Delta V=500 \mathrm{~m} / \mathrm{s}
\end{aligned}
$$$$
\text { Eg.s } \quad \begin{aligned}
\Delta v & =g \operatorname{Isp}_{s}\left(\ln \left(\frac{w_{i}}{w_{f}}\right)\right) \text { (s) } \\
w_{p} & =W_{f}\left[\exp \left(\frac{\Delta v}{g I_{s p}}\right)-1\right]
\end{aligned}
$$

For $I_{s p}=175$
$w_{p}=3 \mathrm{~kg}\left[e^{\left.\frac{(500-1 / 5)}{9.81 \% / \mathrm{s}^{2}(175 s)}-1\right]}\right.$

$w_{p}=1.01 \mathrm{~kg} \quad$ (not pussible) $w_{p}$ must be $<1 \mathrm{~kg}$ $=$

\begin{tabular}{l|l}
$I_{s p}$ & $W_{p}$ \\
\hline 200 & 0.87 \\
225 & 0.76 \\
250 & 0.68 \\
275 & 0.61 \\
300 & 0.56 \\
325 & 0.51 \\
350 & 0.47 \\
375 & 0.44
\end{tabular}

mass fraction: $\frac{W_{p}}{W_{f}}$ 
Appendix B. Performance vs. Dry Mass Fraction data for Figure 3.

\begin{tabular}{|c|c|c|c|c|c|c|c|}
\hline \multicolumn{8}{|c|}{ Assumes $3 \mathrm{~kg}$ (fueled) spacecraft } \\
\hline \multicolumn{2}{|c|}{$\mathrm{Isp}=150$} & \multicolumn{2}{|c|}{$\mathrm{Isp}=180$} & \multicolumn{2}{|c|}{ Isp $=210$} & \multicolumn{2}{|c|}{ Isp $=240$} \\
\hline $\begin{array}{l}\text { Propulsion } \\
\text { Dry Mass } \\
\text { fraction }\end{array}$ & $\begin{array}{c}\text { Delta V } \\
(\mathrm{m} / \mathrm{s})\end{array}$ & $\begin{array}{c}\text { Propulsion } \\
\text { Dry Mass } \\
\text { fraction }\end{array}$ & $\begin{array}{c}\text { Delta V } \\
(\mathrm{m} / \mathrm{s})\end{array}$ & $\begin{array}{l}\text { Propulsion } \\
\text { Dry Mass } \\
\text { fraction }\end{array}$ & $\begin{array}{c}\text { Delta V } \\
(\mathrm{m} / \mathrm{s})\end{array}$ & $\begin{array}{l}\text { Propulsion } \\
\text { Dry Mass } \\
\text { fraction }\end{array}$ & $\begin{array}{c}\text { Delta } \\
\text { V } \\
(\mathrm{m} / \mathrm{s})\end{array}$ \\
\hline 0.67 & 589 & 0.67 & 707 & 0.67 & 825 & 0.67 & 943 \\
\hline 0.68 & 568 & 0.68 & 681 & 0.68 & 795 & 0.68 & 908 \\
\hline 0.69 & 546 & 0.69 & 655 & 0.69 & 764 & 0.69 & 874 \\
\hline 0.70 & 525 & 0.70 & 630 & 0.70 & 735 & 0.70 & 840 \\
\hline 0.71 & 504 & 0.71 & 605 & 0.71 & 706 & 0.71 & 806 \\
\hline 0.72 & 483 & 0.72 & 580 & 0.72 & 677 & 0.72 & 773 \\
\hline 0.73 & 463 & 0.73 & 556 & 0.73 & 648 & 0.73 & 741 \\
\hline 0.74 & 443 & 0.74 & 532 & 0.74 & 620 & 0.74 & 709 \\
\hline 0.75 & 423 & 0.75 & 508 & 0.75 & 593 & 0.75 & 677 \\
\hline 0.76 & 404 & 0.76 & 485 & 0.76 & 565 & 0.76 & 646 \\
\hline 0.77 & 385 & 0.77 & 462 & 0.77 & 538 & 0.77 & 615 \\
\hline 0.78 & 366 & 0.78 & 439 & 0.78 & 512 & 0.78 & 585 \\
\hline 0.79 & 347 & 0.79 & 416 & 0.79 & 486 & 0.79 & 555 \\
\hline 0.80 & 328 & 0.80 & 394 & 0.80 & 460 & 0.80 & 525 \\
\hline 0.81 & 310 & 0.81 & 372 & 0.81 & 434 & 0.81 & 496 \\
\hline 0.82 & 292 & 0.82 & 350 & 0.82 & 409 & 0.82 & 467 \\
\hline 0.83 & 274 & 0.83 & 329 & 0.83 & 384 & 0.83 & 439 \\
\hline 0.84 & 257 & 0.84 & 308 & 0.84 & 359 & 0.84 & 410 \\
\hline 0.85 & 239 & 0.85 & 287 & 0.85 & 335 & 0.85 & 383 \\
\hline 0.86 & 222 & 0.86 & 266 & 0.86 & 311 & 0.86 & 355 \\
\hline 0.87 & 205 & 0.87 & 246 & 0.87 & 287 & 0.87 & 328 \\
\hline 0.88 & 188 & 0.88 & 226 & 0.88 & 263 & 0.88 & 301 \\
\hline 0.89 & 171 & 0.89 & 206 & 0.89 & 240 & 0.89 & 274 \\
\hline 0.90 & 155 & 0.90 & 186 & 0.90 & 217 & 0.90 & 248 \\
\hline 0.91 & 139 & 0.91 & 167 & 0.91 & 194 & 0.91 & 222 \\
\hline 0.92 & 123 & 0.92 & 147 & 0.92 & 172 & 0.92 & 196 \\
\hline 0.93 & 107 & 0.93 & 128 & 0.93 & 150 & 0.93 & 171 \\
\hline 0.94 & 91 & 0.94 & 109 & 0.94 & 127 & 0.94 & 146 \\
\hline 0.95 & 75 & 0.95 & 91 & 0.95 & 106 & 0.95 & 121 \\
\hline 0.96 & 60 & 0.96 & 72 & 0.96 & 84 & 0.96 & 96 \\
\hline 0.97 & 45 & 0.97 & 54 & 0.97 & 63 & 0.97 & 72 \\
\hline 0.98 & 30 & 0.98 & 36 & 0.98 & 42 & 0.98 & 48 \\
\hline 0.99 & 15 & 0.99 & 18 & 0.99 & 21 & 0.99 & 24 \\
\hline 1.00 & 0 & 1.00 & 0 & 1.00 & 0 & 1.00 & 0 \\
\hline
\end{tabular}


Appendix C. Graham Edney catalyst design sketches.

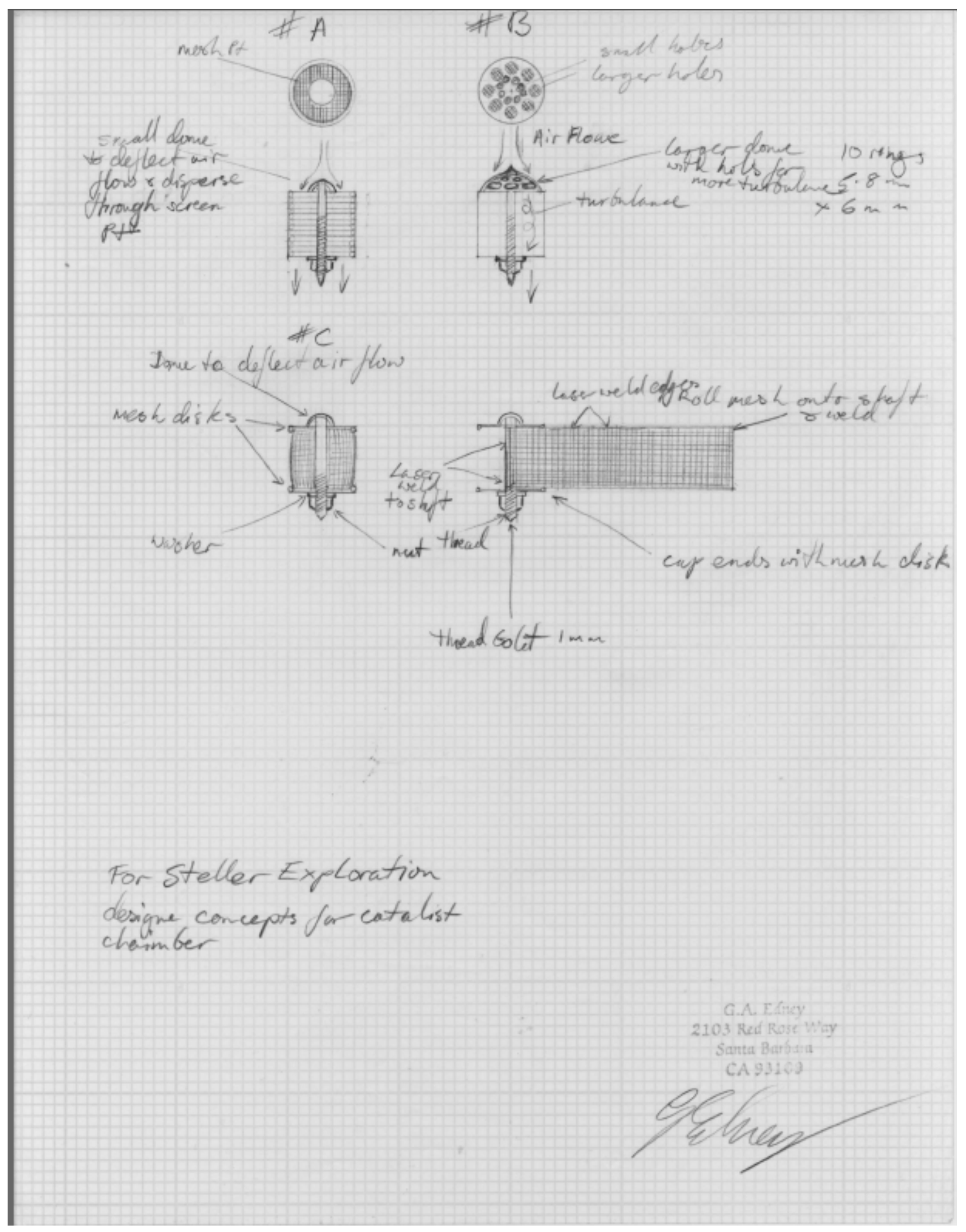


Appendix D. Nozzle Area Ratio Calculation and Derivation.

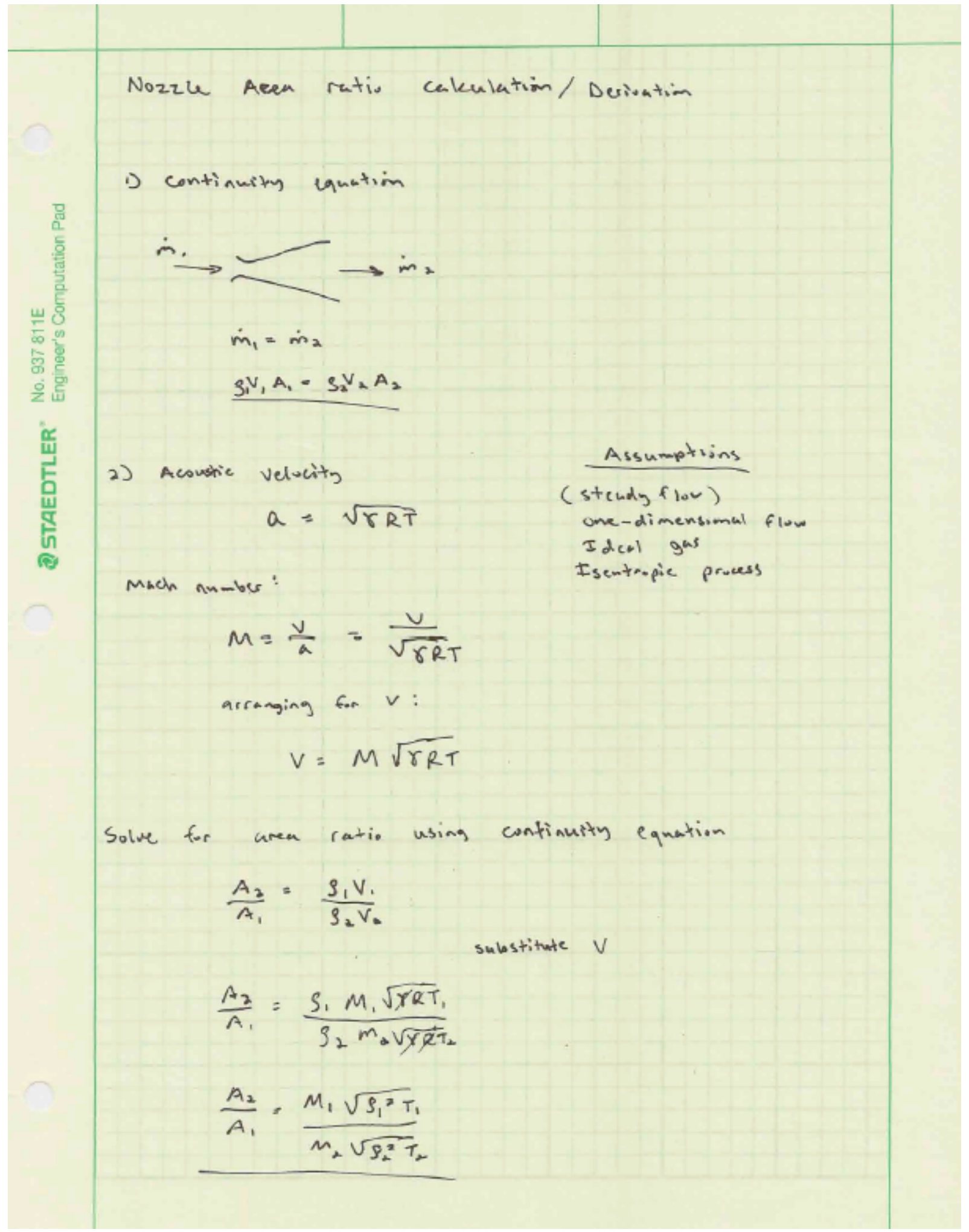




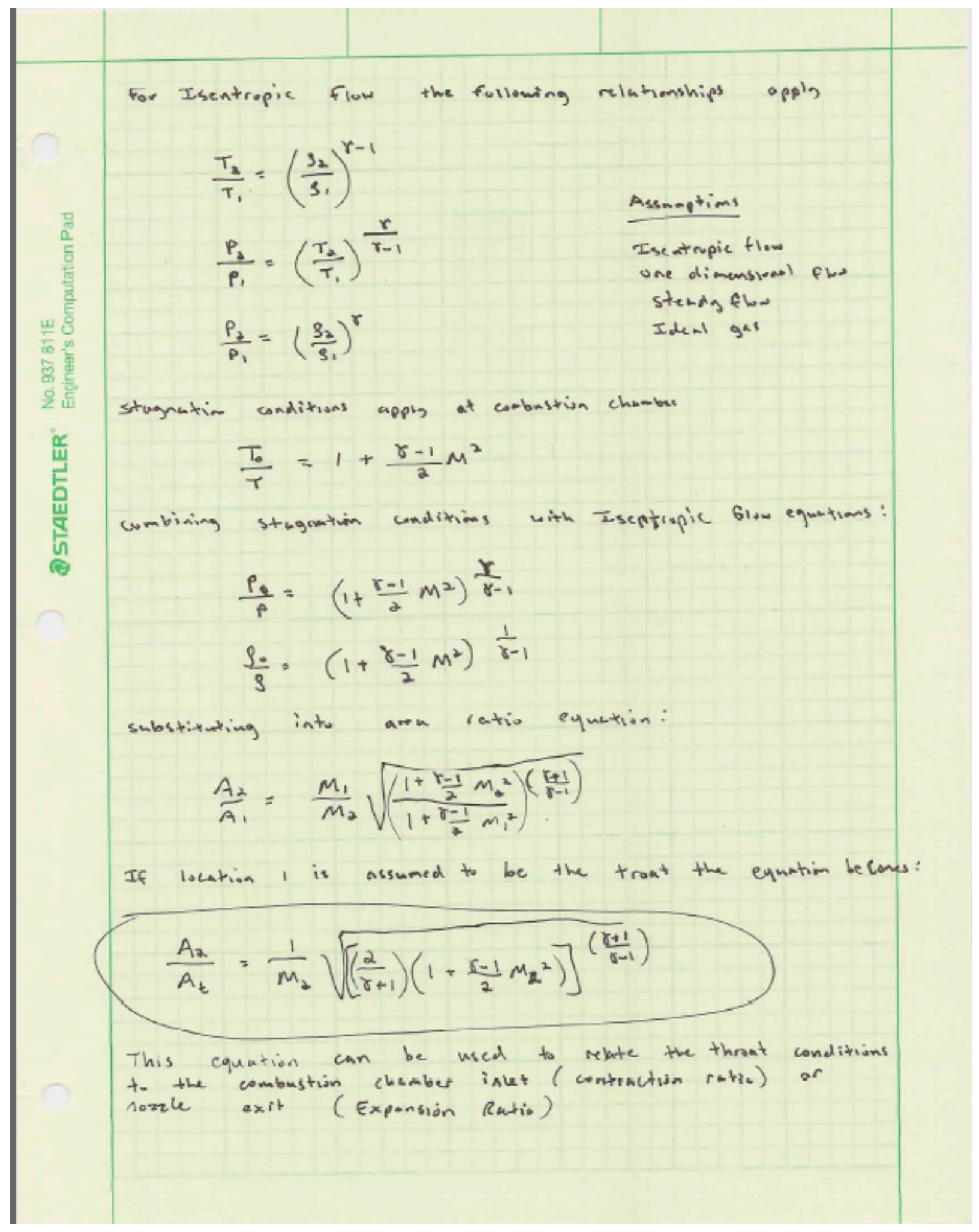




\section{Appendix E. Isp vs. Expansion Ratio data for Figure 6.}

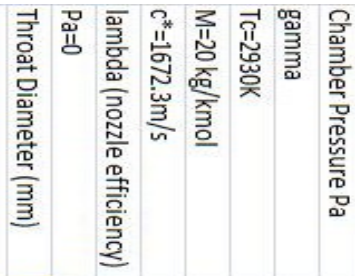

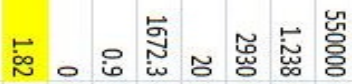

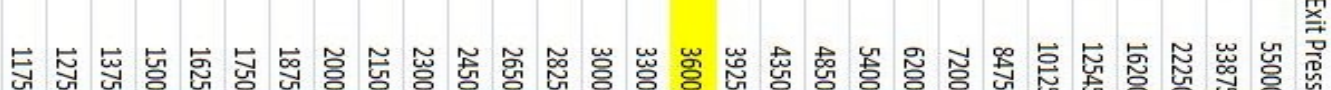
б.

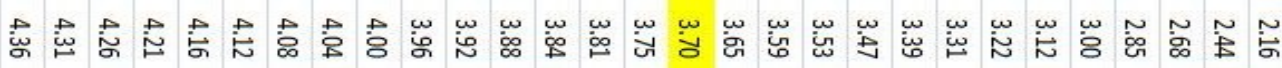

出出药

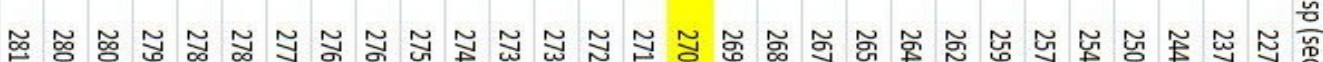

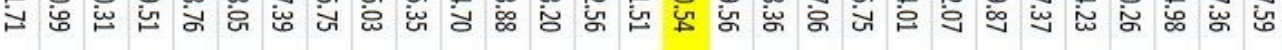

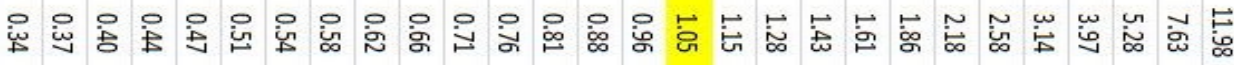

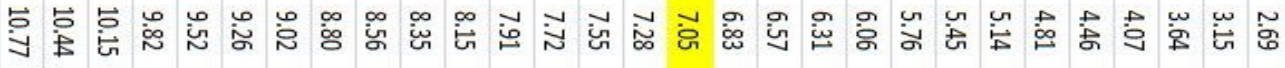

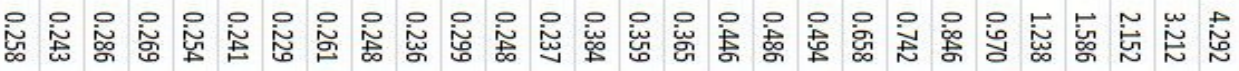


Appendix F. Micropropulsion system data sheets and drawings.

\section{ASCO miniature solenoid valve}

\section{$2 / 2$}

$3 / 2$

Series

General Service

AL

\section{2 and 3-Way Miniature Solenoid Valves}

10-32 UNF Porting, In-line Porting

The Series AL Valves are suitable for a wide range of OEM applications where small size, low power and long life are a must.

- Cycle life in the hundreds of millions

- Corrosion resistant materials of construction

- In-line porting for use with standard metal or plastic \#10-32 UNF fittings

- Magnetic latching construction available to maintain valve position with loss of power, eliminate coil heat rise, and extend battery life

\section{Construction}

\begin{tabular}{|c|c|}
\hline \multicolumn{2}{|c|}{ Valve Parts In Contact with Flulds } \\
\hline Body & POM or 300 Series Stainless Steal \\
\hline Dist & FKM \\
\hline Ga:kets & FKM \\
\hline Bobblo/CoreTube & PET \\
\hline core and Pugout & 400 Seriles Stanless Stest \\
\hline Springs & 300 Sentes Stanless Stest \\
\hline
\end{tabular}

Electrical

\begin{tabular}{|c|c|}
\hline Standard Voltages & $\begin{array}{c}6,12,24 V D C+10 \%,-5 \% \\
115 \text { VAC (with rectingr in laad wires) }\end{array}$ \\
\hline Power Consumplion & $\begin{array}{c}0.65-2.0 \text { Watts } \\
(10 \text { watts for latching versisn) }\end{array}$ \\
\hline Duty Cycle Rallig & Continuous (Intermittert for latching versisn) \\
\hline Coll Insulation & $265^{\prime} \mathrm{F}\left(130^{\prime} \mathrm{C}\right)$ \\
\hline Electrital Connetillon & 26 gaga kad wire \\
\hline
\end{tabular}

Valve

\begin{tabular}{|c|c|}
\hline Response TIme & $\begin{array}{l}-5 \mathrm{~ms} \text { at rated woltage (2 walt coll) } \\
-12 \mathrm{~ms} \text { at rated witage ( } 0.65 \text { watt colin) }\end{array}$ \\
\hline Internal Volume & 2-way $N C=330 \mu \mathrm{L}, 2$-way N0 - $310 \mu, 3$-waj $=370 \mu \mathrm{L}$ \\
\hline Mounllig Bracket & Optisnal mounting clip, pin 5188-CQ (see drawhy) \\
\hline Options & $\begin{array}{l}\text { - Oxygen service corsistruction avalabla } \\
\text { - Lubricant free construction avalable }\end{array}$ \\
\hline Vacuum Ratlıg & $29^{\circ} \mathrm{HJ}$ \\
\hline
\end{tabular}

\section{Alternative Constructions}

Many altemative constructions are available and indude a variety of volteges, electrical connectors, and materiak of construction. ASCO Scientific can also arstom design a vahe for your specific application.

Contact your local ASCO sales office for more information. 
Specifications

\begin{tabular}{|c|c|c|c|c|c|c|}
\hline Ports & $\begin{array}{l}\text { Orilice } \\
\text { Sireo } \\
\text { (ina) }\end{array}$ & $\begin{array}{c}\text { Cy Flow } \\
\text { Fartor }\end{array}$ & $\underset{\text { Pressure (psi) }}{\text { Moximum }}$ & Cablog Humier & $\begin{array}{l}\text { Wat Patiog } \\
\text { ब. }\end{array}$ & Woipht(oz.) \\
\hline \multicolumn{7}{|c|}{ 2-WAY HOFMLLY Y OSED (Closed when do-enerpized) } \\
\hline$\$ 10-32$ UNF & 0.025 & 0.015 & 110 & AL11x & 0.65 & 1.3 \\
\hline$\$ 10-32$ LNF & 0.005 & 0.038 & 50 & AL21xx & 0.65 & 1.3 \\
\hline \$10-32 LNF & 0.005 & 0.038 & 100 & AL31xx & 2.0 & 1.3 \\
\hline$\$ 10-32$ LNF & 0.099 & 0.07 & 30 & AL41 $x$ & 2.0 & 1.3 \\
\hline \multicolumn{7}{|c|}{ 2-WAY HOFMAL Y OFEH (Open when de-enerpized) } \\
\hline$\$ 10-32$ LWF & $0.0 \mathrm{~s}$ & 0.013 & 110 & AL1200 & 0.65 & 1.3 \\
\hline$\$ 10-32$ UNF & 0.048 & 0.033 & 80 & AL22 20 & 0.65 & 1.3 \\
\hline$\$ 10-32$ UNF & 0.048 & 0.033 & 100 & AL320 & 2.0 & 1.3 \\
\hline $710-32$ UNF & 0.078 & 0.06 & 30 & AL4200 & 2.0 & 1.3 \\
\hline \multicolumn{7}{|c|}{ 3-WAY UHIVERSLL OPERATION Pregaure at amy perf) } \\
\hline$\$ 10-32$ UNF & 0.0080 .025 & 0.0130 .013 & 110 & AL130 & 0.65 & 1.3 \\
\hline $510-32$ LWF & 0.0050 .048 & 0.0380003 & 80 & AL23:00 & 0.65 & 1.3 \\
\hline$\$ 10-32$ UNF & 0.0050 .048 & 0.03800033 & 100 & AL3200 & 2.0 & 1.3 \\
\hline$\$ 10-32$ LNF & 0.0920 .078 & 0.070066 & 30 & AL430x & 2.0 & 1.3 \\
\hline \multicolumn{7}{|l|}{ 2-WAY LATCHIHG } \\
\hline$\$ 10-32$ UNF & 0.025 & 0.015 & 110 & AL11xxL & $10^{*}$ & 1.8 \\
\hline $510-32$ LNF & 0.005 & 0.038 & 100 & AL31xxL & $10^{\circ}$ & 1.8 \\
\hline$\$ 10-32$ UNF & 0.092 & 0.07 & 30 & ALA4xxL & $10^{*}$ & 1.8 \\
\hline \multicolumn{7}{|l|}{ 3-WAY LATCHIHG } \\
\hline$\$ 10-32$ UNF & $0.0 e s, 0.025$ & 0.0150013 & 110 & AL130xL & $10^{*}$ & 1.8 \\
\hline $510-32$ UWF & 0.0650 .048 & 0.03800033 & 100 & AL33oxL & $10^{*}$ & 1.8 \\
\hline$\$ 10-32$ LNF & 0.0900 .078 & 0.07006 & 30 & ALA30xL & $10^{*}$ & 1.8 \\
\hline \multicolumn{7}{|c|}{ 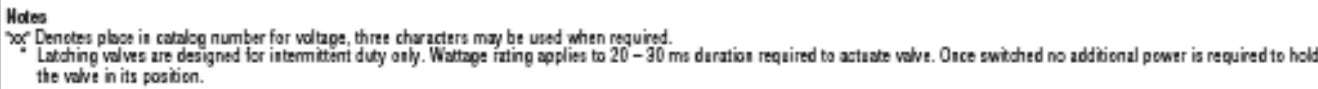 } \\
\hline
\end{tabular}

Catalog Number Description and Options

\begin{tabular}{|c|c|c|c|c|}
\hline AL33 & $x x$ & $\mathbf{L}$ & 0 & $\mathrm{~S}$ \\
\hline $\begin{array}{l}\text { Base Catalog } \\
\text { Number }\end{array}$ & $\begin{array}{l}\text { Voltage } \\
-06(\mathrm{DC}) \\
-12(\mathrm{DC}) \\
-24(\mathrm{DC}) \\
-115(\mathrm{AC})\end{array}$ & Latching Suffix & $\begin{array}{l}\text { Options Suffix } \\
A=A C \text { service (rectifier in lead wire) } \\
0=\text { No Lubricant } \\
K=\text { Oxygen Service Construction } \\
\text { PBT Valve Body, FKM Seals, PFPE }\end{array}$ & $\begin{array}{l}\text { Optional Body Material } \\
S=300 \text { Series Stainless Sted }\end{array}$ \\
\hline
\end{tabular}

To Construct Catalog Number

- Select base catalog number

- Insert voltage into the 5th, 6th, (and 7th when required), digits denoted by " $x x "$

- Add suffix for optional features to end of base catalog number

Examples

AL1124 = 2-way normally closed valve with $0.025^{*}$ orifice, 110 peig max pressure rating, and 24 VDC coil rated at 0.65 watts. AL32115A = 2-way normally open valve with $0.048^{*}$ orifice, 100 psig max pressure rating, and 115 VAC coil with rectifier.

AL4306LK = 3-way latching valve with $0.090^{\prime \prime}$ and $0.078^{\circ}$ orifices, 30 psig max pressure rating, 6 VDC coil and suitable for oxygen service. 
Dimensions 2 and 3-Way Standard Solenoid: Inches [mm]
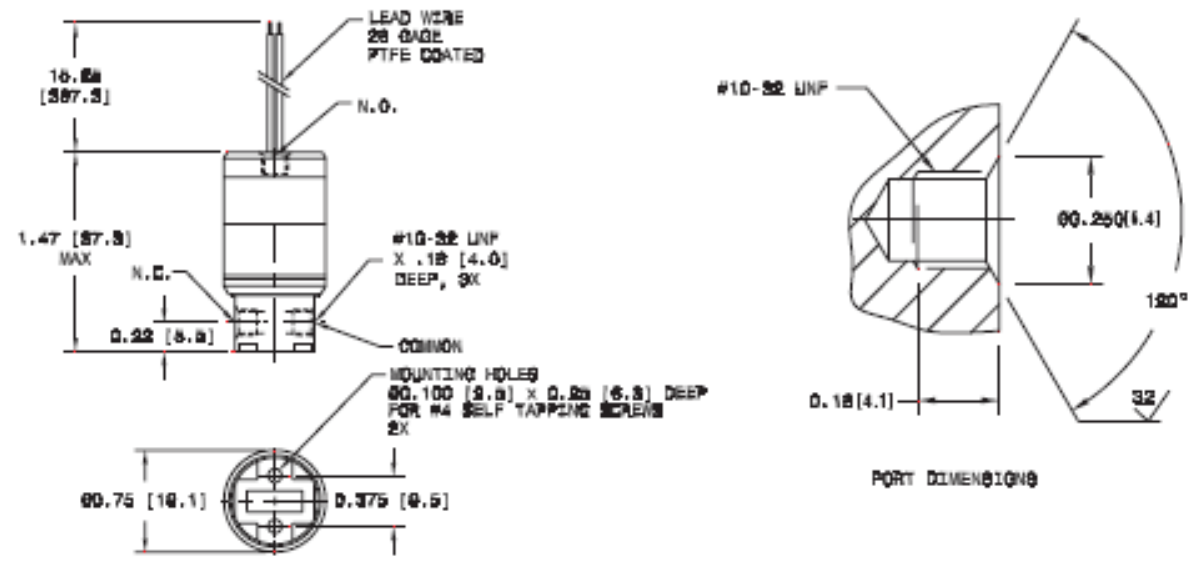

POAT DIMENGIGNa

Dimensions 2 and 3-Way Latching Solenoid: Inches [mm]
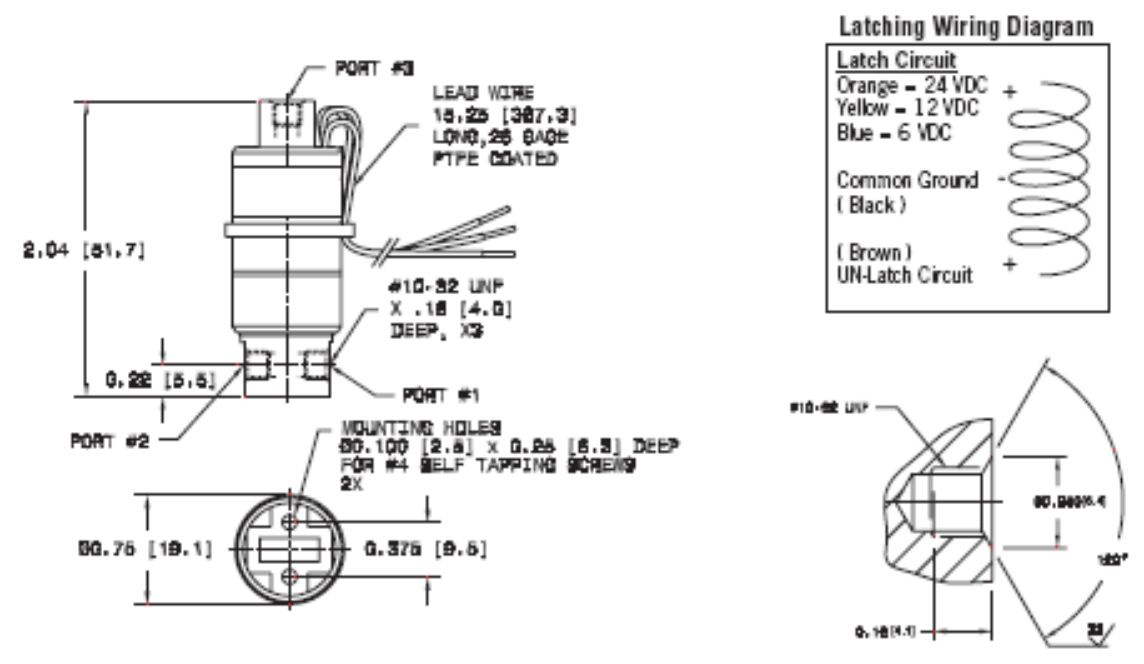

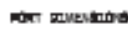


Vented Cap Screw Drawing

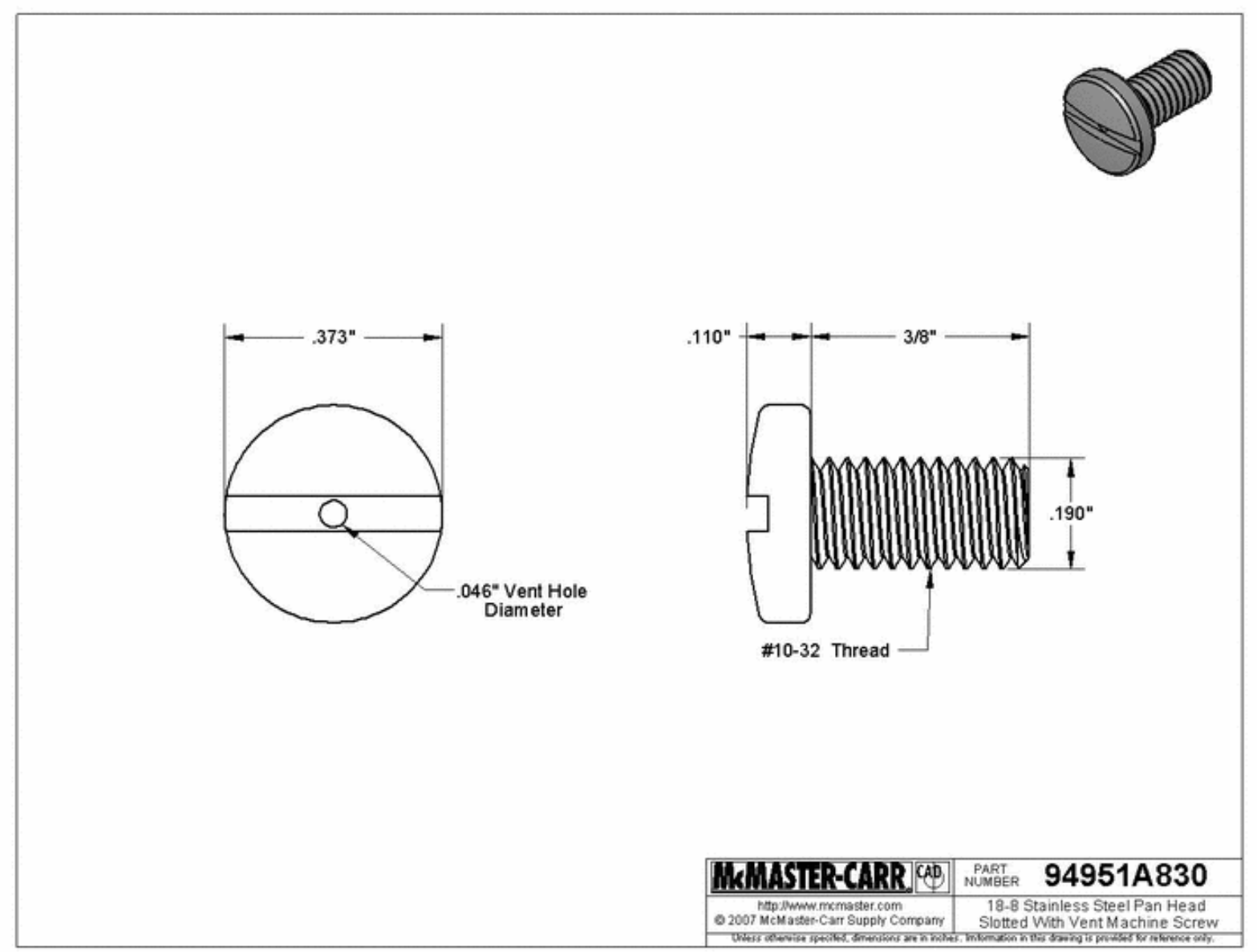


Parker EDPM O-Ring Data Sheets

\begin{tabular}{|c|c|c|c|c|c|c|c|c|c|c|c|c|c|c|c|c|c|}
\hline$<\mathrm{Bac}$ & Section & Con & ntel & nts & & & ible & of & CoI & nter & nts & & $\mathrm{Se}$ & arcl & & & \\
\hline & Parker 0-All & ng $\mathrm{Ha}$ & land: & book & & & & & & & & & & & & & \\
\hline $\begin{array}{c}\text { COMPOUND COMPATIBILITY RATING } \\
1 \text { - Satisfactory } \\
\text { 2- Fair (usually OK for static seal) } \\
\text { 3- Doubtrul (sometimes OK for static seal) } \\
4 \text { - Unsatisfactory } \\
\text { x - Insufficient Data }\end{array}$ & Recommended & 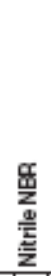 & 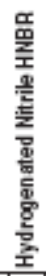 & & & & & $\frac{1}{2}$ & 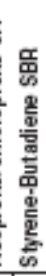 & & & & & 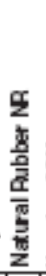 & & 这 & \\
\hline Hexamettry|disillzane & V8545-75 & $\mathrm{x}$ & $x$ & $\mathrm{x}$ & 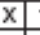 & \begin{tabular}{l|l}
1 & \\
1
\end{tabular} & \begin{tabular}{l|l}
1 & $x$ \\
\end{tabular} & & $x$ & $x$ & $\mathrm{x}$ & \begin{tabular}{l|l}
$x$ & 2 \\
\end{tabular} & \begin{tabular}{l|l}
$x$ & $x$ \\
\end{tabular} & $\mathrm{x}$ & \begin{tabular}{|l|l}
$x$ & \\
\end{tabular} & \begin{tabular}{l|l}
$x$ & $x$ \\
\end{tabular} & \\
\hline Hexamettrylene (Cyclohexane) & No674-70 & 1 & 1 & 4 & 1 & 1 & $1 \mathrm{x}$ & $\begin{array}{l}\mathrm{k} \\
\mathrm{x}\end{array}$ & 4 & 1 & 1 & 4 & \begin{tabular}{l|l}
4 & 4 \\
\end{tabular} & 4 & 2 & 122 & \\
\hline Hexamettrylene Dlammonlum Adlpate & V1164-75 & 2 & 2 & 4 & 1 & 1 & \begin{tabular}{l|ll}
1 & $x$ \\
\end{tabular} & \begin{tabular}{l|l}
6 & 4 \\
\end{tabular} & 4 & 4 & 3 & 4 & \begin{tabular}{l|l}
4 & 4 \\
\end{tabular} & 4 & 4 & \begin{tabular}{l|l}
2 & $x$ \\
2
\end{tabular} & \\
\hline Hexamettrylenedlamine & E05 & 3 & 3 & 1 & 3 ? & 2 & $2 \times$ & \begin{tabular}{l|ll}
6 & 1 \\
\end{tabular} & 1 & 4 & 4 & 1 & \begin{tabular}{l|l}
1 & 1 \\
\end{tabular} & 1 & 1 & 12 & \\
\hline Hexamethylenetetramine & 90 & 3 & 3 & 1 & \begin{tabular}{l|l}
3 & 2
\end{tabular} & 2 & \begin{tabular}{l|l}
2 & $x$ \\
2
\end{tabular} & \begin{tabular}{l|l}
$x$ & 1 \\
\end{tabular} & 1 & 4 & 4 & 1 & \begin{tabular}{l|l}
1 & 1 \\
\end{tabular} & 1 & 1 & 1 & \\
\hline Hexane or n-Hexane & No674-70 & 1 & 1 & 4 & 1 & 1 & \begin{tabular}{l|l}
1 & $x$ \\
\end{tabular} & \begin{tabular}{l|l}
$x$ & 2 \\
\end{tabular} & 4 & 1 & 2 & 4 & \begin{tabular}{c|c}
4 & 4 \\
\end{tabular} & 4 & 2 & \begin{tabular}{l|l}
3 & 4 \\
\end{tabular} & \\
\hline Hexene-1 or n-Hexene-1 & 75 & 2 & 2 & 4 & 1 & 1 & 18 & 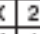 & 4 & 1 & 2 & 4 & \begin{tabular}{c|c}
4 & 4 \\
\end{tabular} & 4 & 2 & 4 & \\
\hline Hexone (Methyl Isobutyl Ketone) & $E 0540 \oplus 0$ & 3 & 3 & 1 & 3 & 1 & \begin{tabular}{l|l}
1 & $x$ \\
\end{tabular} & \begin{tabular}{l|l}
$x$ & 1 \\
\end{tabular} & 1 & 4 & 4 & 1 & \begin{tabular}{l|l}
1 & 1 \\
\end{tabular} & 1 & 1 & 1 & \\
\hline Hexyl Acetate & No674-70 & 1 & 1 & 4 & 1 & 1 & \begin{tabular}{l|l}
1 & $x$ \\
\end{tabular} & \begin{tabular}{l|l}
$x$ \\
\end{tabular} & 4 & 1 & 1 & 4 & \begin{tabular}{l|l}
4 & 4 \\
\end{tabular} & 4 & 2 & \begin{tabular}{l|l}
1 & 2 \\
1
\end{tabular} & \\
\hline Hexyl Alcohol & 70 & 1 & 1 & 3 & 1 & 1 & \begin{tabular}{l|l}
1 & $x$ \\
1
\end{tabular} & \begin{tabular}{l|l} 
& 2 \\
\end{tabular} & 1 & 4 & 4 & 3 & \begin{tabular}{l|l}
1 & 1 \\
\end{tabular} & 1 & 2 & 2 & \\
\hline Hexylene Glycol & $540 \oplus 0$ & 3 & 3 & 1 & 3 & 1 & 1 & \begin{tabular}{l|l}
6 & 1 \\
\end{tabular} & 1 & 4 & 4 & 1 & \begin{tabular}{l|l}
1 & 1 \\
\end{tabular} & 1 & 1 & 1 & \\
\hline Hexylresorcinol & .75 & 2 & 2 & 4 & 1 & 1 & \begin{tabular}{l|l}
1 & $x$ \\
\end{tabular} & \begin{tabular}{l|l}
6 & 4 \\
\end{tabular} & 4 & 4 & 3 & 4 & \begin{tabular}{l|l}
4 & 4 \\
\end{tabular} & 4 & 4 & 2 & \\
\hline HFC-245ta & 70 & $\mathrm{x}$ & $x$ & \begin{tabular}{|l|l}
$x$ & -1 \\
\end{tabular} & $\mathrm{x}+\mathrm{z}$ & 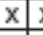 & 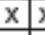 & \begin{tabular}{l|l}
$x$ \\
$x$
\end{tabular} & $x$ & $\mathrm{x}$ & $\mathrm{x}$ & $\mathrm{x}$ & \begin{tabular}{l|l}
$x$ & $x$ \\
\end{tabular} & $\mathrm{x}$ & $\mathrm{x}$ & $\bar{x}$ & \\
\hline High Vlscosity L & 0 & 1 & 1 & 1 & 1 & 1 & \begin{tabular}{l|l}
1 & $x$ \\
\end{tabular} & \begin{tabular}{l|l}
$x$ & 2 \\
\end{tabular} & 1 & 4 & 4 & 1 & \begin{tabular}{l|l}
2 & $x$ \\
\end{tabular} & $\mathrm{x}$ & $\mathrm{x}$ & 2 & \\
\hline HIgh Vlscosity Lubricant, U4 & No674-70 & 1 & 1 & 1 & 1 & \begin{tabular}{l|l}
1 \\
\end{tabular} & \begin{tabular}{l|l}
1 & $x$ \\
\end{tabular} & \begin{tabular}{l|l}
2 \\
\end{tabular} & 1 & 4 & 4 & 1 & \begin{tabular}{l|l}
2 & $x$ \\
\end{tabular} & $\mathrm{x}$ & \begin{tabular}{l|l}
$x$ \\
\end{tabular} & 2 & \\
\hline HILO MS $\neq 1$ & $E 0540-00$ & 4 & 4 & 1 & 4 & 1 & \begin{tabular}{l|l}
1 & $x$ \\
\end{tabular} & \begin{tabular}{l|l}
$x$ & 4 \\
\end{tabular} & 4 & 4 & 4 & 2 & \begin{tabular}{l|l}
4 & 4 \\
\end{tabular} & 4 & 4 & 3 & \\
\hline Houghto-Sate 1010 phosphate ester & 90 & 4 & 4 & 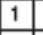 & 1 & 1 & \begin{tabular}{l|l}
1 & $x$ \\
\end{tabular} & \begin{tabular}{l|l}
6 & 4 \\
\end{tabular} & 4 & 4 & $\mathrm{x}$ & 1 & \begin{tabular}{c|c}
4 & 4 \\
\end{tabular} & 4 & 4 & 2 & \\
\hline Houghto-Sate 1055 phosphate ester & $540-00$ & 4 & 4 & 1 & 1 & 1 & 18 & \begin{tabular}{l|l}
6 & 4 \\
4
\end{tabular} & 4 & 4 & $\mathrm{x}$ & 1 & \begin{tabular}{l|l}
4 & 4 \\
\end{tabular} & 4 & 4 & 2 & \\
\hline Houghto-Sate 1120 phosphate ester & $1164-75$ & 4 & 4 & 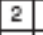 & 1 & 1 & \begin{tabular}{l|l}
1 & $x$ \\
\end{tabular} & \begin{tabular}{l|l}
6 & 4 \\
\end{tabular} & 4 & 4 & 4 & 1 & \begin{tabular}{l|l}
4 & 4 \\
\end{tabular} & 4 & 4 & 2 & \\
\hline Houghto-Sate 271 (Water \& Glycol Base) & 70 & 1 & 1 & \begin{tabular}{|l|l}
1 & $r a r$
\end{tabular} & $2 \mid$ & 1 & \begin{tabular}{l|ll}
1 & $x$ \\
\end{tabular} & \begin{tabular}{l|l}
$x$ \\
\end{tabular} & 1 & 4 & 4 & 2 & \begin{tabular}{l|l}
$x$ \\
$x$
\end{tabular} & $\mathrm{x}$ & $\mathrm{x}$ & & \\
\hline Houghto-Safe $416 \& 500$ Serles & No674-70 & 1 & 1 & 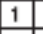 & \begin{tabular}{l|l}
$x$ & 2 \\
\end{tabular} & $\mathrm{x}$ & 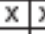 & \begin{tabular}{c|c}
$x$ \\
$x$
\end{tabular} & $x$ & $\mathrm{x}$ & $\mathrm{x}$ & $\mathrm{x}$ & \begin{tabular}{l|l}
$x$ & $x$ \\
\end{tabular} & $\mathrm{x}$ & \begin{tabular}{l|l}
$x$ & \\
\end{tabular} & $\bar{x}$ & \\
\hline Houghto-Sate 5040 (Water/Oll emulsion) & No674-70 & 1 & 1 & 4 & 1 & 1 & 1 & \begin{tabular}{l|l}
5 & 2 \\
\end{tabular} & 4 & 4 & 4 & 4 & $\begin{array}{lll}4 & 4 \\
\end{array}$ & 4 & 4 & 2 & \\
\hline Houghto-Safe 620 WaterjGlycol & 70 & 1 & 1 & 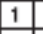 & 2 & 1 & \begin{tabular}{l|ll}
1 & $x$ \\
\end{tabular} & \begin{tabular}{c|c}
$x$ & 2 \\
\end{tabular} & 1 & 4 & 4 & 2 & \begin{tabular}{l|l}
$x$ & $x$ \\
\end{tabular} & $\mathrm{x}$ & $\mathrm{x}$ & 2 & \\
\hline Hydraullc Oll (Petrolaum Base, Industrlal) & 70 & 1 & 1 & 4 & 1 & 1 & 1 & \begin{tabular}{l|l}
6 & 2 \\
\end{tabular} & 4 & 1 & 1 & 4 & \begin{tabular}{l|l}
4 & 4 \\
\end{tabular} & 4 & 2 & 1 & \\
\hline Hydraullic Olls (Synthetlc Base) & & 2 & 2 & 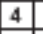 & 1 & 1 & \begin{tabular}{l|ll}
1 & $x$ \\
\end{tabular} & \begin{tabular}{l|l}
$x$ & 4 \\
\end{tabular} & 4 & 4 & 3 & 4 & \begin{tabular}{l|l}
4 & 4 \\
\end{tabular} & 4 & 4 & 2 & \\
\hline Hydrazine & $\infty$ & 2 & 2 & 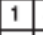 & 4 & 1 & \begin{tabular}{l|l}
1 & $x$ \\
\end{tabular} & \begin{tabular}{l|l}
6 & 2 \\
\end{tabular} & 2 & $\mathrm{x}$ & 4 & 1 & \begin{tabular}{c|c}
$x$ & $x$ \\
\end{tabular} & 1 & 2 & 4 & \\
\hline Hydrazine (Antrydrous) & $540-80$ & 4 & 4 & 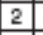 & 4 & 1 & \begin{tabular}{l|ll}
1 & 2 & $r$
\end{tabular} & 2 & 1 & 4 & 4 & 2 & \begin{tabular}{l|l}
4 & 4 \\
\end{tabular} & 4 & 2 & 4 & \\
\hline Hydrazine Dihydrochlorlde & $E 0540 \oplus 0$ & 3 & 3 & 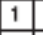 & 3 & 1 & \begin{tabular}{l|l}
1 & $x$ \\
\end{tabular} & \begin{tabular}{l|l}
6 & 1 \\
\end{tabular} & 1 & 4 & 4 & 1 & \begin{tabular}{l|l}
1 & 1 \\
\end{tabular} & 1 & 1 & 1 & \\
\hline Hydrazlne Hydrate & $540-0$ & 3 & 3 & 1 & 3 & 1 & \begin{tabular}{l|l}
1 & $x$ \\
1
\end{tabular} & $\begin{array}{l}1 \\
\end{array}$ & 1 & 4 & 4 & 1 & \begin{tabular}{l|l}
1 & 1 \\
\end{tabular} & 1 & 1 & & \\
\hline Hydrlodle Acld & V1164-75 & 2 & 2 & \begin{tabular}{|l|l}
4 & $r a r$ \\
\end{tabular} & 1 & 1 & \begin{tabular}{l|l}
1 & $x$ \\
\end{tabular} & \begin{tabular}{l|l}
6 & 4 \\
\end{tabular} & 4 & 4 & 3 & 4 & \begin{tabular}{l|l}
4 & 4 \\
\end{tabular} & 4 & 4 & 2 & \\
\hline Hydroabletyl Akcohol & & $\mathrm{x}$ & $x$ & \begin{tabular}{|l|l}
$\mathrm{x}$ & -1 \\
\end{tabular} & 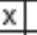 & 1 & \begin{tabular}{l|l}
1 & $x$ \\
\end{tabular} & \begin{tabular}{c|c}
$x$ \\
$x$
\end{tabular} & $x$ & $\mathrm{x}$ & $\mathrm{x}$ & $x$ & \begin{tabular}{l|l}
$x$ & $x$ \\
\end{tabular} & $\mathrm{x}$ & $\mathrm{x}$ & $\bar{x}$ & \\
\hline Hydrobromk Acld & 60 & 4 & 4 & \begin{tabular}{|l|l|l|l|}
1 & $r$ \\
\end{tabular} & 1 & 1 & \begin{tabular}{l|l}
1 & $x$ \\
\end{tabular} & \begin{tabular}{l|l}
6 & 4 \\
\end{tabular} & 4 & 4 & 4 & 1 & \begin{tabular}{l|l}
4 & 1 \\
\end{tabular} & 1 & 1 & 3 & \\
\hline Hydrobromk Acld $40 \%$ & $E 0540-00$ & 4 & 4 & 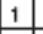 & 1 & 1 & 1 & \begin{tabular}{l|l}
6 & 2 \\
\end{tabular} & 4 & 4 & 4 & 1 & \begin{tabular}{l|l}
4 & 1 \\
\end{tabular} & 1 & 1 & 3 & \\
\hline Hydrocarbons, Saturated & $4-70$ & 1 & 1 & 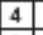 & 1 & 1 & \begin{tabular}{l|l}
1 & $x$ \\
\end{tabular} & \begin{tabular}{l|l}
$x$ & 2 \\
\end{tabular} & 4 & 1 & 2 & 4 & \begin{tabular}{l|l}
4 & 4 \\
\end{tabular} & 4 & 3 & & \\
\hline Hydrochlorle Ackd (cold) $37 \%$ & V1164-75 & 4 & $\mathrm{x}$ & \begin{tabular}{|c|c|c|c|}
3 & $r a$ \\
\end{tabular} & 1 & 1 & 1 & 154 & $x$ & $\mathrm{x}$ & $\mathrm{x}$ & $\mathrm{x}$ & \begin{tabular}{l|l}
$x$ \\
\end{tabular} & $\mathrm{x}$ & $\mathrm{x}$ & $\bar{x}$ & \\
\hline Hydrochlorlc Ackl (hot) $37 \%$ & V1164-75 & 4 & $\mathrm{x}$ & 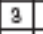 & 1 & 1 & \begin{tabular}{l|ll}
1 & $x$ \\
\end{tabular} & \begin{tabular}{l|l}
$x$ & 4 \\
\end{tabular} & 4 & 4 & 3 & 4 & \begin{tabular}{l|l}
4 & 4 \\
\end{tabular} & 4 & 4 & 2 & \\
\hline Hydrochlorle Ackd, 3 Molar to $158^{\circ} \mathrm{F}$ & V1164-75 & 2 & 2 & 1 & 1 & 1 & 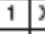 & \begin{tabular}{l|l}
2 & 2 \\
\end{tabular} & 3 & 3 & 4 & 1 & \begin{tabular}{c|ccc}
$x$ & $x$ \\
\end{tabular} & 3 & 1 & 3 & \\
\hline Hydrochlorlc Ackd, Concentrated Ro & Vog34-70 & 2 & 2 & 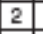 & 1 & 1 & \begin{tabular}{l|ll}
1 & $x$ \\
\end{tabular} & \begin{tabular}{c|c}
$x$ \\
$x$
\end{tabular} & $x$ & $\mathrm{x}$ & $\mathrm{x}$ & $\mathrm{x}$ & \begin{tabular}{l|l}
$x$ \\
$x$
\end{tabular} & $\mathrm{x}$ & $\mathrm{x}$ & $\bar{x}$ & \\
\hline Hydrochlorlc Ackd, concentrated to $158^{\circ} \mathrm{F}$ & V1164-75 & 4 & 4 & 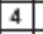 & 1 & 1 & \begin{tabular}{l|ll}
1 & $x$ \\
\end{tabular} & \begin{tabular}{l|l}
$x$ & 4 \\
\end{tabular} & 4 & 4 & 4 & 4 & \begin{tabular}{c|c}
$x$ \\
$x$
\end{tabular} & 4 & $\mathrm{x}$ & 4 & \\
\hline Hydrocyanic Acld & $E 0540 \oplus 0$ & 2 & 2 & \begin{tabular}{|l|l|}
1 \\
\end{tabular} & 1 & 1 & \begin{tabular}{l|l}
1 & $x$ \\
\end{tabular} & $\begin{array}{ll}6 & 2 \\
\end{array}$ & 2 & $4 \mid$ & $\mathrm{x}$ & & & 11 & \begin{tabular}{|l|l|}
1 & \\
\end{tabular} & & \\
\hline
\end{tabular}

Approximate Service Temperature Ranges for Commonly Used Basic Polymer Types*

\begin{tabular}{|c|c|c|c|}
\hline $\begin{array}{l}\text { Nirle (General Service) } \\
\text { Nirle (Low Tamperabure) } \\
\text { Hyurogenated Nible } \\
\text { Eihylene Propylene } \\
\text { Puorocarton } \\
\text { Hiluor } \\
\text { Pemuoroelasismer (Parchuon) }\end{array}$ & $\begin{array}{l}-34^{\circ} \mathrm{C} \text { to } 121^{\circ} \mathrm{C}\left(-30^{\circ} \mathrm{F} \text { to } 250^{\circ} \mathrm{F}\right) \\
-55^{\circ} \mathrm{C} \text { to } 107^{\circ} \mathrm{C}\left(-65^{\circ} \mathrm{F} \text { to } 225^{\circ} \mathrm{F}\right) \\
-32^{\circ} \mathrm{C} \text { to } 149^{\circ} \mathrm{C}\left(-23^{\circ} \mathrm{F} \text { to } 300^{\circ} \mathrm{F}\right) \\
-57^{\circ} \mathrm{C} \text { to } 121^{\circ} \mathrm{C}\left(-70^{\circ} \mathrm{F} \text { to } 250^{\circ} \mathrm{F}\right) \\
-26^{\circ} \mathrm{C} \text { to } 205^{\circ} \mathrm{C}\left(-15^{\circ} \mathrm{F} \text { to } 400^{\circ} \mathrm{F}\right) \\
-26^{\circ} \mathrm{C} \text { to } 205^{\circ} \mathrm{C}\left(-15^{\circ} \mathrm{F} \text { to } 400^{\circ} \mathrm{F}\right) \\
-26^{\circ} \mathrm{C} \text { to } 320^{\circ} \mathrm{C}\left(-15^{\circ} \mathrm{F} \text { to } 608^{\circ} \mathrm{F}\right)\end{array}$ & $\begin{array}{l}\text { AFLAS } \\
\text { Naoprene } \\
\text { Polyesrylate } \\
\text { Polyurelhane } \\
\text { Butyl } \\
\text { Fussosilicone } \\
\text { Sllosre } \\
\end{array}$ & 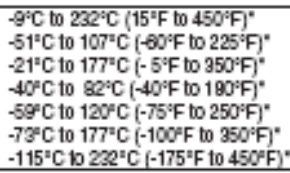 \\
\hline $\begin{array}{l}\text { NOTE: "These temporsure ran } \\
\text { tomperature range ma }\end{array}$ & 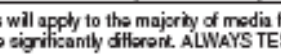 & $\begin{array}{l}\text { naterial is pote } \\
\text { CTUAL SERVIC }\end{array}$ & ded. With eorne modia however, the \\
\hline
\end{tabular}




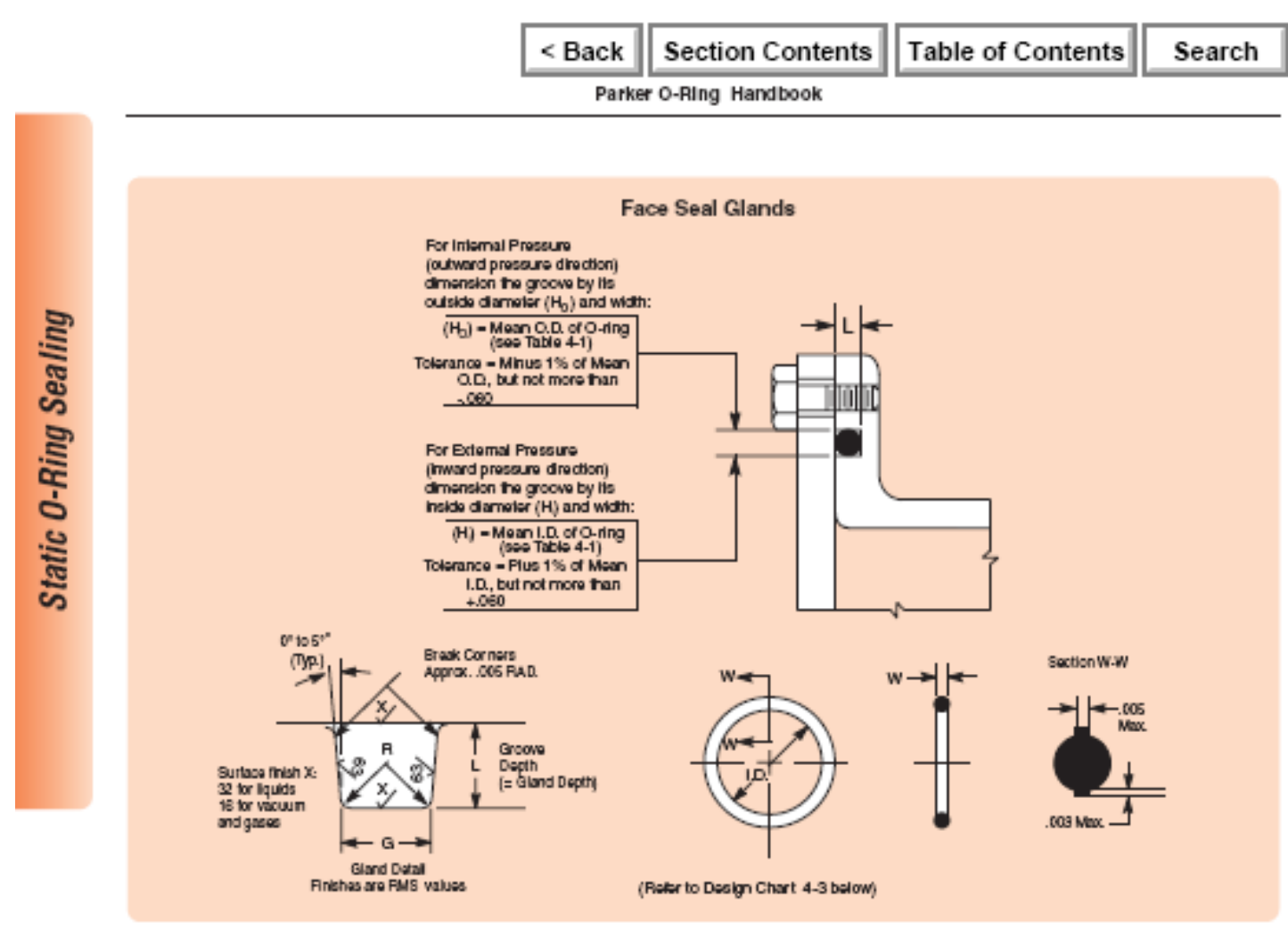

\begin{tabular}{|c|c|c|c|c|c|c|c|c|}
\hline \multirow{2}{*}{$\begin{array}{c}\text { O-Ring } \\
\text { Size } \\
\text { Parker } \\
\text { No. } 2\end{array}$} & \multicolumn{2}{|c|}{$\begin{array}{c}\text { W } \\
\text { Cross Section }\end{array}$} & \multirow{2}{*}{$\begin{array}{c}\text { L } \\
\text { Gland } \\
\text { Depth }\end{array}$} & \multirow{2}{*}{\multicolumn{2}{|c|}{ Squeeze }} & \multicolumn{2}{|c|}{$\begin{array}{c}\mathrm{G} \\
\text { Groove Width }\end{array}$} & \multirow{2}{*}{$\begin{array}{c}\text { R } \\
\text { Groove } \\
\text { Radius }\end{array}$} \\
\hline & $\begin{array}{r}\text { Cros } \\
\text { Nominal }\end{array}$ & tion & & $\begin{array}{r}\text { Sc } \\
\text { Actual }\end{array}$ & & Liquids & $\begin{array}{c}\text { Vacuum } \\
\text { and Gases }\end{array}$ & \\
\hline $\begin{array}{c}\infty 04 \\
\text { trough } \\
\infty 60\end{array}$ & $1 / 16$ & $\begin{array}{l}.070 \pm .000 \\
(1.78 \mathrm{~mm})\end{array}$ & $\begin{array}{l}.060 \\
\text { to } \\
.054\end{array}$ & $\begin{array}{c}.013 \\
b \\
.023\end{array}$ & $\begin{array}{c}19 \\
\text { to } \\
32 \\
\end{array}$ & $\begin{array}{c}.101 \\
\text { to } \\
.107\end{array}$ & $\begin{array}{l}.084 \\
\text { to } \\
.089\end{array}$ & $\begin{array}{c}.006 \\
b \\
.015\end{array}$ \\
\hline $\begin{array}{c}102 \\
\text { trough } \\
178\end{array}$ & $3 / 32$ & $\begin{array}{l}.103 \pm .000 \\
(2.62 \mathrm{~mm})\end{array}$ & $\begin{array}{c}.074 \\
\text { to } \\
.090 \\
\end{array}$ & $\begin{array}{c}.020 \\
b \\
.032 \\
\end{array}$ & $\begin{array}{c}20 \\
\text { to } \\
30 \\
\end{array}$ & $\begin{array}{c}.138 \\
\text { to } \\
.142 \\
\end{array}$ & $\begin{array}{l}.120 \\
\text { to } \\
.125 \\
\end{array}$ & $\begin{array}{c}.006 \\
b \\
.015 \\
\end{array}$ \\
\hline $\begin{array}{c}201 \\
\text { trough } \\
284\end{array}$ & $1 / 8$ & $\begin{array}{l}.139 \pm .004 \\
(3.53 \mathrm{~mm}\end{array}$ & $\begin{array}{c}.101 \\
\text { to } \\
.107\end{array}$ & $\begin{array}{c}.028 \\
b \\
.042 \\
\end{array}$ & $\begin{array}{l}20 \\
\text { to } \\
30 \\
\end{array}$ & $\begin{array}{c}.177 \\
\text { to } \\
.187\end{array}$ & $\begin{array}{c}.158 \\
\text { to } \\
.164 \\
\end{array}$ & $\begin{array}{c}.010 \\
b \\
.025\end{array}$ \\
\hline $\begin{array}{c}309 \\
\text { trough } \\
395\end{array}$ & $3 / 16$ & $\begin{array}{l}.210 \pm .005 \\
(5.33 \mathrm{~mm})\end{array}$ & $\begin{array}{c}.152 \\
\text { to } \\
.162 \\
\end{array}$ & $\begin{array}{c}.043 \\
b \\
.068 \\
\end{array}$ & $\begin{array}{l}21 \\
\text { to } \\
30 \\
\end{array}$ & $\begin{array}{c}270 \\
\text { to } \\
290 \\
\end{array}$ & $\begin{array}{l}.239 \\
\text { to } \\
.244 \\
\end{array}$ & $\begin{array}{c}.020 \\
b \\
.035 \\
\end{array}$ \\
\hline $\begin{array}{c}425 \\
\text { trough } \\
475\end{array}$ & $1 / 4$ & $\begin{array}{l}.275 \pm .006 \\
(6.89 \mathrm{~mm})\end{array}$ & $\begin{array}{c}.201 \\
\text { to } \\
.211\end{array}$ & $\begin{array}{c}.058 \\
b \\
.090\end{array}$ & $\begin{array}{c}21 \\
\text { to } \\
29 \\
\end{array}$ & $\begin{array}{c}342 \\
\text { to } \\
362 \\
\end{array}$ & $\begin{array}{c}.309 \\
\text { to } \\
.314 \\
\end{array}$ & $\begin{array}{c}.020 \\
b \\
.005\end{array}$ \\
\hline Special & $3 / 8$ & $\begin{array}{l}.375 \pm .007 \\
(9.52 \mathrm{~mm})\end{array}$ & $\begin{array}{c}.278 \\
\text { to } \\
.298 \\
\end{array}$ & $\begin{array}{c}.092 \\
b \\
.106 \\
\end{array}$ & $\begin{array}{l}22 \\
\text { to } \\
28 \\
\end{array}$ & $\begin{array}{c}475 \\
\text { to } \\
485 \\
\end{array}$ & $\begin{array}{c}.419 \\
\text { to } \\
.424 \\
\end{array}$ & $\begin{array}{c}.030 \\
b \\
.045\end{array}$ \\
\hline Special & $1 / 2$ & $\begin{array}{l}.500 \pm .008 \\
(12.7 \mathrm{~mm})\end{array}$ & $\begin{array}{l}.370 \\
\text { to } \\
.390\end{array}$ & $\begin{array}{c}.112 \\
b \\
.138\end{array}$ & $\begin{array}{l}22 \\
\text { to } \\
27\end{array}$ & $\begin{array}{c}628 \\
\text { to } \\
645\end{array}$ & $\begin{array}{l}.500 \\
\text { to } \\
.565\end{array}$ & $\begin{array}{c}.030 \\
b \\
.045\end{array}$ \\
\hline
\end{tabular}

Design Chart 4-3: Design Chart for 0-PIng Face Seal Glands 


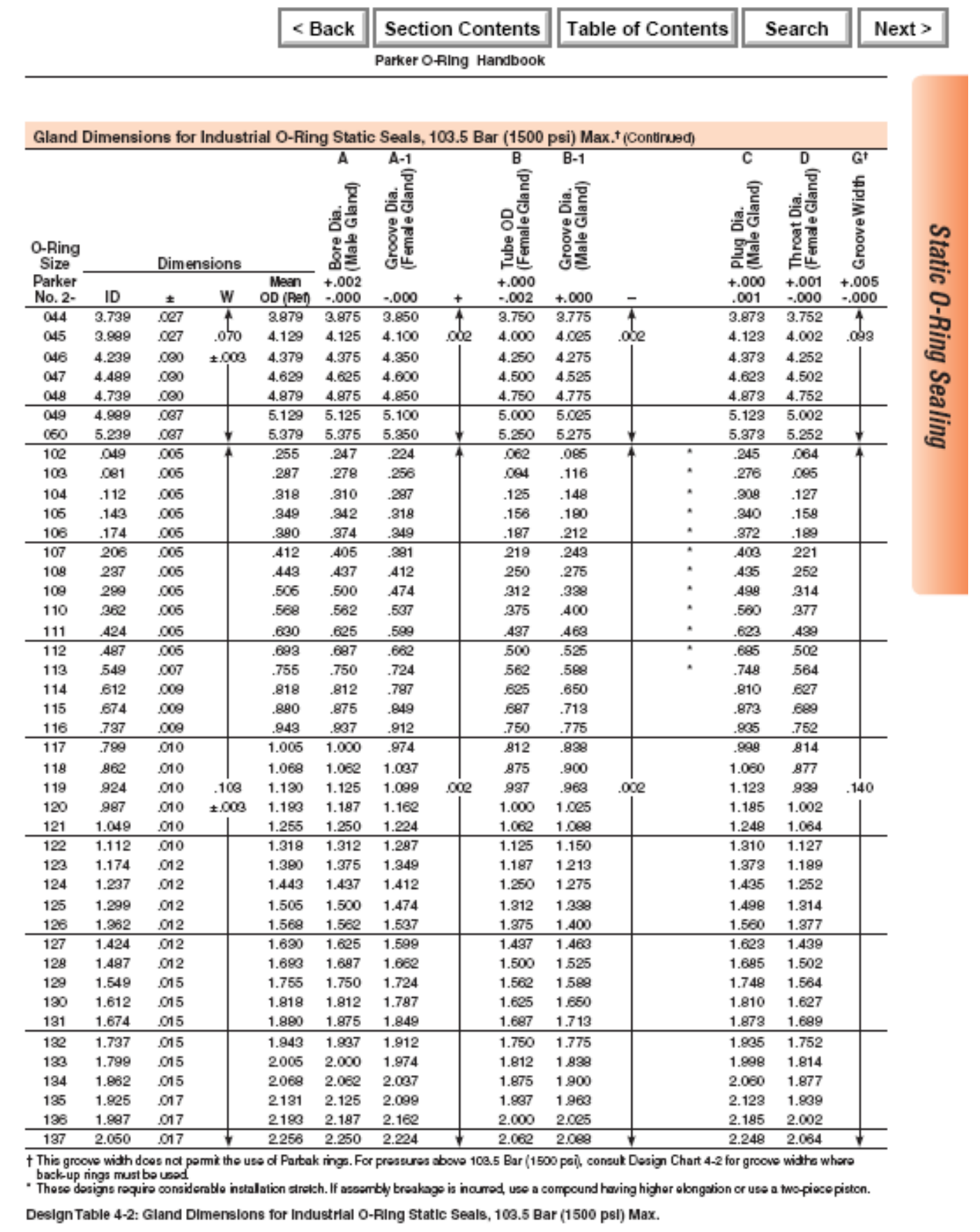




\section{Tank Fasteners}
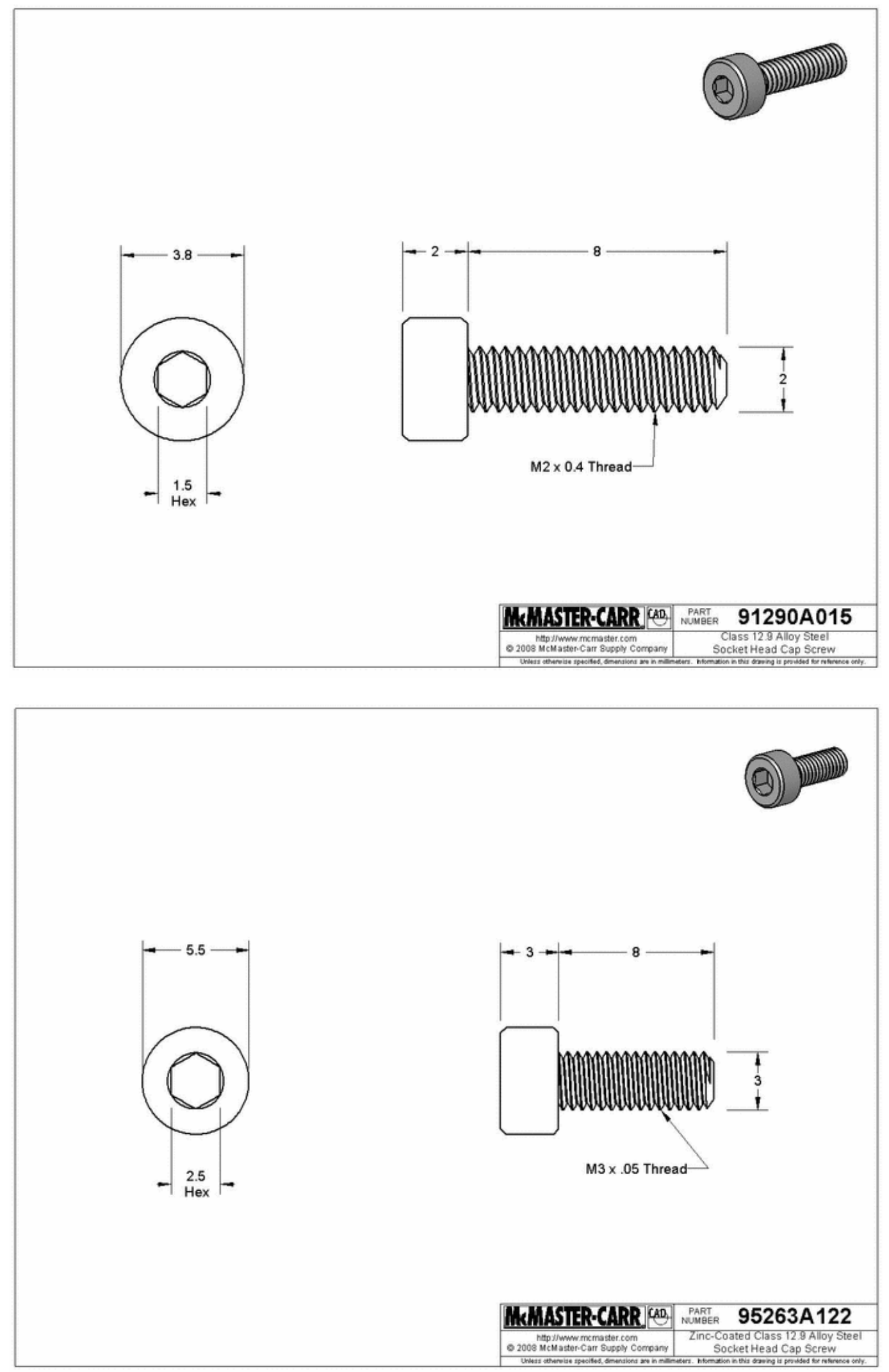


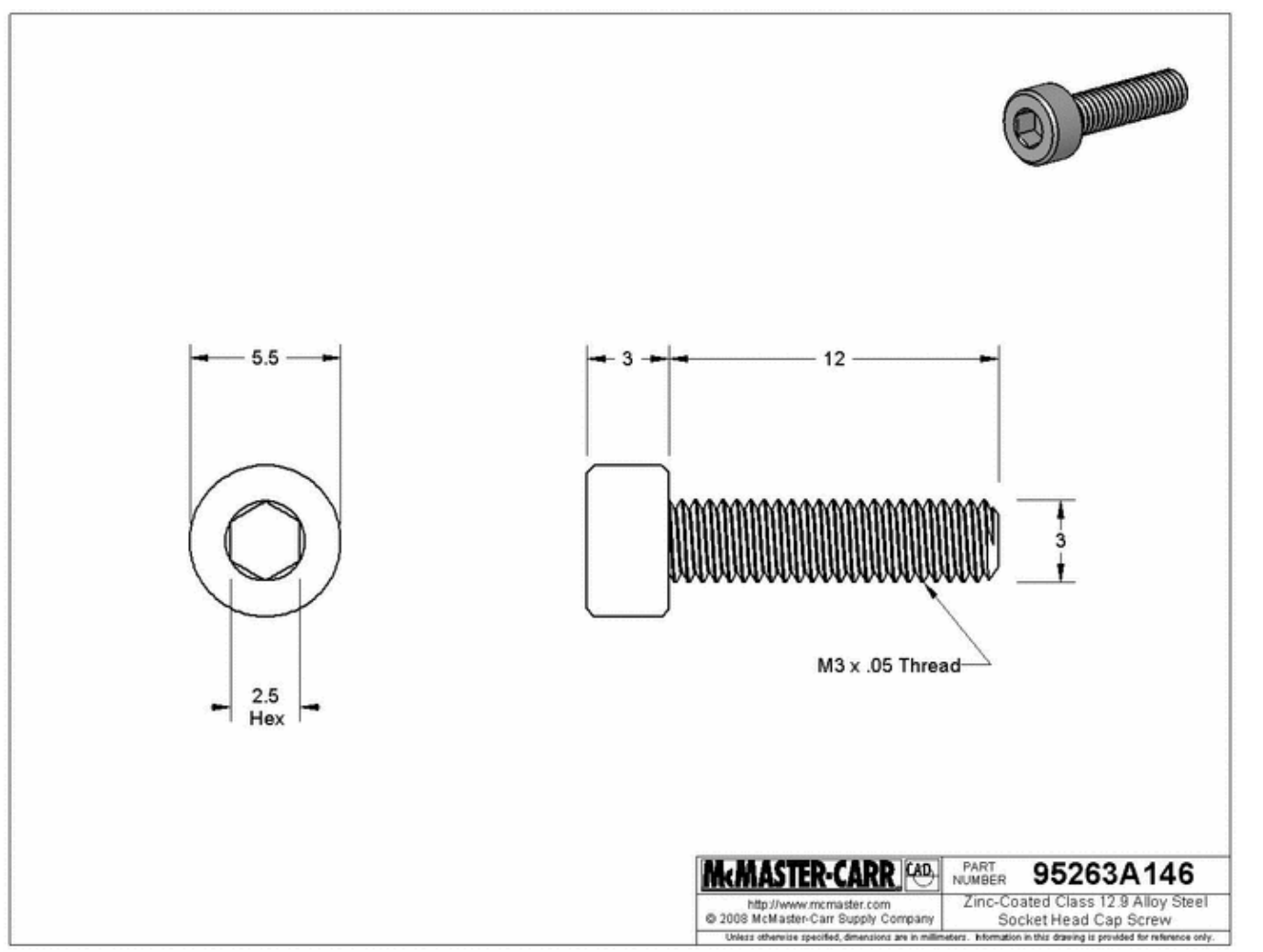


Micropropulsion tank and cap detailed drawings

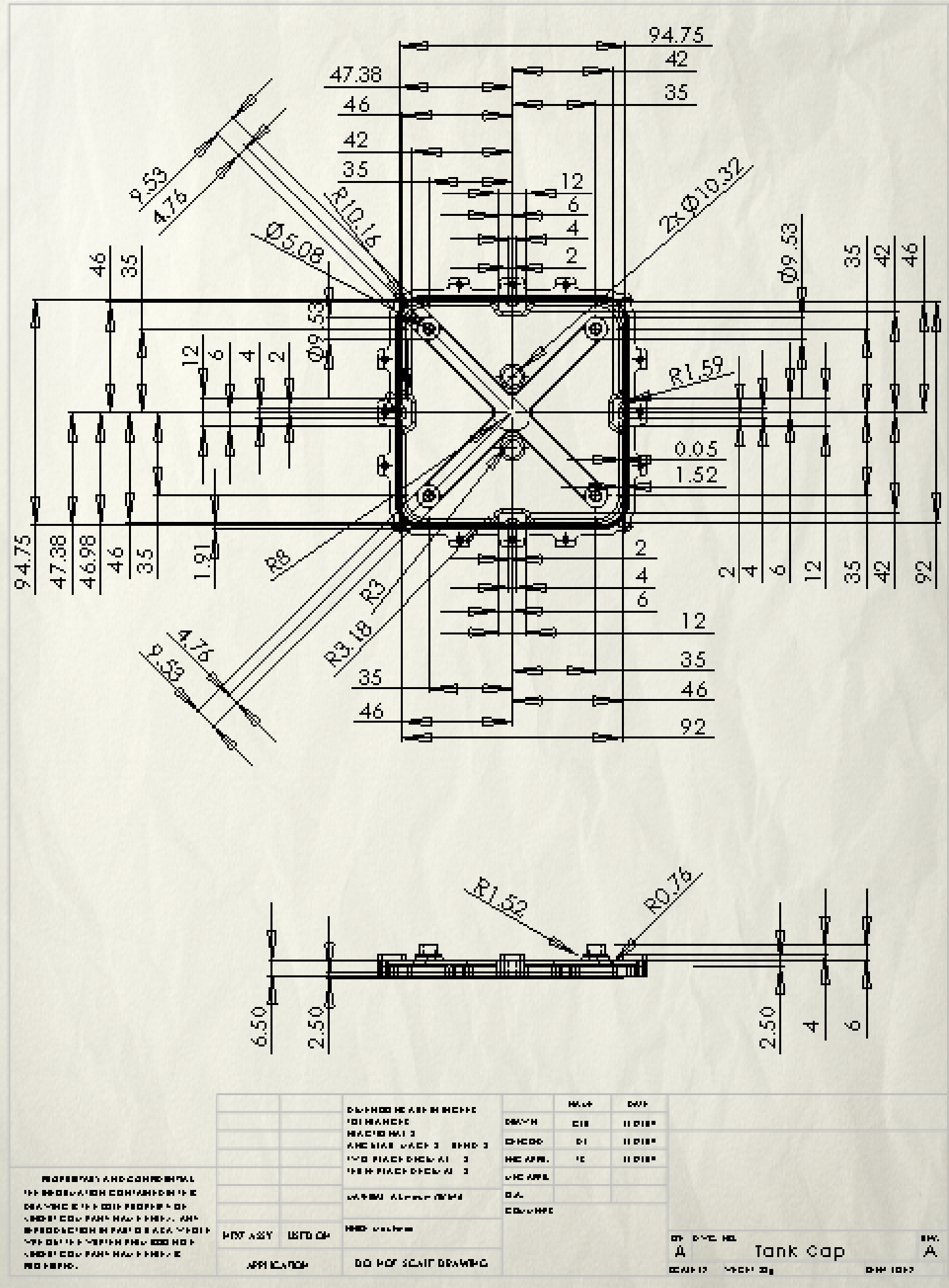




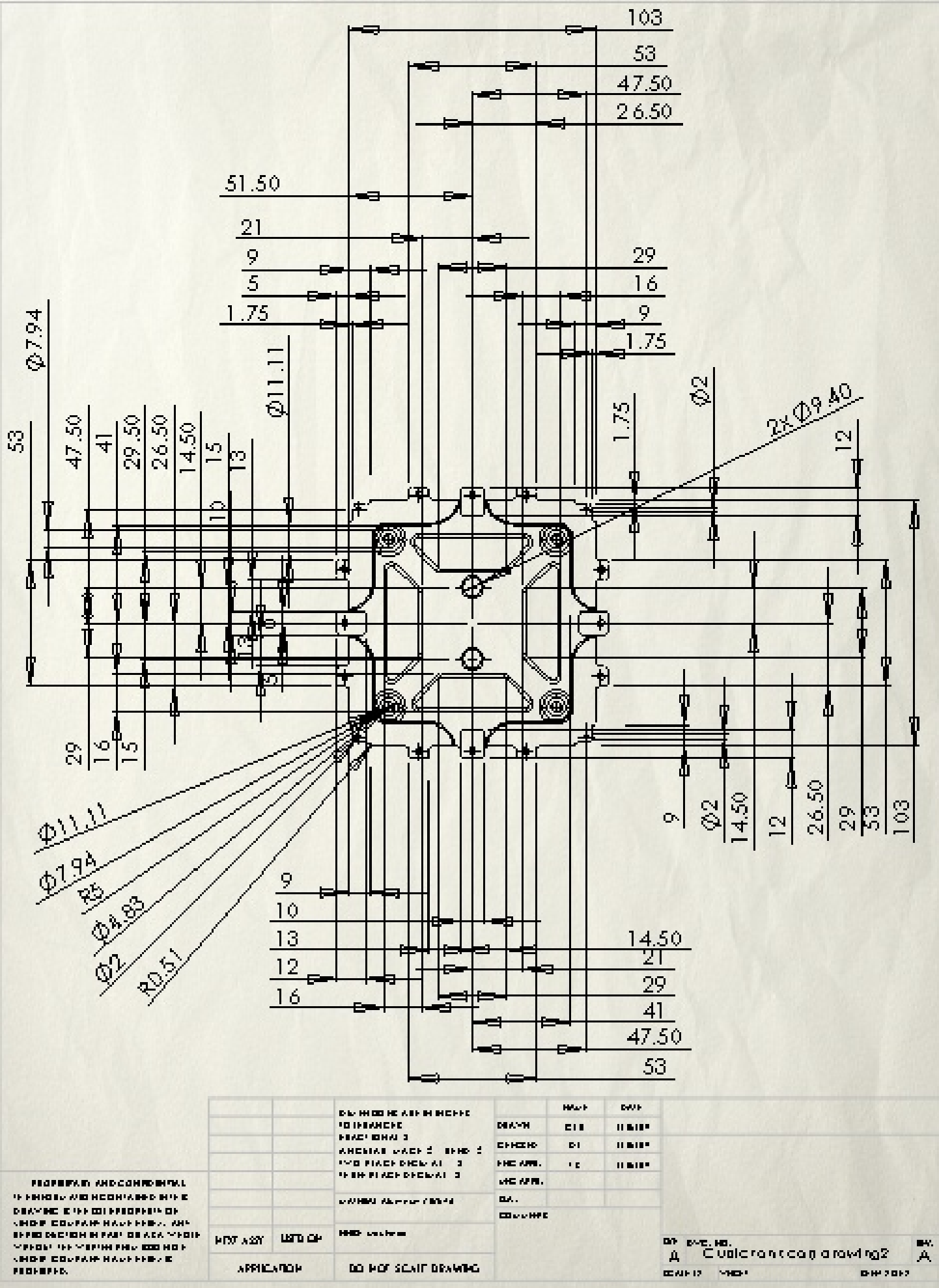



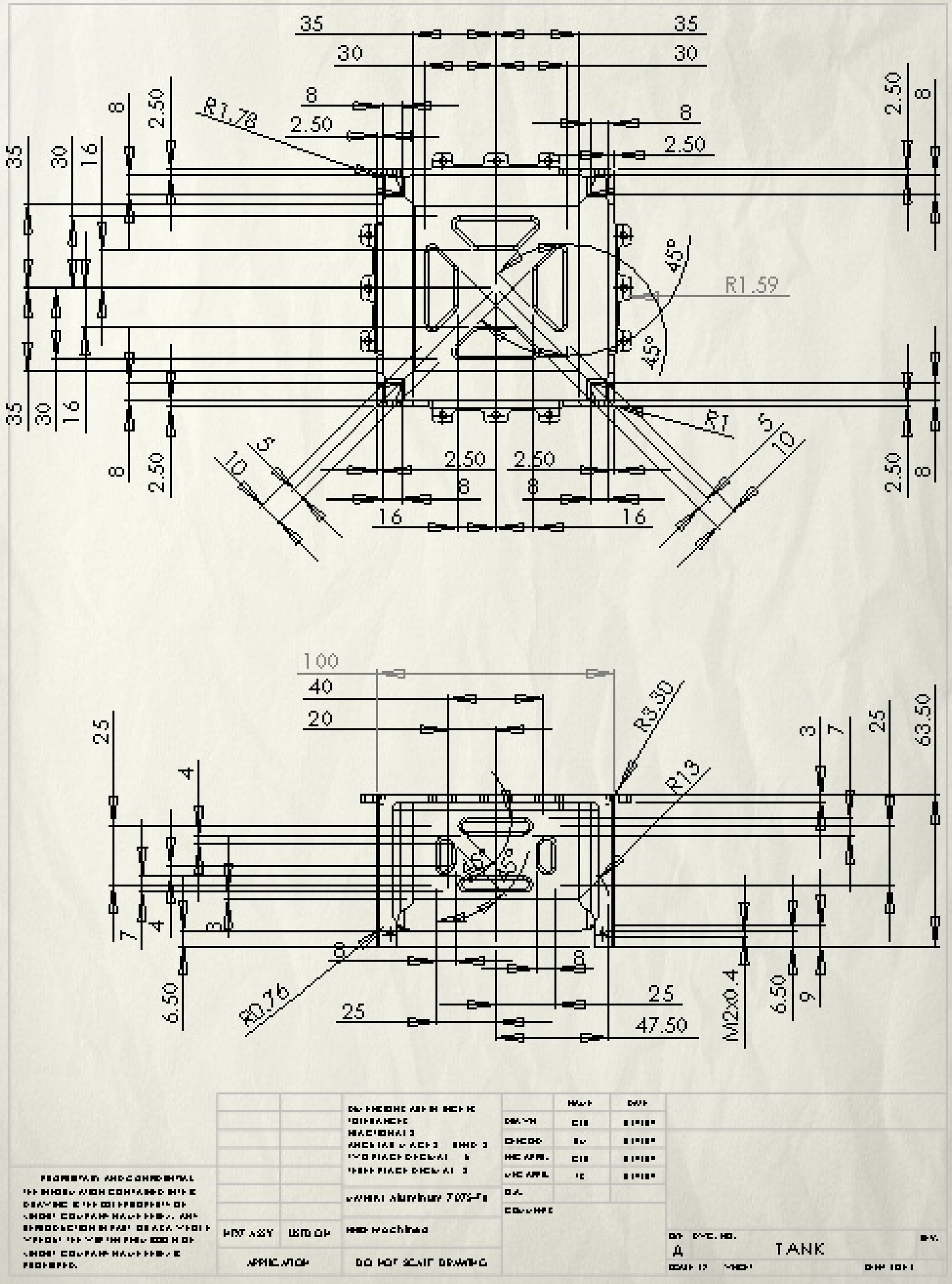
Appendix G. COSMOS simulation results with table of mechanical properties used.

\section{Tank Simulations}

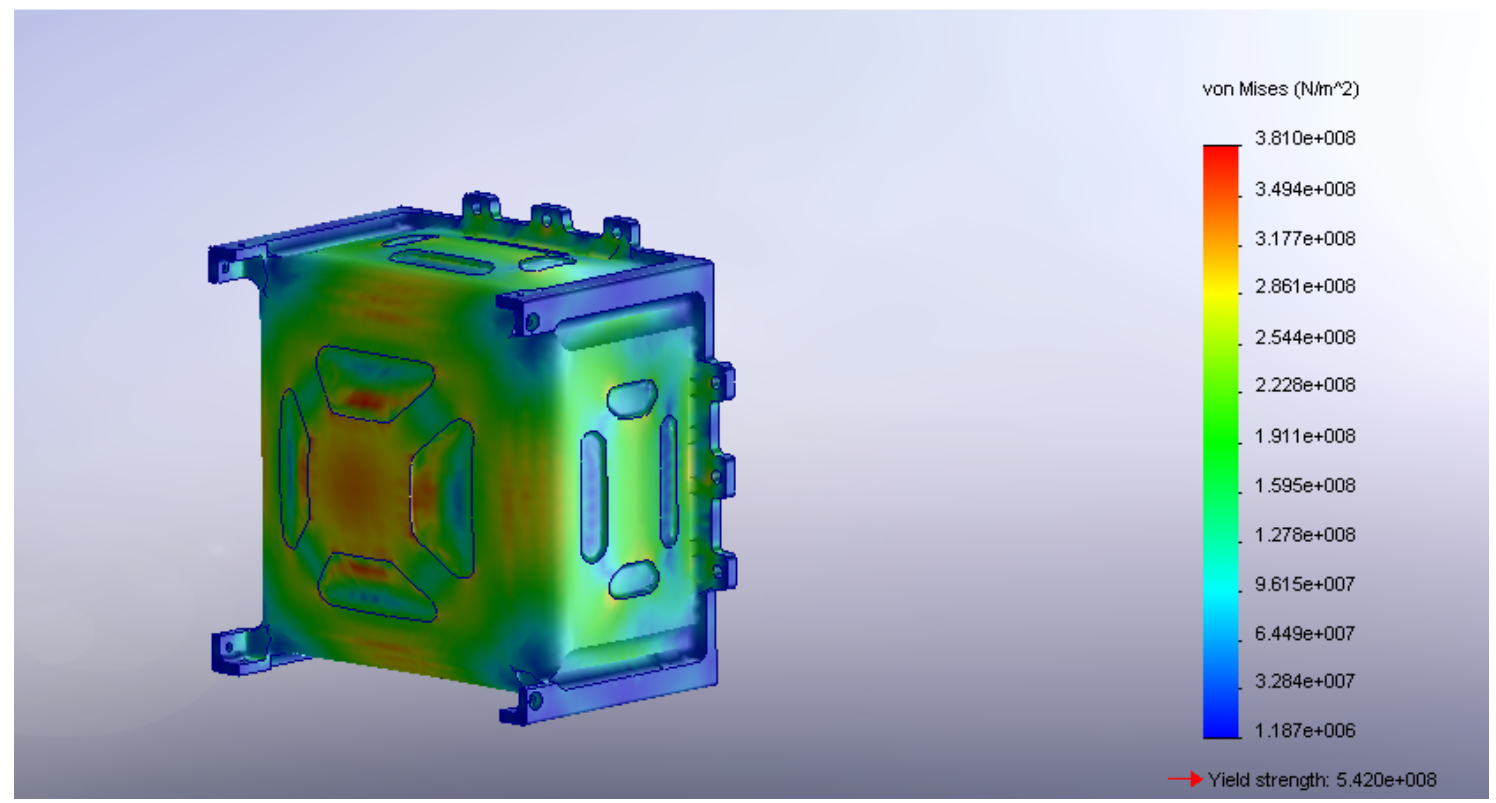

Stress simulation with $1200 \mathrm{kPa}$ pressure and all cap mounting holes and CubeSat interface holes constrained.

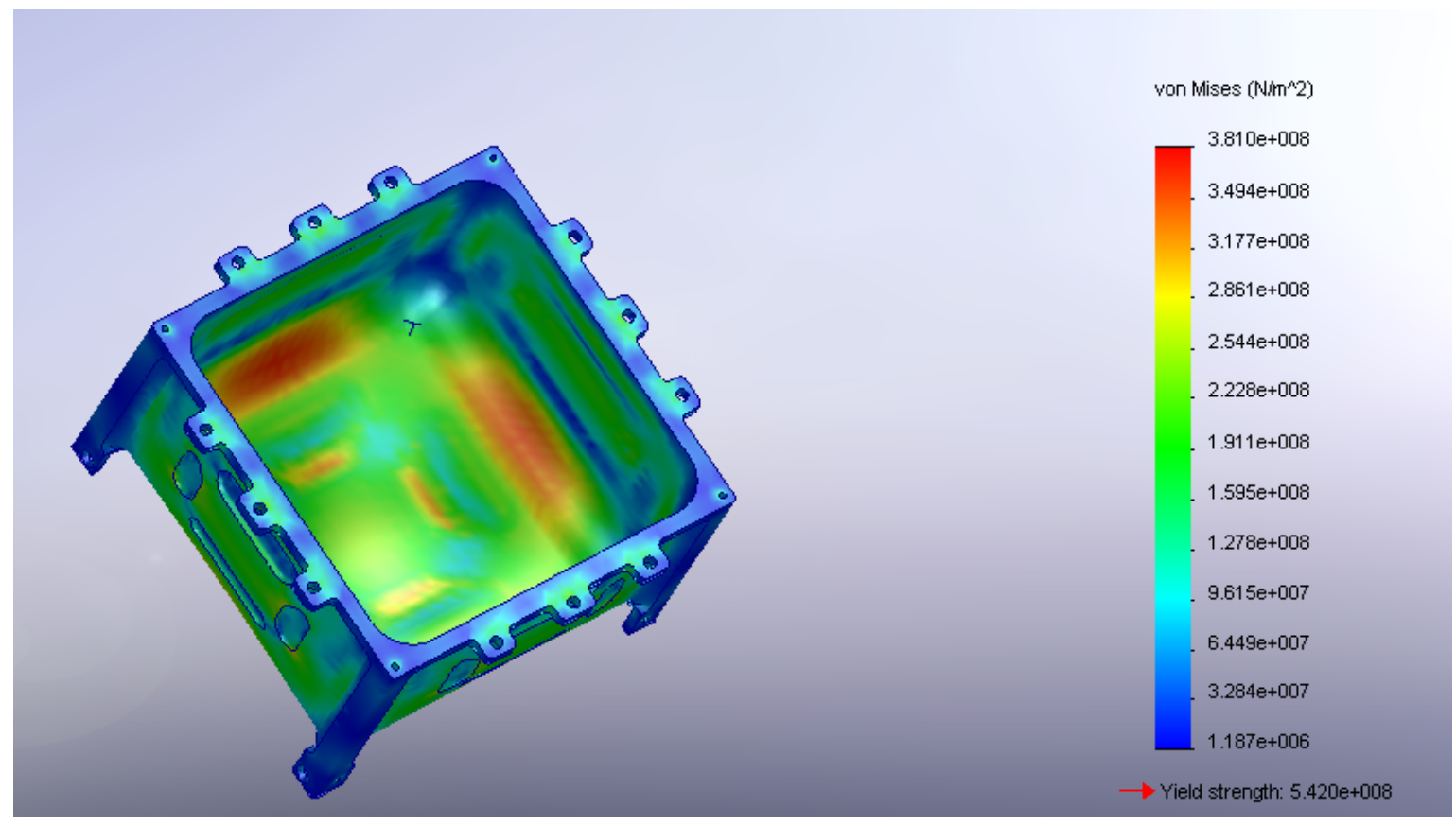

Stress simulation with lowest yield factor of safety $=1.42$ 


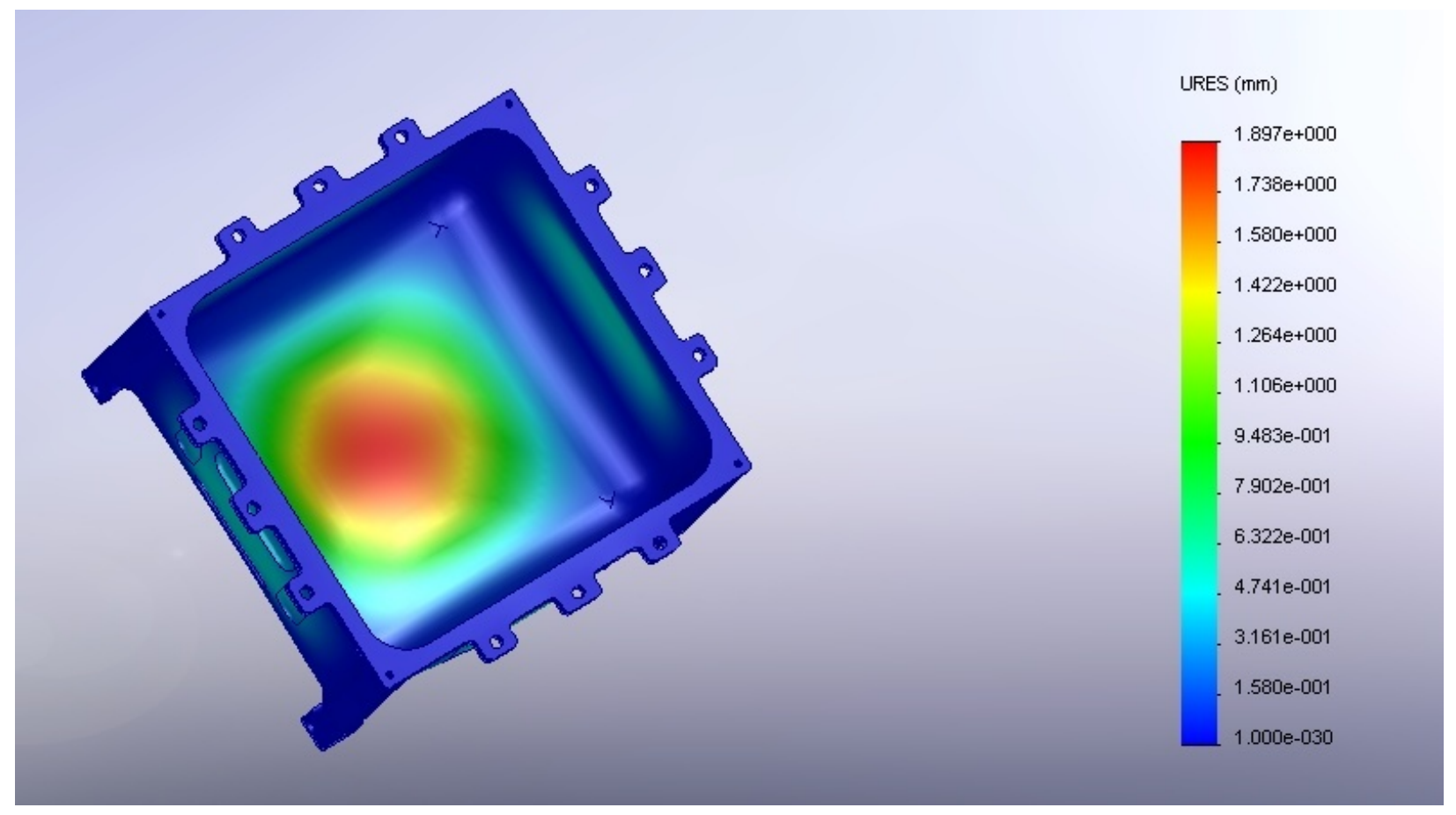

Deflection simulation with $1200 \mathrm{kPa}$ internal pressure and all cap mounting holes and CubeSat interface holes constrained.

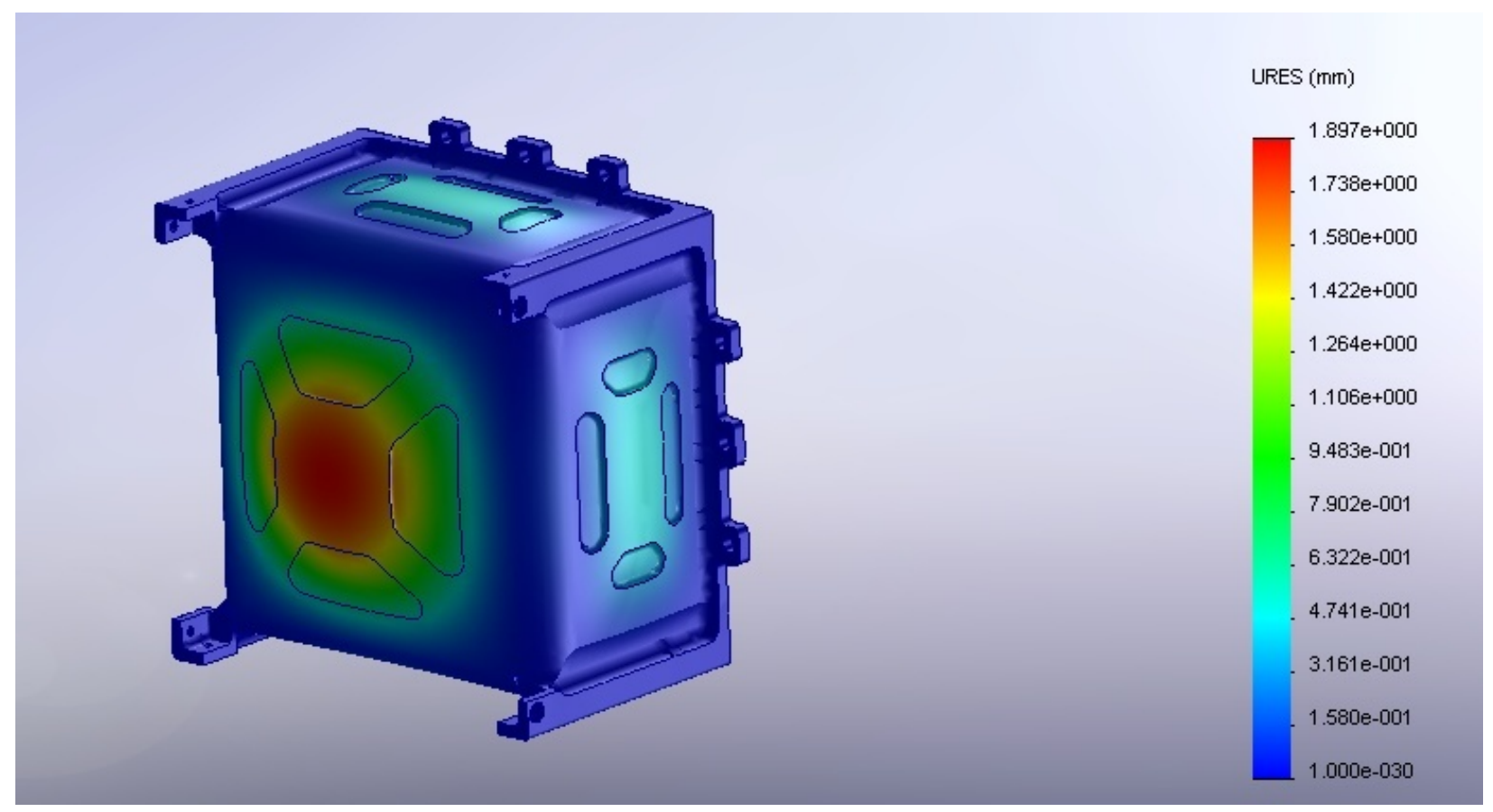

Maximum deflection of $1.9 \mathrm{~mm}$ at bottom base of cap. 


\section{Cap simulations}

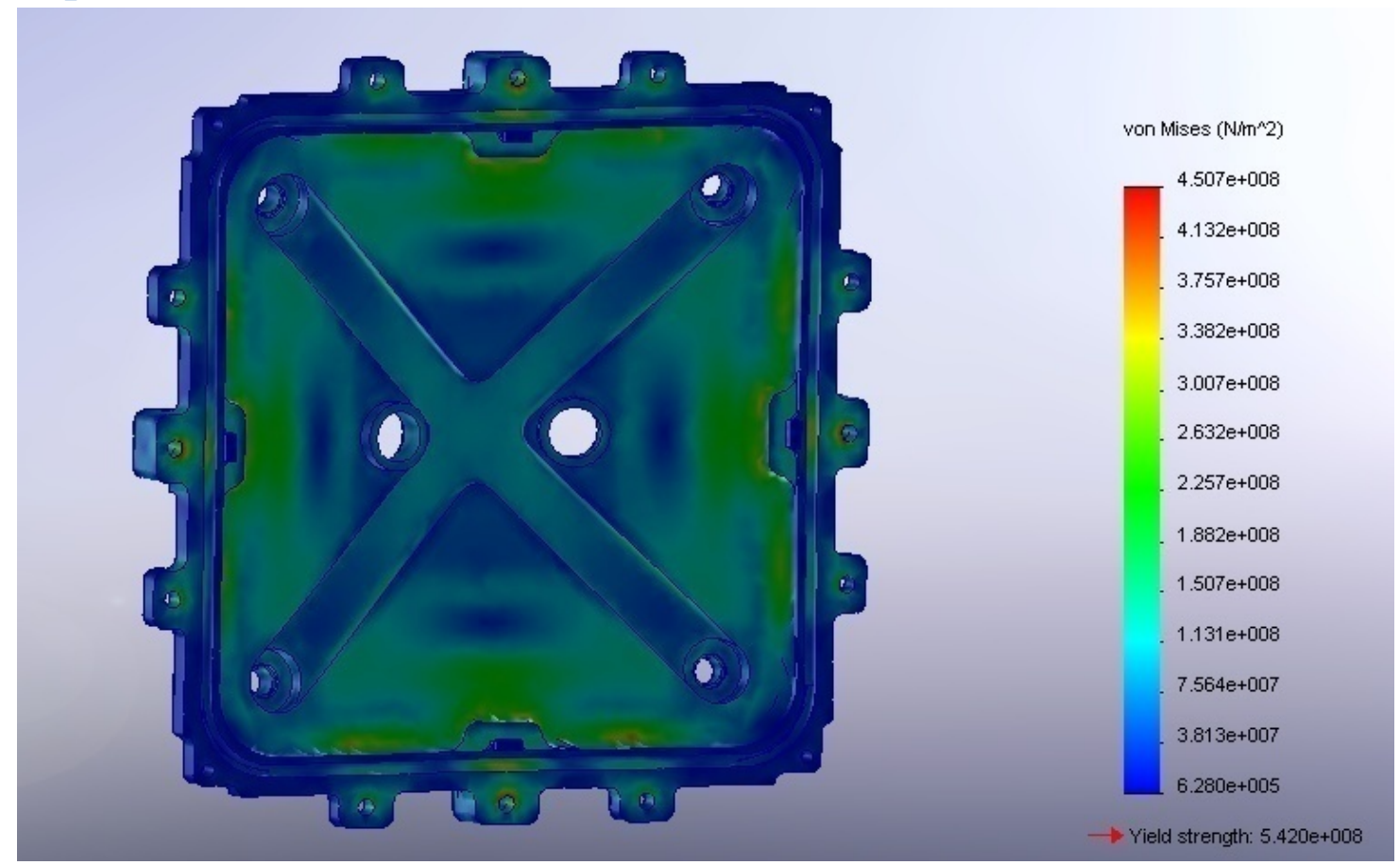

Stress simulation on cap with $1200 \mathrm{kPa}$ internal pressure with all cap mounting holes constrained.

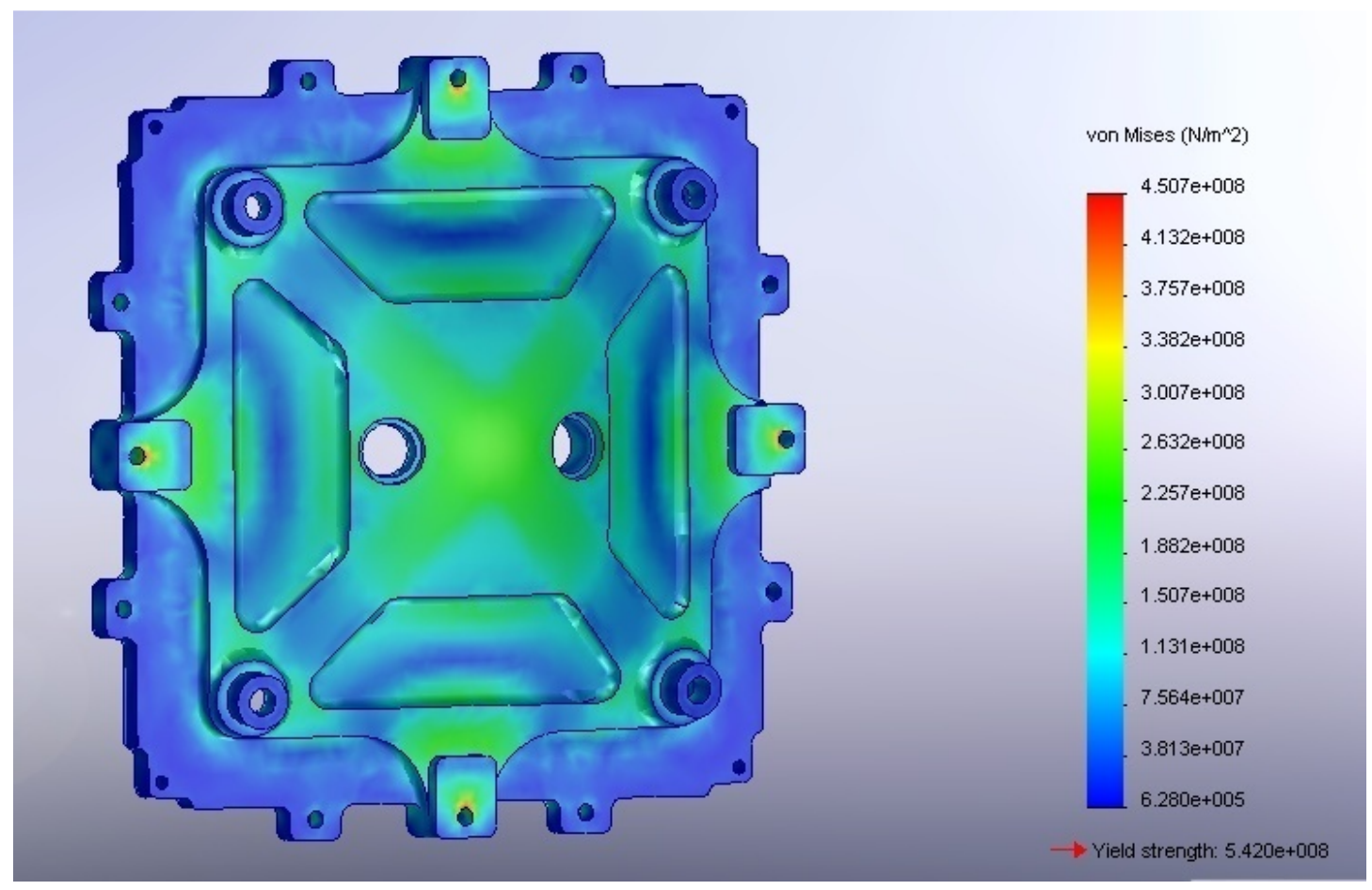

Lowest yield factor of safety for conditions listed above $=1.20$. 


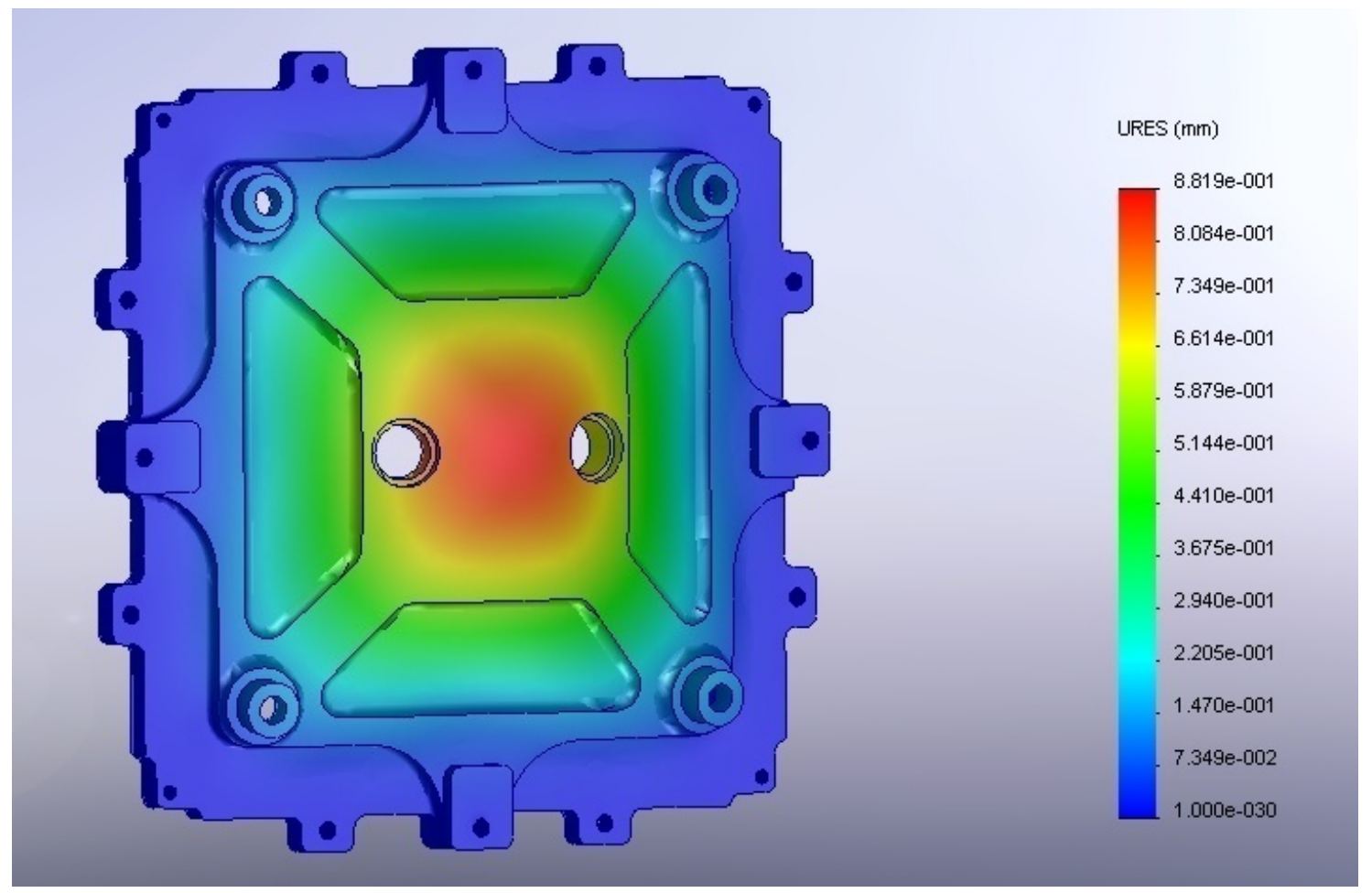

Deflection simulation for $1200 \mathrm{kPa}$ internal pressure and all cap mounting holes constrained.

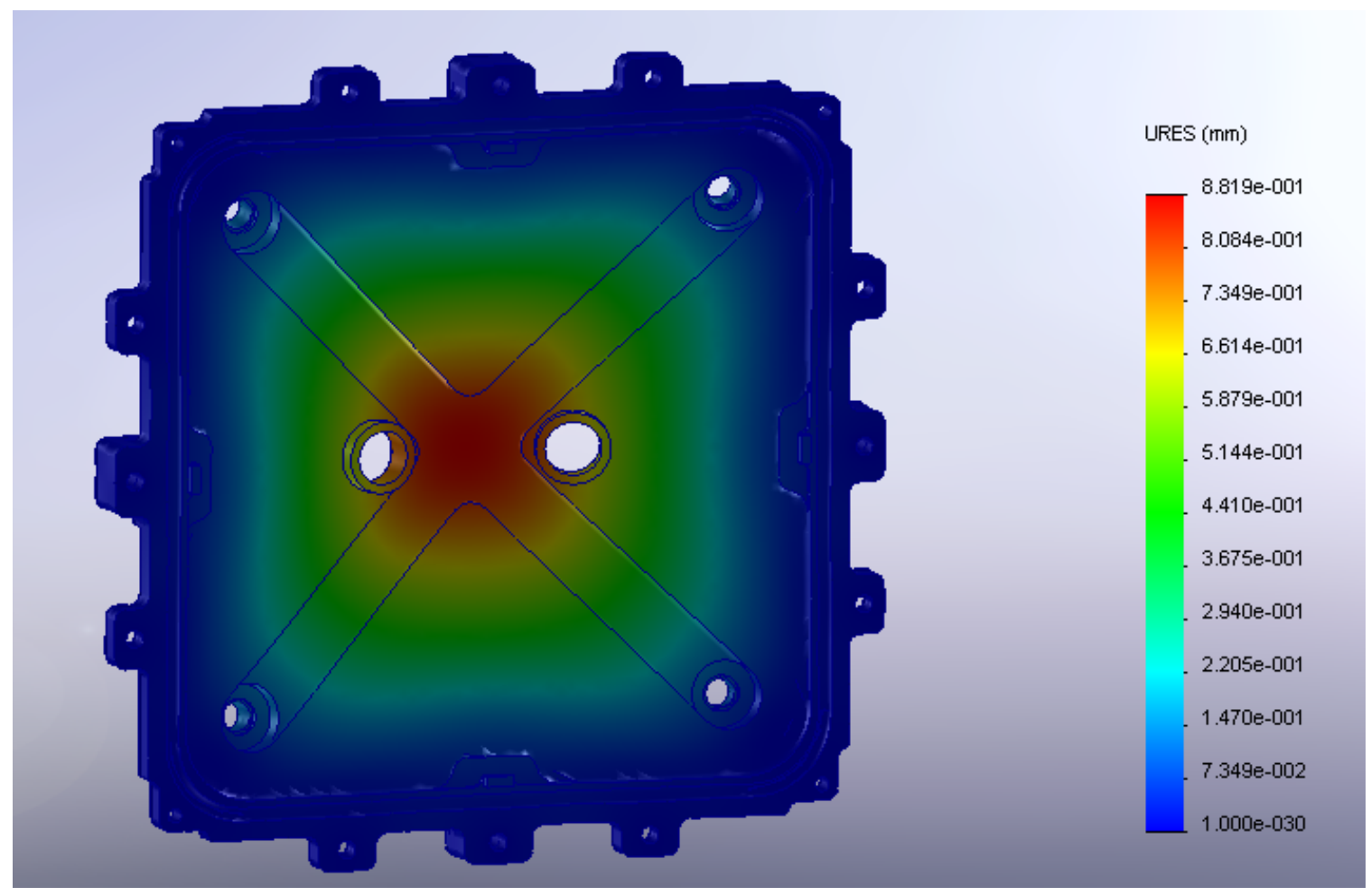

Maximum deflection at center of cap $=0.88 \mathrm{~mm}$. 


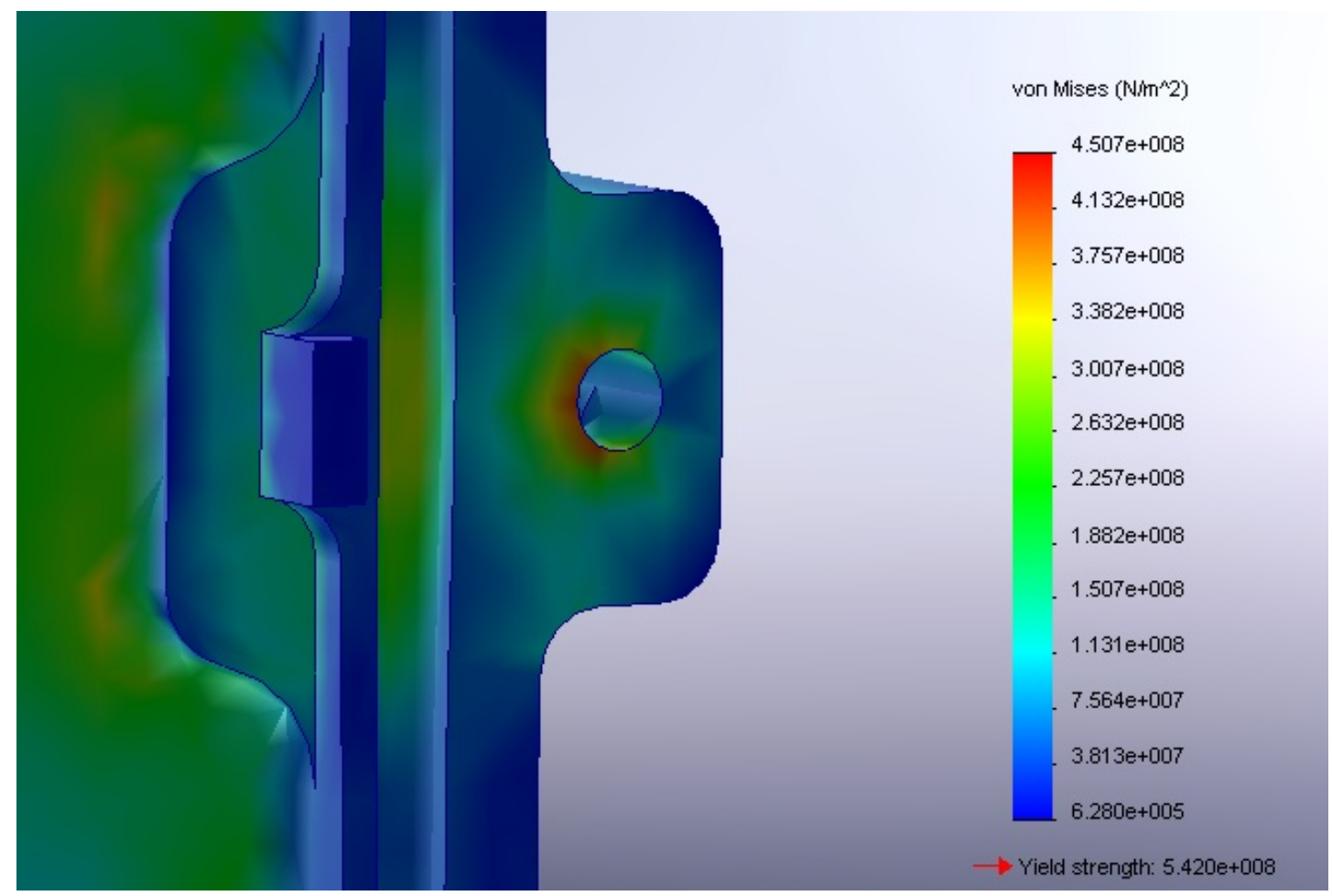

Cap mounting hole stress concentrations shown produce lowest factor of safety.

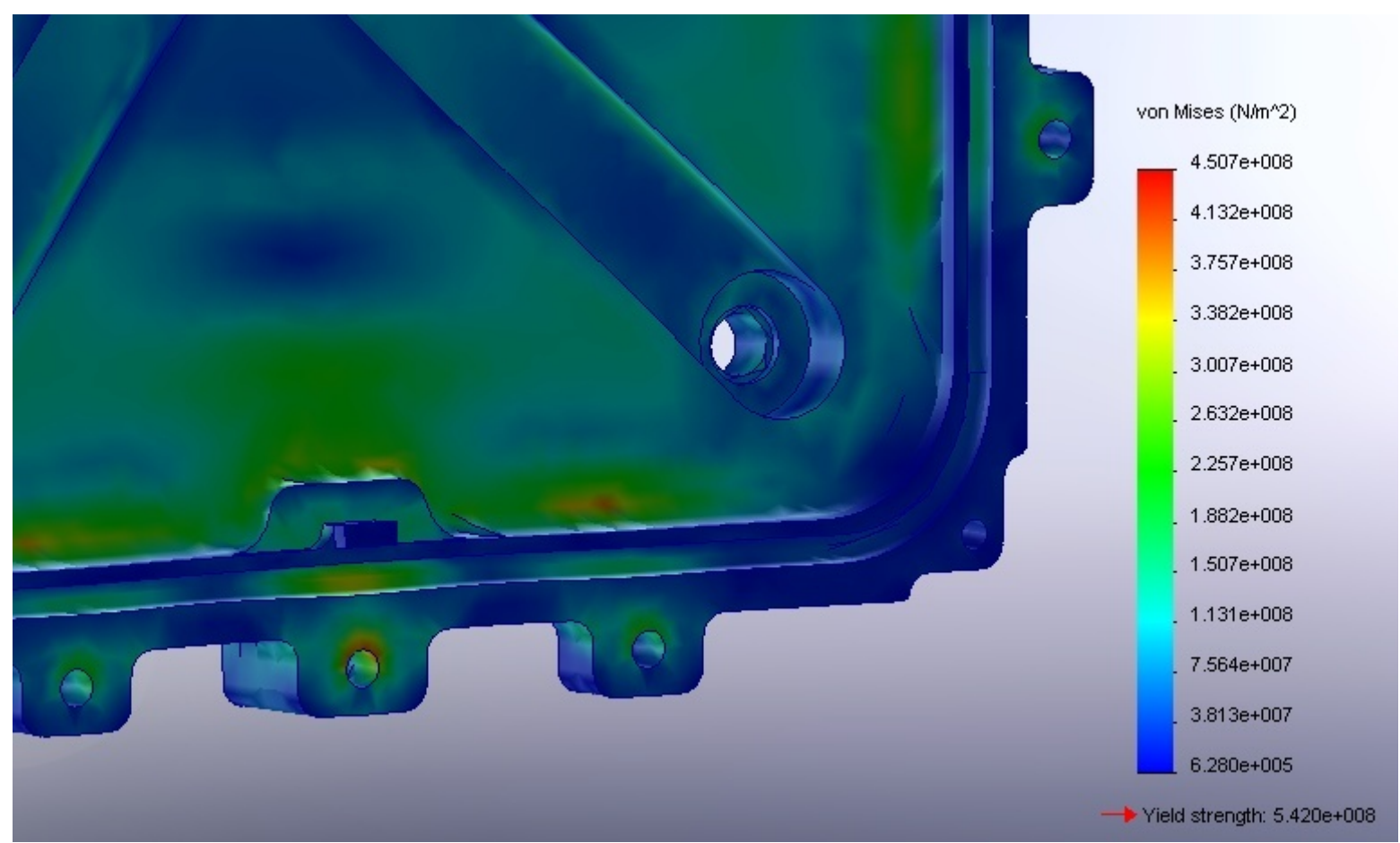

O-ring stress concentrations also limiting factor in cap strength. 
Aluminum 7075-T6 mechanical

properties used in simulations

\begin{tabular}{|c|c|}
\hline Density $(\mathrm{kg} / \mathrm{m} 3)$ & 2800 \\
\hline Elastic Modulus $(\mathrm{GPa})$ & 71.7 \\
\hline Tensile Strength $(\mathrm{MPa})$ & 593 \\
\hline Shear Modulus $(\mathrm{GPa})$ & 542 \\
\hline Poissons Ratio & 0.33 \\
\hline
\end{tabular}


Appendix H. Tension Joint Analysis data for Figure 20.

\begin{tabular}{|c|c|c|c|c|c|c|c|}
\hline C & 0.2 & & & & & & \\
\hline At & $5.03 E+00$ & & & & & & \\
\hline Sy & 1100 & & \multicolumn{2}{|c|}{ Recommended } & & & \\
\hline$S p$ & 970 & & \multicolumn{2}{|c|}{$75 \%$ of proof load } & & & \\
\hline & $\begin{array}{c}\text { Tank } \\
\text { Pressure } \\
(\mathrm{kPa})\end{array}$ & $\begin{array}{l}\text { External } \\
\text { Force per } \\
\text { Bolt }(\mathrm{N})\end{array}$ & $\begin{array}{l}\text { Preload } \\
\text { Force }(\mathrm{N})\end{array}$ & $\begin{array}{l}\text { Bolt Torque } \\
\text { Required } \\
\left(\mathrm{N}^{*} \mathrm{~m}\right)\end{array}$ & $\begin{array}{l}\text { Bolt Stress } \\
\text { (Mpa) }\end{array}$ & $\begin{array}{c}\text { Bolt Yield } \\
\text { Factor of } \\
\text { Safety }\end{array}$ & $\begin{array}{l}\text { Joint } \\
\text { Separation } \\
\text { Factor of } \\
\text { safety }\end{array}$ \\
\hline & 1100 & 775.87 & 3659.33 & 2.20 & 758.35 & 1.45 & 5.90 \\
\hline & 1200 & 846.40 & 3659.33 & 2.20 & 761.15 & 1.45 & 5.40 \\
\hline & 1300 & 916.93 & 3659.33 & 2.20 & 763.96 & 1.44 & 4.99 \\
\hline & 1400 & 987.47 & 3659.33 & 2.20 & 766.76 & 1.43 & 4.63 \\
\hline & 1500 & 1058.00 & 3659.33 & 2.20 & 769.57 & 1.43 & 4.32 \\
\hline & 1600 & 1128.53 & 3659.33 & 2.20 & 772.37 & 1.42 & 4.05 \\
\hline & 1700 & 1199.07 & 3659.33 & 2.20 & 775.18 & 1.42 & 3.81 \\
\hline & 1800 & 1269.60 & 3659.33 & 2.20 & 777.98 & 1.41 & 3.60 \\
\hline & 1900 & 1340.13 & 3659.33 & 2.20 & 780.79 & 1.41 & 3.41 \\
\hline & 2000 & 1410.67 & 3659.33 & 2.20 & 783.59 & 1.40 & 3.24 \\
\hline & 2100 & 1481.20 & 3659.33 & 2.20 & 786.39 & 1.40 & 3.09 \\
\hline & 2200 & 1551.73 & 3659.33 & 2.20 & 789.20 & 1.39 & 2.95 \\
\hline & 2300 & 1622.27 & 3659.33 & 2.20 & 792.00 & 1.39 & 2.82 \\
\hline & 2400 & 1692.80 & 3659.33 & 2.20 & 794.81 & 1.38 & 2.70 \\
\hline & 2500 & 1763.33 & 3659.33 & 2.20 & 797.61 & 1.38 & 2.59 \\
\hline & 2600 & 1833.87 & 3659.33 & 2.20 & 800.42 & 1.37 & 2.49 \\
\hline & 2700 & 1904.40 & 3659.33 & 2.20 & 803.22 & 1.37 & 2.40 \\
\hline & 2800 & 1974.93 & 3659.33 & 2.20 & 806.03 & 1.36 & 2.32 \\
\hline & 2900 & 2045.47 & 3659.33 & 2.20 & 808.83 & 1.36 & 2.24 \\
\hline & 3000 & 2116.00 & 3659.33 & 2.20 & 811.64 & 1.36 & 2.16 \\
\hline & 3100 & 2186.53 & 3659.33 & 2.20 & 814.44 & 1.35 & 2.09 \\
\hline & 3200 & 2257.07 & 3659.33 & 2.20 & 817.24 & 1.35 & 2.03 \\
\hline & 3300 & 2327.60 & 3659.33 & 2.20 & 820.05 & 1.34 & 1.97 \\
\hline & 3400 & 2398.13 & 3659.33 & 2.20 & 822.85 & 1.34 & 1.91 \\
\hline & 3500 & 2468.67 & 3659.33 & 2.20 & 825.66 & 1.33 & 1.85 \\
\hline & 3600 & 2539.20 & 3659.33 & 2.20 & 828.46 & 1.33 & 1.80 \\
\hline & 3700 & 2609.73 & 3659.33 & 2.20 & 831.27 & 1.32 & 1.75 \\
\hline & 3800 & 2680.27 & 3659.33 & 2.20 & 834.07 & 1.32 & 1.71 \\
\hline & 3900 & 2750.80 & 3659.33 & 2.20 & 836.88 & 1.31 & 1.66 \\
\hline & 4000 & 2821.33 & 3659.33 & 2.20 & 839.68 & 1.31 & 1.62 \\
\hline & 4100 & 2891.87 & 3659.33 & 2.20 & 842.48 & 1.31 & 1.58 \\
\hline & 4200 & 2962.40 & 3659.33 & 2.20 & 845.29 & 1.30 & 1.54 \\
\hline & 4300 & 3032.93 & 3659.33 & 2.20 & 848.09 & 1.30 & 1.51 \\
\hline & 4400 & 3103.47 & 3659.33 & 2.20 & 850.90 & 1.29 & 1.47 \\
\hline & 4500 & 3174.00 & 3659.33 & 2.20 & 853.70 & 1.29 & 1.44 \\
\hline & 4600 & 3244.53 & 3659.33 & 2.20 & 856.51 & 1.28 & 1.41 \\
\hline & 4700 & 3315.07 & 3659.33 & 2.20 & 859.31 & 1.28 & 1.38 \\
\hline & 4800 & 3385.60 & 3659.33 & 2.20 & 862.12 & 1.28 & 1.35 \\
\hline & 4900 & 3456.13 & 3659.33 & 2.20 & 864.92 & 1.27 & 1.32 \\
\hline & 5000 & 3526.67 & 3659.33 & 2.20 & 867.73 & 1.27 & 1.30 \\
\hline
\end{tabular}


Appendix I. Thrust Calculation for Cold Gas Test Hand Calculations.

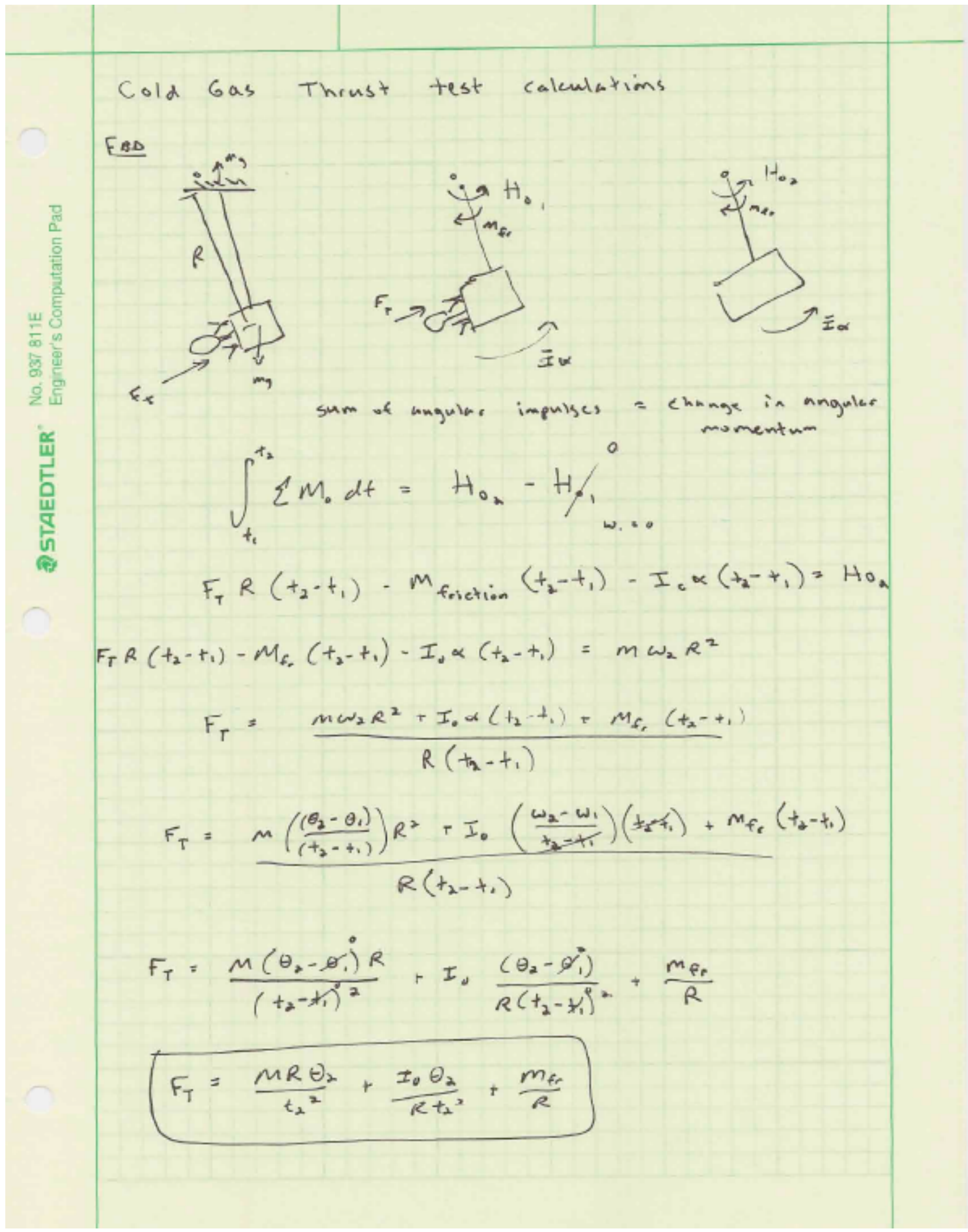

- 99 - 


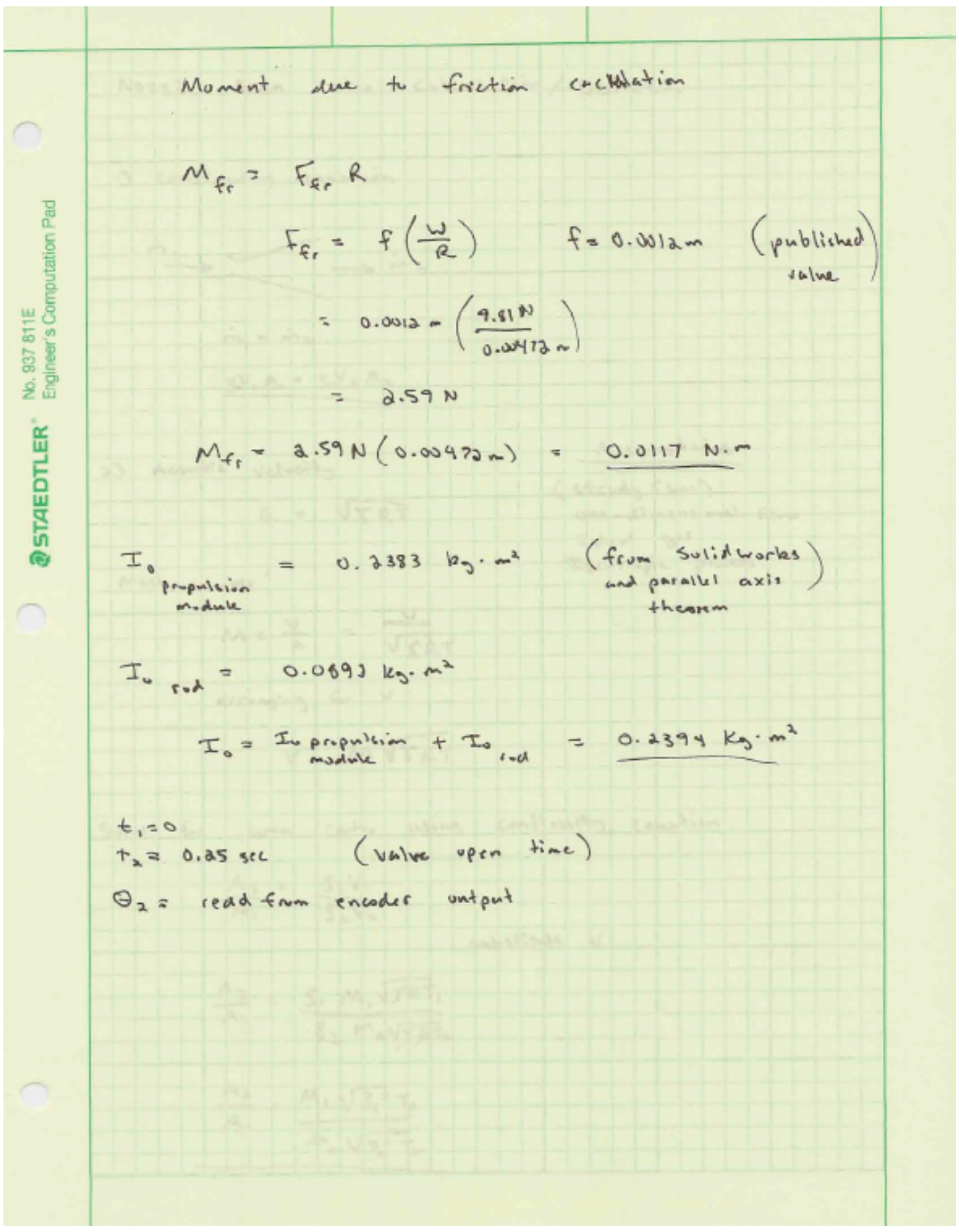

- 100 - 